Florida International University FIU Digital Commons

$11-10-2010$

\title{
An Economic Valuation Analysis of Buccoo Reef Marine Park, Tobago, West Indies
}

Dionne J. Da Costa

Florida International University, ddaco002@fiu.edu

DOI: $10.25148 /$ etd.FI10120311

Follow this and additional works at: https:// digitalcommons.fiu.edu/etd

Part of the Natural Resource Economics Commons, Natural Resources and Conservation Commons, and the Natural Resources Management and Policy Commons

\section{Recommended Citation}

Da Costa, Dionne J., "An Economic Valuation Analysis of Buccoo Reef Marine Park, Tobago, West Indies" (2010). FIU Electronic Theses and Dissertations. 290.

https://digitalcommons.fiu.edu/etd/290 


\section{FLORIDA INTERNATIONAL UNIVERSITY}

Miami, Florida

\section{AN ECONOMIC VALUATION ANALYSIS OF BUCCOO REEF MARINE PARK, TOBAGO, WEST INDIES}

A thesis submitted in partial fulfillment of the

requirements for the degree of

MASTER OF SCIENCE

in

ENVIRONMENTAL STUDIES

by

Dionne Da Costa 
To: Dean Kenneth Furton

College of Arts and Sciences

This thesis, written by Dionne Da Costa, and entitled An Economic Valuation Analysis of Buccoo Reef Marine Park, Tobago, West Indies, having been approved in respect to style and intellectual content, is referred to you for judgment.

We have read this thesis and recommend that it be approved.

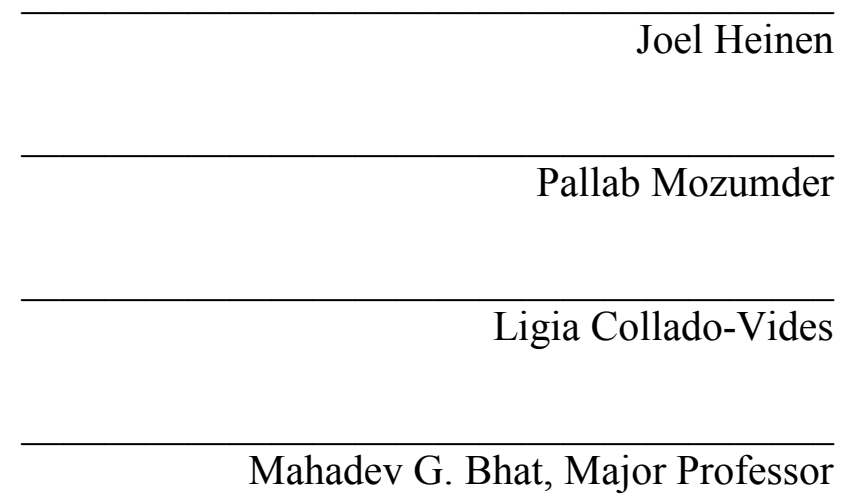

Mahadev G. Bhat, Major Professor

Date of Defense: November 10, 2010

The thesis of Dionne Da Costa is approved.

\begin{tabular}{r}
$\begin{array}{r}\text { Dean Kenneth Furton } \\
\text { College of Arts and Sciences }\end{array}$ \\
\hline Interim Dean Kevin O’Shea \\
University Graduate School
\end{tabular}

Florida International University, 2010 


\section{DEDICATION}

I dedicate this thesis to my parents. Without their patience, understanding, continued support and most of all unconditional love, the completion of this work would not have been possible. 


\section{ACKNOWLEDGMENTS}

I wish to thank the members of my committee for their support, patience, and good advice. Their direction has been most appreciated. Dr. Joel Heinen and Dr. Ligia Collado-Vides were especially influential in fostering my interest in Marine Protected Areas and supplying me with a well rounded knowledge base on the topic, and Dr. Mozumder for giving much needed advice with regards to my economic valuation. Finally I would like to thank my major professor, Dr. Mahadev G. Bhat. Without his continued support, patience and advice, and confidence in my abilities this work would not have been possible. His gentle but firm direction has afforded me the opportunity to not only complete a degree, but to do so with excellence. I would like to thank the Graduate School and the Department of Earth and Environment for awarding me funding to pursue my Master's degree. I have found my coursework throughout my stay in the Earth and Environment program to be stimulating and thought provoking, providing me with the tools with which to explore the environmental arena with confidence. 
ABSTRACT OF THE THESIS

AN ECONOMIC VALUATION ANALYSIS OF BUCCOO REEF MARINE PARK, TOBAGO, WEST INDIES

\author{
by
}

Dionne Da Costa

Florida International University, 2010

Miami, Florida

\title{
Professor Mahadev G. Bhat, Major Professor
}

The purpose of this study was to evaluate tourism capacity, the effectiveness of the management plan and the visitors' willingness to pay (WTP) for increased conservation effort in the Buccoo Reef Marine Park (BRMP) in Tobago. Non-market contingent valuation was applied to estimate tourists' WTP, using the data from a survey of 164 tourists. Local residents and government agencies were consulted to evaluate the management plan and the tourism capacity.

Eighty-eight percent of local residents stated that the park was not well managed and that they lacked trust in the park agency. The density of tourists was $67-97 \%$ more than socially acceptable crowding norm. The tourists were willing to pay an additional entry fee of US\$11.72 per person, which would generate additional revenue for the park management. In conclusion, the BRMP management needs modification in order to increase stakeholders' trust, reduce tourists crowding intensity, and generate additional user-based revenue. 


\section{TABLE OF CONTENTS}

CHAPTER

PAGE

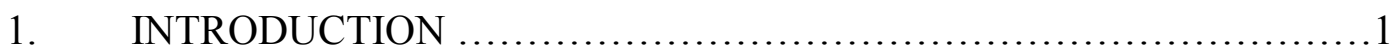

Coral Reefs in the Caribbean..........................................

Trinidad and Tobago - Background .............................. 5

Buccoo Reef Marine Park (BRMP) ................................ 8

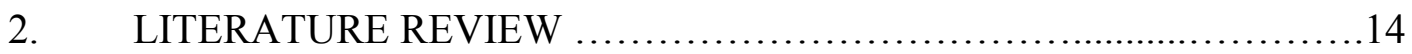

Marine Protected Areas (MPAs)....................................14

MPA Management Approaches \& Effectiveness .......................15

Community Involvement .............................................18

Management Examples..............................................22

Tourism and Carrying Capacity ...................................27

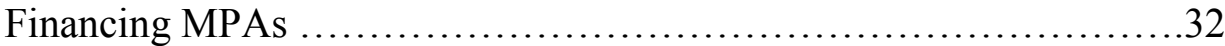

Non-Market Valuation ...........................................

Willingness to Pay Benefits........................................... 38

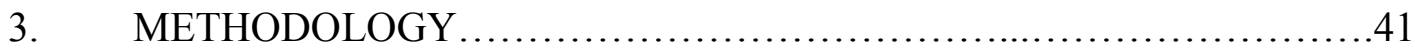

Research Aim................................................... 41

Research Questions..........................................41

Characterization of Study Area ....................................42

Delineation of Study Site in Tobago..................................45

Statistical Model.................................................49

Model Variables.....................................................53

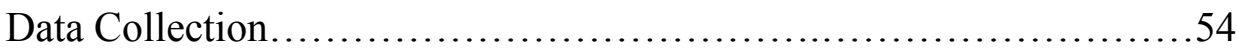

4. RESULTS AND DISCUSSION ....................................56

The Analysis of Buccoo Reef Marine Park Management Plan..............56

Management Goals \& Objectives ...................................56



Implementation and Enforcement ...............................61

Stakeholder Participation \& Local Perception...........................61

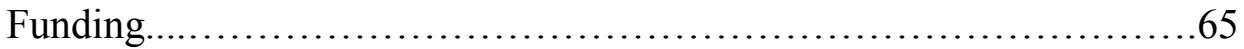

Growth of Tourism in Trinidad and Tobago............................68

Accommodation ................................................. 70

Tourism Carrying Capacity Estimates...................................72

Contingent Economic Valuation of Reef Use...........................75

Sample Characteristics .............................................. 75

Willingness to Pay for Reef......................................76

Reasons for Willingness to Pay...................................... 80

Analysis of User Fees ............................................. 85 
5. POLICY IMPLICATIONS AND CONCLUSION .........................92

REFERENCES............................................96

APPENDICES ................................................... 


\section{LIST OF TABLES}

TABLE

PAGE

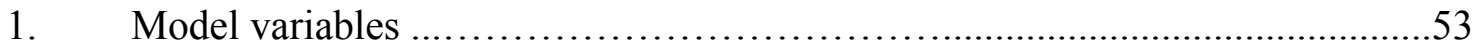

2. Questions used in Local Resident Survey for graphical analysis .......................62

3. Accommodation Availability in Tobago ............................................

4. Frequency of Bid Amounts and Percent Saying YES.......................................76

5. Double-Bound Logit Regression Model of WTP for improving BRMP.............78

6. Reasons and Percentage Distribution of Responses.....................................81

7. User Fee Analysis (Based on Current Usage) .............................. 90

8. User Fee Analysis (Based on Proposed Carrying Capacity) ....................91 


\section{LIST OF FIGURES}

FIGURE

PAGE

1. Threatened Reefs in the Caribbean...................................................4

2. (a) Location of Trinidad and Tobago in the Caribbean.......................6

(b) Map of Trinidad and Tobago...................................... 7

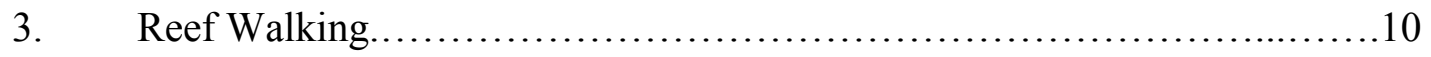

4. Buccoo and Bon Accord Region................................... 10

5. Management Effectiveness of MPAs in the Caribbean.......................27

6. (a) Glass Bottom Boat Tour .........................................43

(b) Glass Bottom Boat Tour .....................................43

7. Glass Bottom Boat tour - Coral Gardens..............................44

8. Nylon Pool.......................................................44

9. WTP Survey Sites........................................... 45

10. Proposed Management Structure for BRMP ..............................59

11. Actual/Observed Management of BRMP and affected stakeholders.........60

12. Local Respondent Survey.....................................63

13. Visitor Air and Cruise Arrivals to Tobago 2000-2007...................69

14. Domestic Arrivals to Tobago by Mode of Transport .........................71



16. Percentage Distribution of Respondents saying YES to Bid Amounts........77

17. Probability Distribution of Bid Amounts (Entire Sample)..................79

18. Probability Distribution of Bid Amounts (Domestic)...................... 79

19. Probability Distribution of Bid Amounts (International).................80 
20. Percent Distribution of Reasons for YES (entire sample)..................81

21. Percent Distribution of Reasons for NO (entire sample) $\ldots \ldots \ldots \ldots \ldots \ldots \ldots . \ldots 2$

22. Percent Distribution of Reasons for YES (domestic) $\ldots \ldots \ldots \ldots \ldots \ldots \ldots \ldots . \ldots 3$

23. Percent Distribution of Reasons for 'NO' (domestic)......................83

24. Percent Distribution of Reasons for 'YES' (International)....................84

25. Percent Distribution of Reasons for 'NO' (International) ..................85 


\section{Chapter I}

\section{$\underline{\text { Introduction }}$}

Coral reefs are a vital part of the ecological fabric and economic activities of small Caribbean Islands. Coral reefs, considered the "rainforests of the sea" are unique ecosystems and are among the most productive and biologically diverse ecosystems on the planet (Connell, 1978). Not only are these ecosystems aesthetically luring and culturally beneficial, but they supply vast numbers of people with goods and services such as seafood, recreational potential and coastal protection (Smith, 1978). Costanza et al. (1997) estimated this value of shoreline protection by coral reefs to be as much as US\$275,000 per year.

The rapid expansion of the scales of human actions has resulted in significant environmental changes on earth (Deutsch et al., 2003). As a result of this transformation, the capacity of life-support ecosystems to generate a flow of essential ecosystem services and maintain resilience in the face of disturbance has become an increasingly limiting factor for societal development (Deutsch et al., 2003). Unfortunately this is extremely evident in the marine environment of the world. With the exponential increase of the human population so too followed an increase in demand for ocean resources, both living and non-living, which has already lead to loss of biodiversity and habitat, and irreversible damage to the marine environment (Maes, 2008). As much as $15 \%$ of degradation of the aquatic environment is done to coral reef systems (Maes, 2008). The current worldwide degradation of coral reefs constitutes an international problem that calls for immediate attention (Briggs, 2005). In Florida alone, because of the current degradation rate, the 
coral reef ecosystem is expected to disappear in less than 10-25 years, unless restoration efforts are launched immediately (The New York Times, 1994). This prediction is alarming when one considers the ecological importance of these reef systems.

Coral reefs, estimated to cover approximately $0.1 \%-0.5 \%$ of the ocean floor, are habitat for almost a third of the world's marine fish species (Moberg and Folke, 1999) with the catch from these reef areas constituting about $10 \%$ of fish consumed by humans (Briggs, 2005). There are more than 100 countries that have coastlines with coral reefs, with at least tens of millions of these people depending on these systems as part of their livelihood and existence (Moberg and Folke, 1999). In some parts of the Indo-pacific region, reef fishery amounts to as much as $25 \%$ of total fish catch (Briggs, 2005). It is therefore evident that degradation of coral reef systems will have grave effects worldwide on the human population.

Economically, coral reefs provide the basis for the two most important, yet conflicting regional industries: fishing and tourism (Bhat, 2003). Reefs in Florida for example, are the major fishing ground for lobster, snapper and mackerel, generating at least $\$ 60$ million a year for the fishery industry (US Department of Commerce, 1995 in Bhat, 2003). The tourism industry largely depends on coral reefs to attract thousands of recreational users: boaters, divers and snorkelers, which is an obvious benefit to any economy. Costanza et al. (1997) estimated that reef recreation and tourism values at US $\$ 300,800 / \mathrm{km}^{2} / \mathrm{yr}$. In Florida, coral reef related tourism is estimated to have the potential to generate more than $\$ 1.69$ billion in income throughout the regional economy (US Department of Commerce, 1995). 
Marine resource authorities around the world, including the Caribbean area, have tried a variety of reef protection measures. However, the question that often arises is if such measures are working in the midst of ever growing demand for reef resources, unstable governments and un-coordinated government efforts. Often times, the management authorities may not have the necessary regulatory authority nor the adequate funding. The main purpose of this research is to find out how successful the management program in the case of Buccoo Reef Marine Park in Tobago had been and what factors might have affected its success or failure.

\section{Coral Reefs in the Caribbean}

Caribbean coral reefs are some of the most widely studied coral reefs (Guarderas et al., 2008). About $9 \%$ of the world's mapped reefs are found in the Caribbean region, most of which are located along the Central American coast and off the Caribbean islands (Bryant et al., 1998). The Caribbean has $25,960 \mathrm{~km}^{2}$ of reef area, $64 \%$ of which is threatened because of human activities (Burke and Maidens, 2004). Analyses conducted by the World Resources Institute (WRI) indicate that almost two-thirds of reefs within this region are at risk with about one-third being considered 'high risk' (Bryant et al., 1998). Most reefs of the Antilles and Lesser Antilles (including Haiti, the Dominican Republic, Puerto Rico, Dominica, and Barbados) are under high potential threat (Bryant et al., 1998) (see Figure 1). The main threats to many reefs within these regions are sedimentation from upland deforestation, poor agricultural practices, coastal development, pollution and overfishing (Cortés, 1997).

The WRI has estimated that in the next 5-10 years, $61 \%$ of Caribbean reefs may be impacted by overfishing, $33 \%$ by coastal development, $35 \%$ by sedimentation and 
inland agricultural practices and 14\% by marine-based pollution (Carr and Heyman, 2009). Thus far, the Caribbean region has had an average reported loss of $40 \%$ absolute coral cover since the 1970s (Gardner at al., 2003). Researchers have attributed these losses primarily to overfishing, coupled with disease-induced mass mortality of Diadema antillarum (Aronson and Precht, 2006), resulting in a regional-scale collapse of Caribbean reef ecosystems in the 1908s. Research scientists contend that coral assemblages of the Caribbean have lost their resilience because of the collapse, thus affecting their capacity to recover after disturbance (Aronson and Precht, 2006).

Figure 1 - Threatened Reefs in the Caribbean

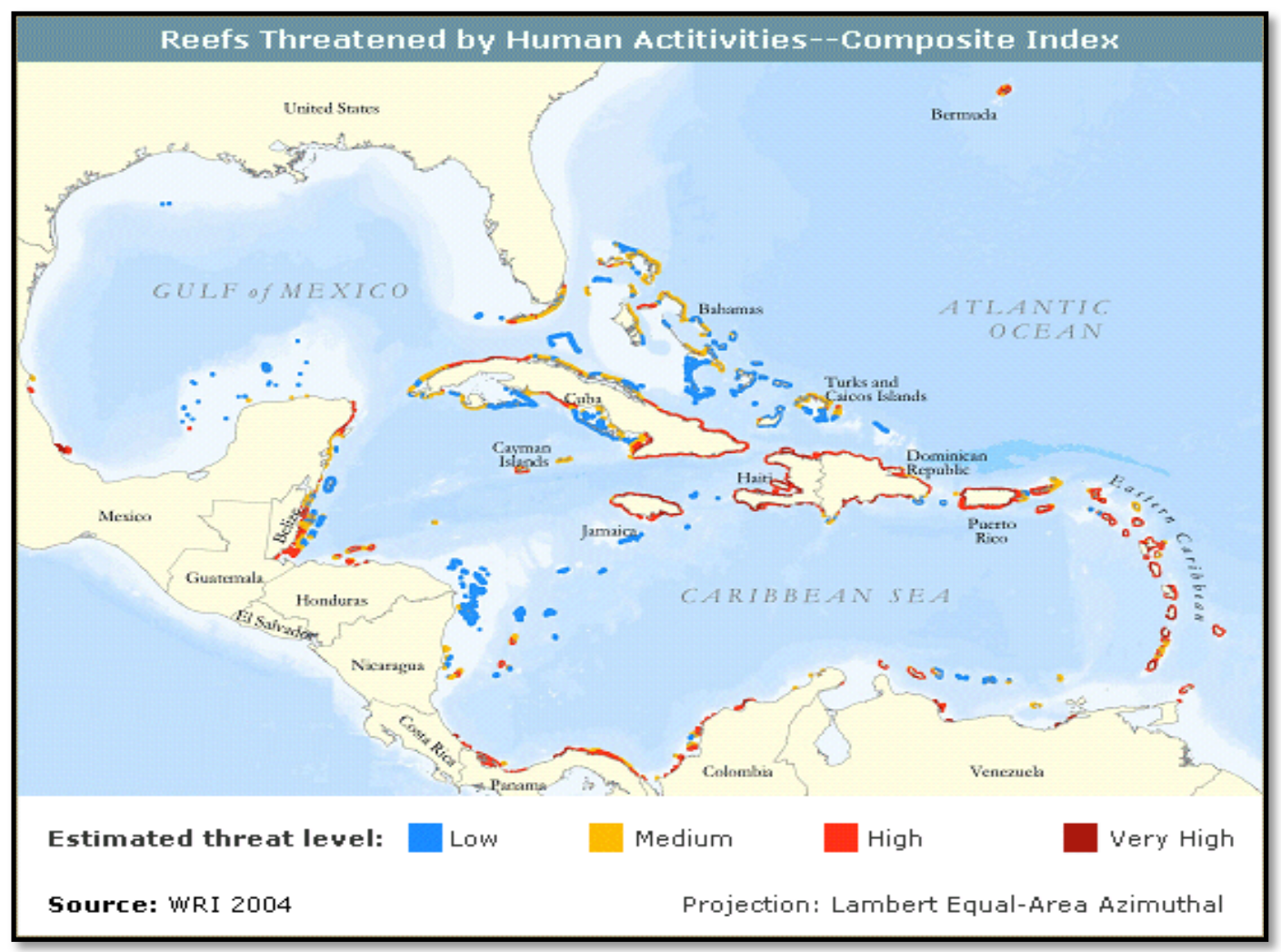

Source: WRI - Burke and Maidens, 2004

Though quantifying the absolute value of coral reefs is still not fully understood, analysis of the tangible amounts of fisheries and recreational activities along with estimations of services such as shoreline protection are ways to attempt to place a value 
on this ecosystem and such studies have been conducted by the WRI. According to Burke and Maidens (2004), goods and services provided by the reefs of the Caribbean are worth between US\$3.1 billion and US\$6 billion annually, with coral reef-associated fisheries estimated at US\$310 million, dive tourism estimated at US\$2.1 billion and shoreline protection services at US\$700 million and US\$2.2 billion. Coral reef degradation could result in annual losses of US\$100 million to US\$300 million to the Caribbean tourism industry, with the potential for even bigger losses due to tourism shifts from areas where corals are damaged to areas largely intact (Burke and Maidens, 2004).$$
\text { Trinidad and Tobago - Background }{ }^{1}
$$

Trinidad and Tobago is a beautiful twin island republic located close to the South American continental shelf and share estimated geographical coordinates of $1100 \mathrm{~N}, 61$ $00 \mathrm{~W}$. The islands are situated between the North Atlantic Ocean and the Caribbean Sea and are the southernmost islands of the Lesser Antilles (see Figure 2a). Trinidad lies just a mere 11 kilometers off the northeast coast of Venezuela and 130 kilometers south of the Grenadines. It is 60 kilometers long and 80 kilometers at its maximum width, comprising and area of 4,828 square kilometers. Its twin island, Tobago, is located 30 kilometers northeast of Trinidad and is and comprises a total area of just 300 square kilometers. Trinidad and Tobago are divided into 8 boroughs (see figure $2 \mathrm{~b}$ ) and has an estimated population (as of July 2010) of 1,228,691 with ethnic distributions (as of a 2000 census) of Indian (South Asian) 40\%, African 37.5\%, mixed 20.5\%, other 1.2\%, unspecified $0.8 \%$. The capital city, Port of Spain is located in the north western side of the island of Trinidad and has an estimated population (as of 2000 census) of 49,031 (2000 census -

\footnotetext{
${ }^{1}$ The Information provided in this section is highly dependent upon data obtained from the World Factbook Publication of The Central Intelligence Agency - www.cia.gov
} 
Central Statistical office). According to the Central Statistical Office of Trinidad and Tobago, as of $2007,17 \%$ of the population was recorded as being below the poverty line and as of 2009, with an unemployment rate of 5.8\%, the Gross Domestic Product (GDP) per capita was estimated at $\$ 23,100$.

Figure 2a - Location of Trinidad and Tobago in the Caribbean

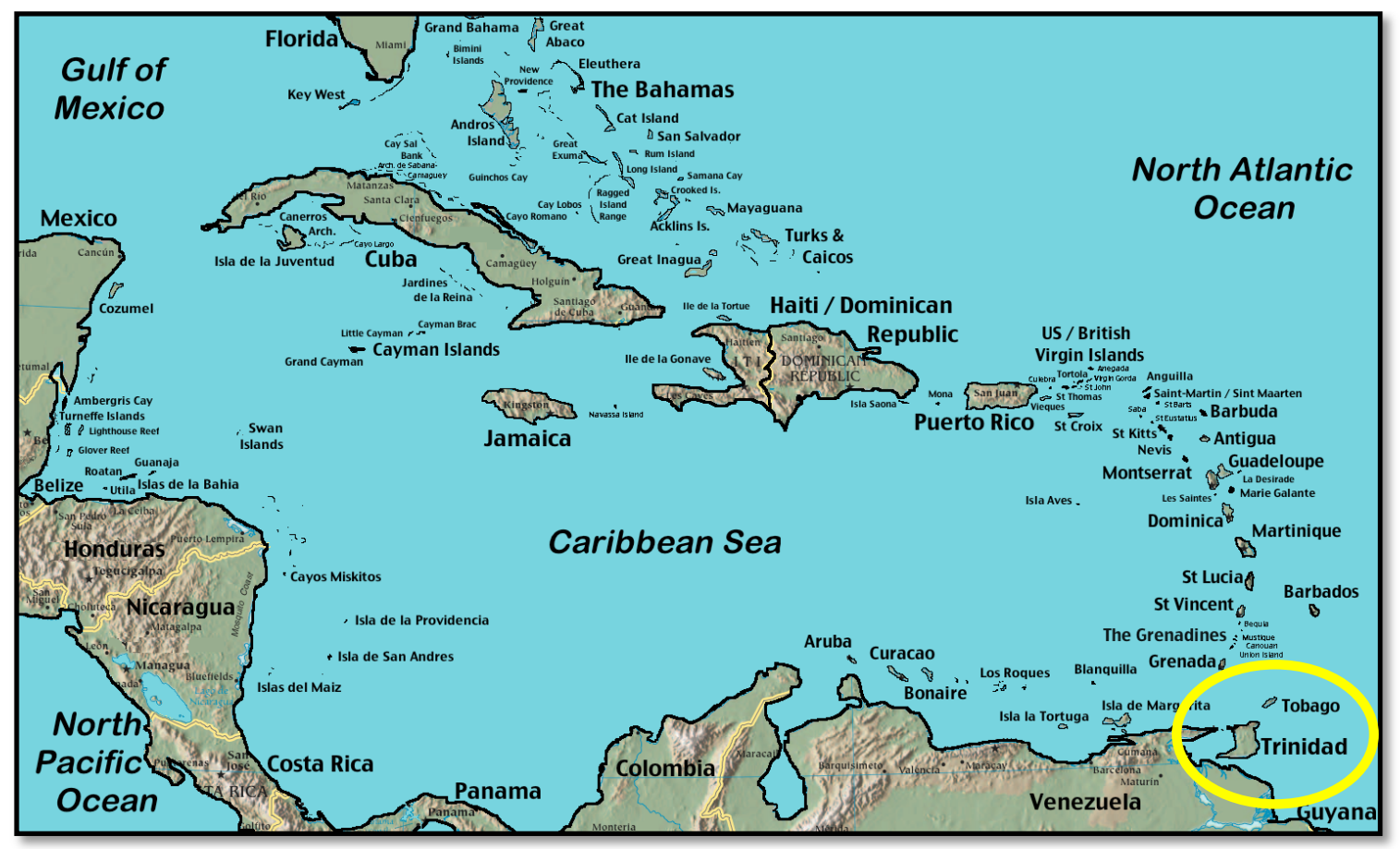

Image provided by: http://www.westindiesgate.com/

Trinidad and Tobago is well within the tropics and both islands enjoy a generally pleasant maritime tropical climate influenced by the northeast trade winds. The annual mean temperature is $26^{\circ} \mathrm{C}$, and the average maximum temperature is $33^{\circ} \mathrm{C}$. Rains are seasonal and are generally concentrated between the months of June through December. The islands lie outside the hurricane belt and thus do not face any real threat of natural hazards with the last damaging storm recorded over three decades ago in the 1960s. 
Figure 2b- Map of Trinidad and Tobago

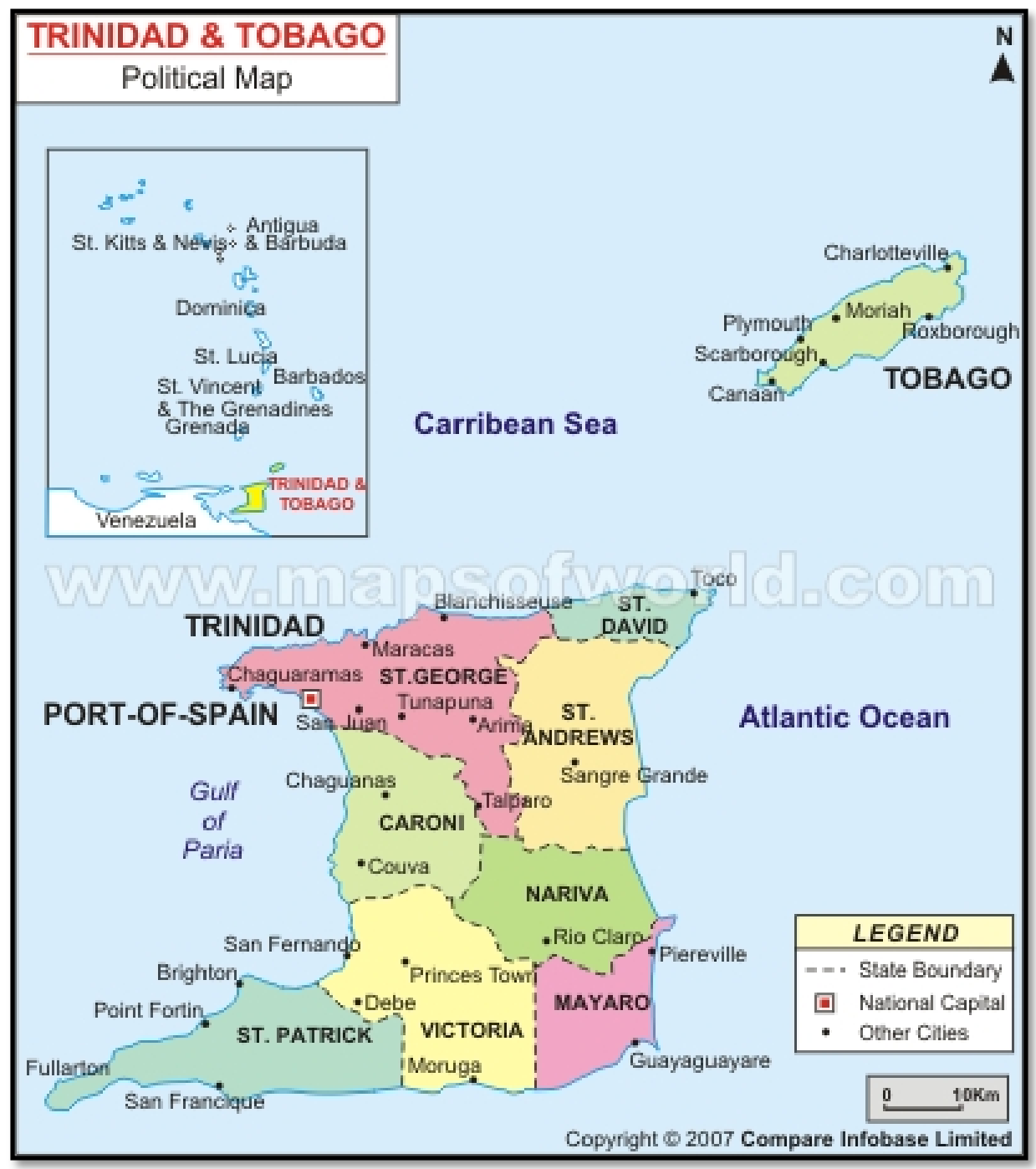

Image provided by: http://www.mapsofworld.com/

The economy of this twin island republic is heavily dependent upon natural resources with oil and gas accounting for about $40 \%$ of GDP and $80 \%$ of exports (CIA World Factbook). Unlike the other Caribbean islands, tourism plays quite a minor role in the economy of Trinidad and Tobago, representing only a mere 3\% of GDP in the 1980 s. Tourism is a growing sector with nature based tourism on the rise with spectacular bird 
watching and sport fishing being a main attraction in Trinidad and diving and other marine recreational activities taking place in Tobago. Unlike Trinidad, Tobago is surrounded by rich and colorful reefs with 300 species of South Atlantic coral and more than 600 species of fish (Laydoo, 1987). Though influx of the Orinoco River allows for the vast biodiversity of the islands by introducing nutrient rich fresh waters, it is also a significant contributor to water pollution from run-off during the rainy season, which in turn has a slight seasonal affect on the water quality especially for the reefs on the southwestern top of Tobago (Laydoo, 1987). Like many developing nations, Trinidad and Tobago face many environmental pressures of water pollution from agricultural chemicals, industrial wastes and raw sewage; oil pollution of beaches; deforestation and soil erosion.

An economic evaluation of Tobago's coral reefs was conducted in 2008 by the World Resources Institute (WRI). Burke at al. (2009) estimated coral reef associated tourism and recreation to contribute between US\$100 and \$130 million to the national economy in 2006. Coral reef associated fisheries, known to be an important cultural tradition, safety net and livelihood, had annual economic benefits estimated at between US $\$ 0.8-1.3$ million. Shoreline protection by coral reefs was valued between US\$18 and \$33 million per year. These economic contributions are significant to Tobago’s GDP, which were documented to be a total of \$286 million in 2006 (Central Statistical Office).

\section{Buccoo Reef Marine Park (BRMP)}

The Buccoo Reef-Bon Accord Lagoon area is unique to the southern Caribbean because of its size, attractiveness, and easy accessibility (Goreau, 1967). Being located on the low-energy, leeward southwestern coast of Tobago, has led to its 
development as a major tourist attraction. The promotion of the Buccoo Reef area as a major tourist attraction, combined with hotel and residential development in adjacent coastal areas, has resulted in direct and indirect negative impacts on the ecosystems (Laydoo et al., 1998). Direct impacts are evident as there has been noted physical damage over an extensive area of the Outer Reef flat where the Buccoo Reef Tour once frequented. Corals have been broken or crushed by trampling feet (see Figure 3), falling anchors, and intermittent boat groundings (Goreau, 1967; Kenny, 1976). Indirect impacts are more subtle and are linked to the discharge of untreated sewage and to increased surface run-off (Laydoo and Heileman, 1987). The major population centers adjacent to the Buccoo Reef system are the villages of Buccoo and Bon Accord, as well as numerous hotels and guest houses along the coast from Plymouth to Crown Point (see Figure 4). As a result of this development, pollution threatens the viability of the reef through accelerated eutrophication of the seawater resulting in increased algal growth. This development and subsequent pollution, combined with the effects of reef-walking, potentially reduces the coral resilience reducing the possibility of coral regeneration in damaged areas (Laydoo et al., 1998). Recognition of the resource value of the Buccoo Reef system resulted in its designation in 1973 as the country's only marine protected area under the Marine Areas Preservation and Enhancement Act of 1970 (Laydoo et al., 1998).

Buccoo Reef is considered an IUCN category IV protected area: "Protected area managed mainly for conservation through management intervention [Habitat/Species Management Area]" (WCPA, 1999). However, no effective management has been implemented since its designation as a protected area (Laydoo, 1998). 
Figure 3 - Reef Walking

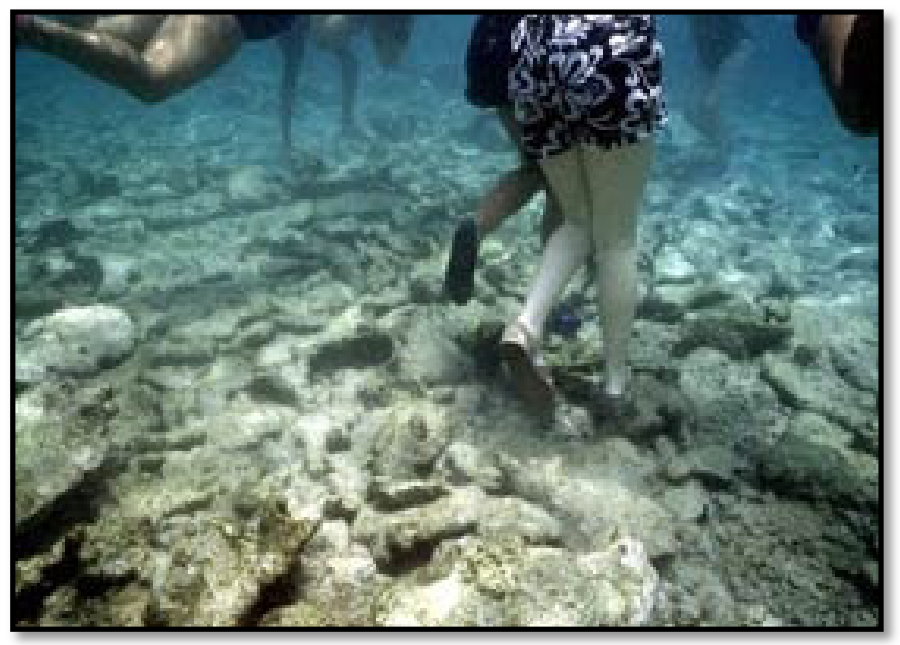

Source: Tobago Reefs - http://www.mytobago.info/diving06.php

Figure $4-\underline{\text { Buccoo and Bon Accord Region }}$

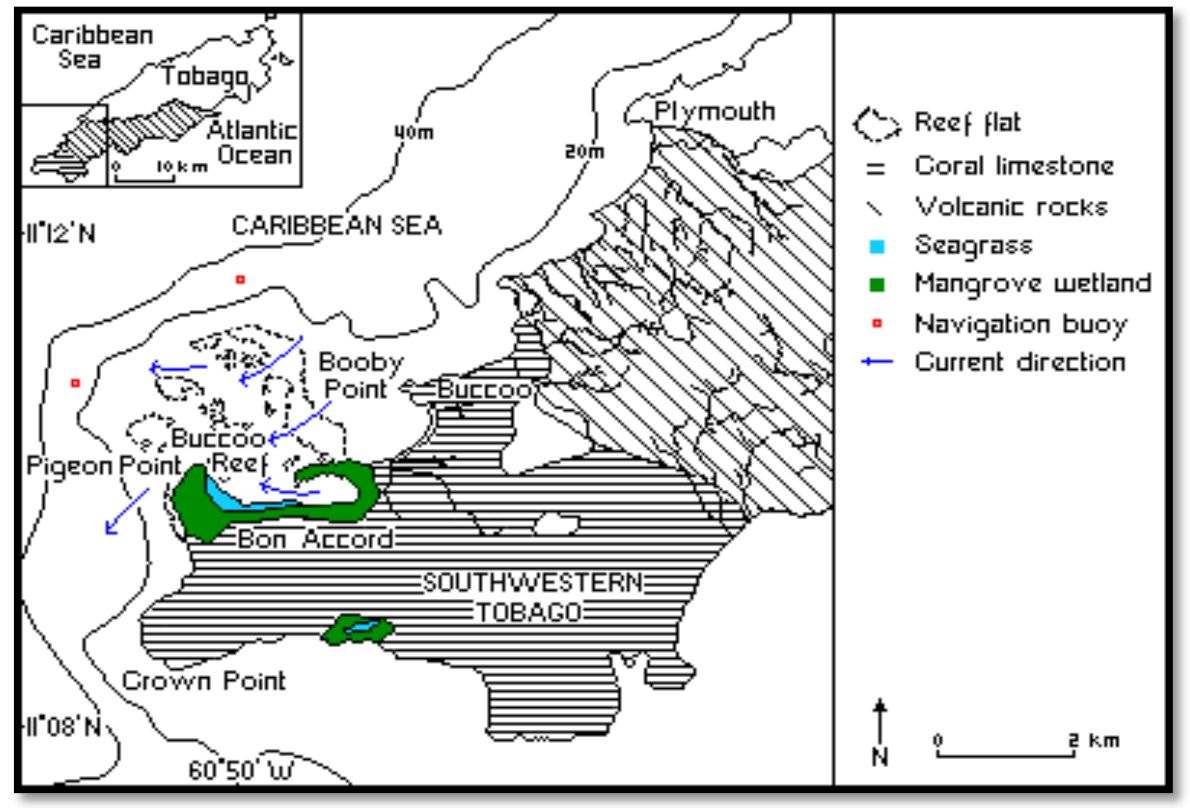

Source: www.unesco.org 
The Institute of Marine Affairs, with assistance from the Tobago House of Assembly (the local government authority), developed a management plan for the proposed Buccoo Reef Marine Park in 1996 and no modifications have been made since this drafted plan (Laydoo,1998).

As in many developing countries, the Buccoo Reef Marine Park is plagued with many adverse situations. On the basis of preliminary research, informal conversations with relevant authorities and stakeholders involved in the goings-on of BRMP and personal experiences I was able to point out some major issues affecting BRMP. There are inefficiencies within management and enforcement coupled with insufficient budget woes and lack of communication. As stated by Dr. Owen Day, the former director of the Buccoo Reef Trust, "the gaps and disconnects in the management of this reef have encouraged unsustainable practices which have ultimately combined to cause the continued degradation of this once majestic reef near to skeletal proportions" (Tobago Reefs).

The current state of this reef begs the question what the sustainable use should involve and how it can be achieved. Further, if the sustainable management of the reef calls for downsizing of the current level of tourism, this industry will obviously experience economic losses, which the industry stakeholders might expect to be compensated for. The management of this reef currently faces a budget crisis wherein the current budget set aside for management and monitoring is insufficient as stated by key informants, and the main financier of a key agency involved in management and monitoring has recently filed for bankruptcy posing threats to much needed management processes. Any regulatory program put in place to enforce a sustainable policy will 
require additional revenues. In order to finance a sustainable management plan, it is necessary to investigate the possibility of more reliable sources of funding like user based financing. Considering these issues, the specific objectives of this study are to:

1- Review existing management plan,

2- Estimate tourism trend and economic impact,

3- Assess attitude of locals and residents toward the Buccoo Reef management,

4- Analyze Willingness to Pay (WTP) of tourists for different management plans and assess the viability of user based financing, and

5- Make policy inferences

These objectives are set in a way such that they will provide the background information necessary to paint a clear picture of the current management plan, its specific objectives and visitor allowances along with designated budget to achieve such objectives to better understand the intended and actual goings-on of BRMP. Comparing the current management plan to the actual happenings of the BRMP can allow managers to identify the current weaknesses and propel them to make the relevant changes. Buccoo Reef is the most visited reef on the island and is an important contributor to marine recreational activities in Tobago thus analyzing this information can be of pivotal importance for adaptive management. It is important for the necessary authorities to encourage evaluation of the current management plan in order to determine whether the current plan is effective and if not, what actions must be taken in order to increase effectiveness and 
sustainability. Without an evaluation scheme, ineffective practices or ignored objectives will continue to fall under the radar rendering the intentions of the BRMP to be futile.

For successful protected area management it is also essential to examine the socio-economic issues surrounding the areas in question. As a result of the high visitation rate of BRMP and on the basis of existing literature, a contingent valuation model of visitor's willingness to pay seems to be a plausible option in order to access the viability of user based financing. All this information is integral to the process of determining how to correctly and effectively run this MPA and will be utilized to make policy inferences in order to achieve maximum sustainable resource use.

To understand the importance of MPAs, Chapter 2 will contain a detailed review of relevant literature. Chapter 3 will contain a description of my methodology, inclusive of my research questions, reasons for delineation of study site, data collection and finally I will attempt to explain my statistical model and the method used to determine the WTP of visitors surveyed. Chapter 4 will then be a presentation of the results obtained which will then be analyzed and discussed. In the final Chapter 5, the conclusions, recommendations and policy inferences will be stated. 


\section{Chapter II}

\section{Literature Review}

Considering the issues currently facing Buccoo Reef Marine Park and the intent of this research, chapter 2 will give a detailed account of the relevant literature surrounding marine protected areas (MPAs). This chapter will first take an in-depth look at MPAs, including a look at IUCN guidelines, different management plans and effectiveness of these plans. It will then look at the impact of tourism on MPAs and finally, possible funding options through ecosystem valuation methods.

\section{Marine Protected Areas (MPAs)}

Marine protected areas (MPAs) are declared principally to protect biological and environmental values in areas where such values are considered special (Davis and Tisdell, 1995). An MPA as defined by the IUCN is:

"Any area of intertidal or subtidal terrain, together with its overlying water and associated flora, fauna, historical and cultural features, which has been reserved by law or other effective means to protect part or all of the enclosed environment" (WCPA, 1999).

A significant use of marine protected areas is as an asset to support tourism, much of which is marine-based in Tobago. Continued growth in the tourism industry combined with unsustainable practices, may conflict with the ecological values which form the basis of marine protected area (MPA) status, and may lead to accelerated environmental degradation in marine areas and is likely to reduce amenity values in affected areas (Davis and Tisdell, 1995). If properly managed, tourism and recreational activities in 
coastal zones can promote conservation of ecosystems and economic development (Burke et al., 2001).

Along with the definition of an MPA, the IUCN states the following recommendations or guidelines on how to effectively establish an MPA:

1- Place MPAs in their wider complex ( considering interconnectedness of the environment and thus integrating land use management along with marine management)

2- Develop a legal framework

3- Work with relevant sectors (eg., fisheries, tourism, local communities, etc.)

4- Make partnerships with communities and other stakeholders

5- Select sites for MPAs (determined by resource use/local needs and intended goals of MPA)

6- Plan and manage MPA (using a systems approach, interdisciplinary teams and follow a clear sequence of decision-making)

7- Zoning (designating specific areas for different levels of usage)

8- Plan for financial sustainability (governmental funding, fund raising, donations, user fees or external donors)

9- Ensure research, monitoring, evaluation and review MPA Management Approaches \& Effectiveness

Management regimes are influenced by the ecological, cultural and political contexts of the regions in which they are established (MPA connections, 2004), and thus 
no one plan can be set for multiple MPAs over different regions. In general, literature has discussed two main, yet contrasting, approaches to marine resource protection: “Topdown" and "bottom-up."

The "top-down" model is a management strategy where scientific investigation leads the process of identifying and designating specific areas and is a model approach whereby planning usually involves a centralized government imposing regulations or laws on resource users (MPA connections, 2004), and thus can be very controversial as it gives rise to opposition by the general public as it fails to adequately take into consideration and represent the concerns of the multitude of stakeholders in the MPA designation process which can result in a community with little understanding of, or support for an MPA site proposal or its management plan (Brody, 2003). This top-down management strategy tends to produce 'paper-parks' especially in developing countries, in which natural resources continue to be degraded due to ineffective enforcement measures and little compliance with rules and regulations (Brody, 2003). This situation seems to be evident with regards to Buccoo Reef, where decisions about the BRMP are largely made by government officials or management authorities without considering the contributions of many stakeholders. The local community especially those indigenous to the Buccoo Village region, feels disrespected by the lack of communication of the management authorities to the general public, and feels that their opinions should be taken into consideration. Lack of communication and support of community involvement, had led to a community that is somewhat disenfranchised, rebellious and uninterested in contributing to protection of the resource. 
The "bottom-up" management strategy employs the emphasis on acknowledging local values and perspectives as well as adapting designations to prior use patterns (Fiske 1992 in MPA connections, 2004). The bottom-up model is a planning approach that usually combines scientific knowledge with traditional knowledge of the users in order to understand and accommodate how they rely on the resource (MPA connections, 2004). Protected areas, either terrestrial or marine, are diverse in their specifications and goals, but share a crucial common ingredient: the role of the public (Springer, 2006). It has thus been realized that biodiversity conversation initiatives cannot be thought in isolation of social issues (Mishra et al., 2009) and biodiversity conservation schemes that do not take local people into account not only raise ethical issues, but also run the risk of being selfdefeating (Few, 2000) since ignoring the role of local communities will only exacerbate the problems associated with natural resources (Camarago at al., 2009). It is important to note however, that social systems are made of complex components, some of which are inevitably oppositional; nevertheless these variable roles played by diverse groups of people can contribute to the success of the designated protected area, or in some cases, fracture the entire scenario (Springer, 2006).

Over the past two decades, it has become widely recognized that the management of protected areas should include the cooperation and support of local communities (Wells \& Brandon, 1992). There has been a growing realization that the conventional 'Gun and Guard' method of conservation is no more effective in dealing with the socioecological complexity and political dimensions of biodiversity conservation (Mishra at al., 2009). Dealing with such a multidimensional issue, requires integrated approaches that recognize the interconnectedness of social and ecological systems and attempt to link 
science, policy and societal goals through interdisciplinary methods of problem solving and multi-stakeholder involvement (Mishra et al., 2009). Failure to adopt an interdisciplinary approach to protected area management and manage protected areas as human ecosystems can compromise the biophysical values for which protection was sought (Lane, 2001). This realization has encouraged the development of 'communitybased conservation' (Mehta \& Kellert, 1998), which emphasizes the role of communities in decision making (Adams \& Hulme, 2001).

\section{Community Involvement}

Community-based conservation approaches to decision-making in the management of protected areas are increasingly being implemented (Bajracharya et al., 2005 ) and many projects have now been initiated in various countries, most notably in Africa, where implementation of such community-based conservation practices have contributed to decreases in poaching and improved conservation (Wainwright \& Wehrmeyer, 1998). Designation of protected areas can sometimes result in a variety of negative consequences for rural or local communities by means of restriction of access to traditionally used resources, disruption of local cultures and economies by tourists, resulting in social and cultural disruption and possibly enforced poverty (Bajracharya et al., 2006). These issues have heightened concerns and have led to the growing recognition that for protected areas to be effective, local people need to be closely involved in their management (Wells \& Brandon, 1992). Several research papers have emphasized that failure to recognize the relationship between nature and people can precipitate local social disruption among other negative impacts (Lane, 2001). The approach of community-based protected area management attempts to influence the 
thinking and attitudes with the hope that it will eventually lead to changes in behavior, although in some communities, such changes do not always occur (Infield \& Namara, 2001 in Bajracharya et al, 2005).

Achieving community-based conservation is very complex. It is very difficult to stipulate a single value or goal onto an entire community of varying stakeholders as that can be restrictive and ultimately ineffective because it does not represent the community as a whole (Springer, 2006). The extent of variation depends on many factors, such as, the size and character of the community in question, the social cohesion of that particular community and the underlying motivation in making unified decisions (Mascia 2004 cited in Springer, 2006). There is no single, definitive framework that can direct diverse communities toward full agreement of any particular issue, thus encouraging communities to come to a decision that represents a broad spectrum of motivations will facilitate the formation and acceptance of alternative and perhaps even more creative solutions (Chrislip, 1994 in Springer, 2006). It is therefore extremely necessary to understand the social dynamics of areas surrounding protected areas as it can have important implications for the implementation of management decisions.

The central idea of community-based management or 'co-management' as it is sometimes interchangeably referred, is the idea that if park managers can establish a cooperative relationship with local residents and park users, in which the responsibility is shared, then the task of the professional manager and the nature and importance of local management problems can be significantly changed (Lane, 2001). Establishing a cooperative relationship however depends on how the issue is addressed to stakeholders. Management must determine how best it can interact with the local community to 
achieve reciprocally acceptable goals (Chrislip, 1994). As suggested by Springer (2006), the best way to guarantee the accomplishment of these goals is through familiarity of the complex social connections within the community of interest (Springer, 2006). In order to gain an understanding of the intricate social dimensions of any community, it requires a close analysis of that particular community which will call for significant consultation and collaboration with various community members (Chrislip, 1994). Collaboration between conservation planners and stakeholders is crucial to integrating protected areas into the local socioeconomic fabric of the community, thus overcoming local opposition and behaviors that would otherwise undermine conservation goals while developing effective partnerships between local stakeholders and conservation planners (Lane, 2001). Co-management or community-based arrangements have the potential to provide economic benefits for local people, however the extent of the economic benefit is determined by the nature of the relationship between the community and managers and the willingness of the managers to consider local economic issues (Lane, 2001).

To achieve effective collaboration, approaches are required that effectively engage the local community in management and decision making, and that enable their livelihood needs to be adequately met (Bajracharya et al., 2006). This concept of linking conservation with community development has resulted in a major shift in conservation management, based on the assumption that if local communities derive some benefits from conservation, they will in turn be more likely to contribute to the conservation of biodiversity (Wells \& Brandon, 1992). The linkage of conservation ideals with the societal realm of protected areas addresses biological, cultural, economic and political 
concerns while empowering communities through effective collaboration and integration in conservation efforts (Granek and Brown, 2005).

Before gaining local stakeholder and institutional participation, it is imperative that stakeholder education be a prerequisite to the planning and participation process. Educational programs should be implemented that acknowledge stakeholder concerns and educate stakeholders about the benefits and limitations of implementing a protected area. Granek and Brown (2005) showed in their studies on the Comoros Islands that educating the local inhabitants about natural history resulted in greater understanding and appreciation of protecting local resources (Lundquist \& Granek, 2005). Education however, should not be limited to only stakeholders, but rather should include scientists and managers to be educated on issues that will increase their understanding of the socioeconomic processes that will habitually affect implementation (Lundquist \& Granek, 2005).

Education, though fundamental to success of an MPA, is not the only area in which focus needs to be placed. Of extreme importance as well is the need for the goal of the protected area to be clearly defined. Explicit goals and objectives that are defined early in the design process is important for improving communication and standardizing expectations of stakeholder groups (Lundquist \& Granek, 2005) thus allowing stakeholders to be fully aware of the expected outcomes and methods for measuring success consequently encouraging more willing support. 


\section{Management Examples}

Marine protected areas have met limited success in many developing countries and some researchers attribute part of these shortcomings to inadequate attention to the social context of conserving marine resources (Cinner, 2007). Marine protected areas are important in protecting the marine environment, but are also have substantial sociocultural impacts (Badalamenti et al., 2000). Research has shown that in many MPAs, the success of the protective initiatives often tends to be proportional to the degree of involvement of the local community (Badalamenti et al., 2000). Considering the fact that effective execution of community involvement programs is quite multifaceted, one may be curious as to how many programs have actually been implemented and what factors contributed to its success or demise.

Granek and Brown (2005) conducted a 3 year study that analyzed the comanagement practices implemented in Mohéli Marine Park, Comoros Islands. Their assessments proved that even though the co-management approach had some inevitable weaknesses, the strengths significantly benefited the park. They showed that comanagement that integrated education, use of indigenous local knowledge, capacity building and community commitment provided partial mitigation where there was a lack of resources, weak governmental enforcement and inadequate scientific data. Through this integration, the local empowerment that resulted contributed to the development of a conservation ethic that provided potential for long-term success through local interest (Granek \& Brown, 2005). Involving the community proved to be of significance because this particular park lacked adequate scientific data, therefore requiring traditional 
knowledge as a substitute for limited ecological data which in turn sparked local interest in being active in tracking the park's success.

Unfortunately however, with these strengths also exists shortcomings of this comanagement approach, for example, parks such as these that are established on the basis of limited scientific data and rely on traditional knowledge may hinder effectiveness. A lack of baseline data limits the ability of future research to quantitatively measure success (Granek \& Brown, 2005). As in many other developing countries, the problem of inadequate government resources affects the park's success, and although community involvement can significantly aid in an MPA's success, lack of adequate government enforcement can continue to plague these MPAs. Other shortcomings include larger scale political and economic issues such as overpopulation, or lack of available funding which can undermine conservation efforts. However, in spite of limited available science, technical and financial resources and federal personnel, the co-management strategy of Mohéli Marine Park has been compensated by the strength of the local community, allowing its success as the park has seen a notable increase in ecotourism with an average of 200 visitors per year (Granek \& Brown, 2005).

Successful community-based management has also been observed in the case of Puerto Morelos reef, México. In this MPA, the establishment and maintenance had five stages (a) community leaders who would participate in the project were identified (b) consensus on the need to protect the reef through discussion among stakeholders, NGOs and scientists were generated (c) involvement of government agencies in establishing the status of the MPA (d) take-over of decision-making by centralized government agencies and; (e) continues problem-solving process between the government and stakeholders 
(Rodríguez-Martinéz, 2008). As previously mentioned, education plays an important role and in Puerto Morelos, public education was a main factor in gaining community support for the creation and management of the MPA. General education programs began in the early 1990s with participation of NGOs and scientists and expanded to schools with local teacher researchers, tourist operators and MPA personnel in 2003 (Rodríguez-Martinéz, 2008). Permanent educational programs began in 2004 which were designed to teach tourist guides about the values, functions, uses and fragility of coral reefs in order to heighten their interest in coral reef conservation and to provide them with better tools for work (Rodríguez-Martinéz, 2008). Visual aids and public awareness materials such as websites, booklets and fliers were also used to educated students and the wider public. The efforts put into community education highly contributed to an increase in the willingness to accept the MPA designation and also allowed all community sectors to be open to participation during and after the creation phase. The ultimate result is that Puerto Morelos reef has a very cohesive management strategy that gives the community a sense of ownership of the process and readiness to comply, resulting in an increase in the development of social capital.

Pollnac et al. (2001) examined the factors that influence the success of community-based marine protected areas in the Visayas, Philippines. The Phillipines is an extreme example where governmental policy, international aid, universities and NGOs have resulted in the establishment of over 400 MPAs (Pollnac et al., 2001). However, only about 20-25 percent of these MPAs in the Phillipines are successful, raising concern that this high failure rate may result in the rejection of the community-based approach. The Pollnac et al. (2001) study was conducted on 45 community-based marine protected 
areas in the Phillipines to conclude what factors led to the small success rate and whether or not these factors can be used to better the situation of the other 75 percent of MPA designation. At the conclusion of their study, it was indicated that six main factors appeared to be the most important in the overall success of the community-based MPAs on their sample.

Population size was the first observed factor, where the population sizes of the successful MPAs was noted to be relatively small (Pollnac et al., 2001). It was observed that for initial cooperation, a perceived crisis was needed before the project was started, for example reduced fish populations. There was also the need for successful alternative income projects considering the community may not be able to use the resource after protection was designated. A relatively high level of community participation in the decision making process that was high on the democracy scale with, continuing advice from the implementing organization along with inputs from the municipal government were also noted. Though these factors were deemed the most important, it is important to note that they are not the only contributors and even though they worked in these areas the factors may differ in other areas.

Hind et al. (2008) conducted studies on Apo Island, Phillipines in attempt to show the benefits of community involvement (bottom-up approach). Hind et al. (2008) analyzed the effects of the transition of Apo Island from being rated one of the best community-involved MPAs to changing into a top-down, solely governmental organized MPA. Observations showed that the MPA went from being fully supported by the community to complete community disenchantment. This change in management strategy 
by governmental take over resulted in the exclusion of the community and stakeholder input, resulting is lack of interest and compliance to regulations.

Considering the complex heterogeneity of the existing community within the Buccoo Reef and Bon Accord region, sole community management may be very difficult to achieve as there will be a plethora of opinions and personal preferences to appease, giving rise to obstacles in achieving effective community management. In the aforementioned examples of successful community management of MPAs, the communities involved are somewhat fluid and more dependent on the resource and thus focused on the goal of conservation rather than that of personal gain as is the community of Buccoo Reef. The suggestion of a combination of both "top-down" and "bottom-up" strategies to ensure effective management therefore may be the most plausible option for BRMP. Recognition is growing for such a combined management strategy as being ideal, as it is an approach that is government-driven but also heavily involves stakeholders (MPA connections, 2004). This therefore can lead to an increase in the social capital of the region as involvement in the decision making process can heighten interest in conservation and protection of the MPA.

In the Caribbean there are said to be greater than 285 MPAs (Burke and Maidens, 2004). The management success of these parks highly varies, with some just being 'paper parks', and others being successfully managed (see figure 5). In order to obtain this information, Burke and Maidens (2004) analyzed effectiveness of MPAs on the basis of four major criteria: the presence of management activity and to what extent enforcement is executed, the presence of a management plan and the presence of resources. The results obtained showed that as much as $49 \%$ of MPAs in the Caribbean region are deemed as 
being inadequate with only $5 \%$ being considered good. Some studies suggest that MPAs are frequently unsuccessful as a reef conservation strategy especially in developing countries, where socio-economic factors such as poverty can drive resource exploitation and the capacity for enforcement is often lacking (McClanahan 1999).

Figure 5- Management Effectiveness of MPAs in the Caribbean



Source: Modified from Burke and Maidens, 2004.

\section{Tourism and Carrying Capacity}

Tourism is the fastest growing sector of the global economy, with coastal tourism being the largest sector of this industry. In many countries, especially developing small island states, tourism contributes a significant and growing portion of GDP and is often the major course of foreign exchange (Burke et al., 2001). In 1998, direct and indirect GDP from travel and tourism in the Caribbean was over US\$28 billion, accounting for approximately $25 \%$ of the region's total GDP (World Travel and Tourism Council 
(WTTC) 1997). In the Caribbean, tourism is largely coastal or marine in nature and has been built upon the traditional aesthetic appeal of beaches, a marine environment suitable for a range of recreational activities, and warm weather conditions all year round (Burke at al., 2001). Considering the lure of the natural environment, the tourism industry within the Caribbean benefits largely from 'pristine' surroundings, and thus, uncontrolled expansion and mismanagement can harm the very resources on which it is based (WTTC, 1997). Tourism growth rates vary greatly among Caribbean states, with U.S. Virgin Islands and Puerto Rico being 15-19\% between 1990 and 1994, while that of Grenada, Aruba, Trinidad and Tobago and the Caymans reported as being 33-37\% growth, and that of Belize, St. Lucia and Guadeloupe amounting to as much as $50-65 \%$ growth for the same time period (Burke et al., 2001).

Marine protected areas are established for the primary purpose of conservation or preservation (Agardy et al., 2003), but their multiple use designation often incorporates a recreation and tourism component (Sorice et al., 2007). Undoubtedly, these use values benefit local and regional economies while also raising awareness and support of coral reef conservation, but unfortunately however, tourism and recreation participation can pose various threats to the marine resources, especially to fragile ecosystems such as coral reefs (Sorice et al., 2007), thus illustrating the well-known concept of tourism as a double-edged sword and the tenuous balance between positive and negative impacts (Diedrich, 2007). In the past 20 years, there have been larger increases in visitation to marine protected areas in many parts of the world (Inglis et al., 1999).With this increase, is an associated increase in rates of participation in marine related activities such as snorkeling, scuba diving and reef walking (David and Tisdell, 1995) and thus, MPAs are 
increasingly challenged to maintain or increase tourism benefits while striving to protect the resource (Sorice at al., 2007).

Tourism has been thought of as a low-impact coral reef use, relative to extractive practices such as harvesting corals and fish for commercial purpose (Talge, 1993), however recent evidence has demonstrated that reefs may become degraded as a result of poorly planned or intensive tourist use (Jameson et al., 1999). A number of studies have shown that recreation and tourism activities such as scuba diving and snorkeling are threats to coral reefs because touching, standing, or trampling on reefs can cause serious damage such as coral breakage, abrasion and mortality (Hawkins et al., 1999). Studies conducted on reef flats in Egypt have proven that heavily trampled reef flat areas showed a linear increase of coral damage with increased trampling intensities resulting in reduced coral cover, higher amounts of coral damage, less old dead coral, less obligate corallivorous fishes and more herbivores (Leujak and Ormond, 2007). Considering these findings, it might become necessary to restrict the number of visitors to a site, which raises the question: How much use is too much?

To answer the question, one must consider looking at the notion of 'carrying capacity.' Carrying capacity in tourism is a term used often to measure the level of tourism or tourism development an area can accommodate without adverse effects on the resident community, the natural environment, or the quality of visitor experience (Burke et al., 2001). The basic concept of carrying capacity, the need for a limit of threshold in the tourist activity should be present in one way or other in the concerns and priorities of local policy makers for sustainable tourism development (Kostopoulou and Kyritsis, 2006). However, to the extent that tourism related pressures on the natural environment 
create problems on the functioning of protected areas, management agencies need to determine what the various thresholds should be (Kostopoulou and Kyritsis, 2006).

When considering thresholds, research has proposed two distinct carrying capacity concepts. Firstly there is the notion of, "ecological or biological carrying capacity," defined by Martin and Uysal (1990) as the maximum number of tourists that can be accommodated without causing excessive environmental degradation; and by Hawkins and Roberts (1997) as the amount of use below which an ecosystem can tolerate the amount of disturbance or stress, but above which degradation ensues (Leujak and Ormond, 2008). Secondly, there is the concept of "social carrying capacity," which is defined as the level of use before a decline in users' recreation experience or satisfaction begins (O’Reilly et al., 1986).

Social carrying capacity has been proposed as a management tool for use in coastal tourism, with a decline in attractiveness of a beach location, as detected by a decline in visitor numbers being taken as an indicator of unsustainable resource use (O’Reilly, 1986). Any tourist destination where the environment is important can lose its attractiveness through deterioration of the environment most likely because of crowding. Several studies have been undertaken to investigate visitor perceptions, mostly in terrestrial settings, with only a few in marine environments (Leujak and Ormond, 2007) and most of these studies have confirmed that crowding is a major contributor to visitor dissatisfaction with perceptions of crowding depending on different factors such as visitor characteristics and the location where encounters take place $\left(\mathrm{O}^{\prime}\right.$ Reilly et al., 1986). Studies have shown that crowding norms appear strongly dependant on personal preference and experience, with visitors with greater experience of nature being more 
sensitive to visitor density (Leujak and Ormond, 2007). Intensified recreational use has been shown to reduce recreational enjoyment as negative impacts such as litter, or damage to plants, trees or corals tend to reduce aesthetic appeal and overall experience, although individuals with a lower degree of environmental concern appear to be more accepting of such impacts (Priskin, 2003). Visitor behavior also has an influence on a location's carrying capacity, as visitors may either simply not be aware of the impact they are having, they may be unable to change their behavior as a result of inexperience (for example inexperienced snorkelers or weak swimmers may be in need of instant rest while being out on a reef), or they may be unaware if existing regulations (Leujak and Ormond, 2007). As such it is important to take visitor perception, awareness and satisfaction into account when accessing any tourist destination, or in this case, a protected area as it can provide essential information for sustainable management (Uyarra et al., 2009).

Leujak and Ormond (2007) used this notion of social carrying capacity and administered questionnaires at various park locations in Egypt which addressed activity preference, coral reef knowledge and park regulation awareness. Visitor perception of reef quality and crowding were also taken into consideration. On the basis of their findings, it was estimated that to achieve a greater than $50 \%$ of visitors being satisfied about reef health, average coral cover would need to be around 25 to $30 \%$, whereas a decrease of coral cover to $20 \%$ would leave only $40 \%$ of visitors satisfied and a reduction to $10 \%$ would leave only $25 \%$ satisfied (Leujak and Ormond, 2007). Results from this study showed that experienced recreationalists were more susceptible to overcrowding, preferring fewer people, whereas the less experienced showed preference to larger crowds. Various literatures have stated that determining the carrying capacity of a reef 
system is highly specific and still somewhat not fully understood. However, despite the difficulty of accurately assessing the carrying capacity of coral reefs for recreational use, the concept of carrying capacity remains an important and useful tool for coral reef management (Davis and Tisdell, 1995). Management must develop a concept that establishes the best allowable rate of visitation for the specific park in question as there is no one way to determine this since each site will have varying factors acting on it. It is important to assess these factors to allow for sustainable tourism within any protected area. The management plan of BRMP has indicated the need to establish some sort of 'cap' on visitation to the reef in order to achieve sustainable usage however no methods to achieving this goal have been mentioned. Sustainable tourism development not only has the potential for longer-term economic benefits for a community, but also can serve to limit environmental degradation (Burke at al., 2001).

\section{Financing MPAs}

Though achieving sustainable tourism plays a pivotal role in the management success of marine protected areas, numerous articles have identified the main problem resulting in ineffectiveness of the MPAs as being attributed to a lack of sustained funding to execute various aspects of management. In the developing world, sustainable conservation funding mechanisms are extremely scarce (Baral at al., 2008). Lack of adequate funding is said to be the main reason for the proliferation of 'paper parks' especially in the Caribbean as it limits the ability of managing entities to carry out critical tasks such as boundary delineation, enforcement and monitoring, visitor management and education (Baral et al., 2008). Though funding is merely one factor affecting MPAs and cannot be deemed the sole cause of MPA management failure, however it is one of the 
most important aspects of management as without it, other aspects cannot be effectively achieved. It is important therefore for funding mechanisms to be a main part of any MPA management plan as its importance should not be underestimated or overlooked.

Funding for MPAs is obtained from many sources that include direct central government support, public donations, trust funds and licenses, amongst others. Studies have shown that reliance solely on the aforementioned sources of obtaining funding is highly risky and subject to unpredictable fluctuations and are therefore unsustainable (Depondt and Green, 2006). For an MPA to be financially sustainable, managers and relevant government agencies must ensure that they maximize the use of the finances they collect; understand exactly the financial benefits and costs involved in maintaining an MPA; understand the socioeconomic fabric of the community and stakeholders and allocate resources accordingly; be innovative and use a variety of novel financial mechanisms and tools; and create a legislation and framework that allows financial flexibility and independence of the MPA (Emerton et al., 2005). Studies have shown that MPAs only become truly successful and economically sustainable when they reach a selffinancing status (Davis and Tisdell, 1996). In the case of BRMP, government subvention provides a large portion of funding for the daily management of the park. However, given the reality of national fiscal constraints facing government, and the need to channel scare resources into other areas which have higher priority within the country's development objectives has resulted in a situation whereby the park is inadequately funded, understaffed and unable to satisfy basic management requirements (BRMP Management Plan). The inability of national budgets throughout the region to adequately finance protected areas on an ongoing basis, has led to the examination of alternative strategies 
that address the need for revenue generation while maintaining the resource conservation as a priority (BRMP Management Plan). Much of the funding for national parks in the region has come from international and regional donor agencies however these sources tend to have many stipulations that may counteract with intended local agendas. The long term success of a national park as stated in the BRMP management plan, will depend on the development of the institution and administrative capability to establish and retain an adequate sustainable revenue base (BRMP Management Plan). As part of the revenue generating mechanisms, the BRMP management plan has proposed incorporating several revenue generating opportunities such as:

- revenue from use or development of state marine and terrestrial property;

- concession fees for service providers within the park;

- commercial-user licensing fees (both non-consumptive and consumptive);

- donations from commercial houses in Trinidad and Tobago;

- fines and penalties for breaches of park regulations;

- permits; and

- royalties

However, currently no mechanisms exist by which government can realize revenues directly from the users of the BRMP.

Tourism could be a major source of revenue, especially in developing countries, for self-financing of protected areas (Dharmaratne et al., 2000). Tourism in the form of user fees to use or enter protected areas has been praised as a way to raise revenue to finance MPAs, and therefore increase their management capacity (Dharmaratne et al., 
2000). Although user fees as a means of funding an MPA is considered to be very lucrative, the system of user fees presents some disadvantages, notably with regard to fee collection (Green and Donnelly, 2003 ), and possible conflicts with conservation goals (Depondt and Green, 2006). However, revenue from tourist and diver user fees remains critical for the sustainable management of many MPAs (Depondt and Green, 2006). Within the Caribbean region, user fees have proven to be a capable MPA funding source. A good example is the Bonaire National Marine Park in Bonaire, Netherlands Antilles, where it has been shown that significant revenue can be collected via appropriately tailored user fees, with the amount of this revenue significantly exceeding the requirements of the management authority without adversely affecting area tourism (Thur, 2010).

The presence of marine protected areas provides support for tourism, which by generating income, makes a contribution to national development goals and economic growth (Mathieu et al., 2003). Considering that government funds are most times inadequate, and that NGO funding is usually short term and limited, it is important to optimally capture and monetize the recreational benefits from tourism (Tongson and Dygico, 2004). The valuation of recreational services from beaches and coral reefs located within the boundaries of protected areas can contribute to the formulation of sustainable tourism and natural resource management policies, particularly in small island developing states with economies largely dependent on fragile coastal ecosystems (Edwards, 2009). Valuing the protection of habitats and species provided by MPAs is one of the ways to identifying and developing potential financing mechanisms and economic incentives for effective MPA management (Ransom and Mangi, 2007). 


\section{Non-Market Valuation}

The most widely used non-market valuation techniques for measuring recreation or tourism values of coral reefs are the contingent valuation method (CVM) and the travel cost method (TCM). The contingent valuation method (CVM) is one of the standard approaches for valuing non-marketed resources, such as recreation, wildlife and environmental quality (Haneman et al., 1991). The use of a contingent valuation approach is very important since marine resources produce benefits which cannot be valued with traditional net revenue analysis (Mathieu at al., 2003). Contingent valuation method is now used worldwide, both by government agencies and the World Bank for assessing a variety of investments (Hanemann, 1994), and is currently widely used in economic literature to estimate the benefits from coral reefs since it is capable of capturing the direct use and indirect use and non-use values of the environmental goods and services (Spurgeon, 1992). Contingent valuation method is a direct method of determining an individual's willingness to pay (WTP) by eliciting people's preferences for public goods. Contingent valuation method is a survey method whereby the individual is provided with information about the resource, in this case is BRMP, and is given a scenario and asked how much they would be willing to pay (or accept in some cases) for a some specified policy change or change in the resource (Ransom and Mangi, 2010), for better preservation or sustainable utilization. The WTP amounts obtained are therefore contingent upon the hypothetical market presented to the respondent (Mitchell and Carson, 1989). Though this form of valuation of an MPA has gained acceptance as it has been fine tuned over the years, there is still a level of uncertainty and apprehensiveness since the situation presented to the respondent is a hypothetical one, thus individuals can 
cause a strategic bias by either over or underestimating their response for their own personal benefit (Field and Field 2006). A hypothetical bias may also occur if respondents answer the question to please the interviewer, or state that they would be willing to pay more than they actually would, knowing that they will not have to spend real money at the time of the interview (Ransom and Mangi, 2010). Information bias is also seen as a potential problem as individual responses can be conditioned based on the amount of information provided to respondents during the interview (Ransom and Mangi, 2010). Raising these concerns has prompted the National Oceanic and Atmospheric Administration (NOAA) Contingent Valuation Panel to recommend guidelines to ensure the reliability of contingent valuation surveys (Ransom and Mangi, 2010). The NOAA panel has suggested that surveys should be conducted as in-person interviews (as opposed to other methods of phone or mail interviews); surveys should use a binary discrete choice question (as opposed to open ended method); and surveys should have a careful and specific description of the good and its substitutes (Arrow et al., 1993).

The TCM is a method used in several studies to measure the demand and/or consumer surplus attached to coral reefs (Ahmed at al., 2007). Using this method, willingness to pay estimates can be determined indirectly. The travel cost method utilizes the fact that travelling to a site, an MPA in this case, has a cost associated with it (Field and Field, 2006), and is often used to estimate the value of public recreation sites. Travel cost method is thus a recreational travel demand model that allows for estimating consumer surplus as a proxy for net WTP of an average tourist for an average number of visits in a given time period (Reid-Grant \& Bhat, 2009) thus allowing for the value of the MPA to be determined. The assumption behind this method is that people will respond to 
the change in the cost of transportation to a recreational area similarly to how they would respond to a change in price of admission fee (Freeman, 1993). The travel cost method is a good means of determining the value individuals place on the amenity as it assumed that person will only pay a certain amount based on they value the resource and no more. It is hypothesized that the recreation demand (measured as number of visits to the amenity) is dependent on a number of economic, demographic and recreation-related variables. The time period for the demand variable (visitation) is usually chosen to be over a 5 year period or more, which allows for more variation in estimating the demand. If the time period was less than 5 years, the demand magnitude would be very small thus resulting in model not capturing a significant degree of variation. This method also requires a statistically significant number of users in order for the estimates to be trustworthy and relevant.

\section{Willingness to Pay Benefits}

Determining WTP estimates proves to be beneficial as it can be used to enlighten resource managers, government or other decision makers about how people value the resource at hand. This knowledge can allow them to price the resource appropriately with minimal opposition from the general public while maximizing economic benefits. Studies conducted by Arin and Kramer in the Philippines showed that conducting a WTP survey proved that the majority of tourists visiting these reefs are willing to pay an entrance fee to visit marine sanctuaries. Annual potential revenues ranged from US\$0.85-1million and could be used to support coral reef conservation and possibly the creation of alternative employment opportunities for locals (Arin and Kramer, 2002). Similarly, studies conducted by Thur (2010) showed through WTP estimates for Tubbataha Reef National 
Marine Park in the Phillippines, that significant revenue could be collected via appropriately set user fees significantly exceeding the requirements for the management authority(Thur, 2010). Blakemore and Williams, (2008) estimated WTP of British tourists valuation of a Turkish Beach (Olu Deniz) where $87 \%$ of British respondents expressed a positive willingness to pay. Studies also conducted in Jamaica showed that $43 \%$ of tourists interviewed said that they would be willing to donate to an MPA and therefore significant monies can be obtained in this way (Reid-Grant and Bhat, 2009). The WTP studies of the visitors of the Annapurna Conservation Area in Nepal have also shown encouraging results where visitors are willing to pay substantially more than the current entry fee (Baral, N., et al, 2008).

On the basis of the aforementioned literature, the importance of coral reefs and necessity for effective management is evident. As shown, effective management is possible; however requirements may vary depending upon location, ecological status, community structure and culture, and socioeconomic dynamics surrounding the particular reef in question. Though effective management is a multifaceted approach, one constant that must be taken into consideration and must be included and promoted, is the sustainable usage of these fragile marine resources in order to assure their continued existence. Tourism supported by these reef ecosystems is a very lucrative business, especially for small-island developing states, and if improperly managed can be selfdefeating and ultimately destroy the very environment it depends on.

Buccoo Reef is the most visited reef on the island of Tobago and thus, on the basis of the literature and the aforesaid positive results, a contingent valuation model of visitor's willingness to pay seems to be a plausible option to investigate. On the basis of 
the results gained it can then be used to determine the potential of a complete user-based financing scheme. 


\section{Chapter III}

\section{Methodology}

After reviewing the plethora of information on the importance of coral reefs and the necessity for sustainable usage and the subsequent potential for economic gain, and considering the problems that face the BRMP and the information gained about this reef, it led me to develop a more focused research aim and research questions that will effectively address the main issues plaguing this reef: namely management, tourism and economic issues.

This chapter will first explain the research aim of this study and the subsequent research questions. It will then discuss the characterization and delineation of the study site in Tobago. The methodology used to answer the research questions will then be presented in three stages. After explanation of the methodology, the statistical model and model variables will be discussed and finally the data collected will be presented.

\section{Research Aim}

The aim of my research was to examine the current management plan of BRMP, assess the current level of reef use in relation to its carrying capacity, and conduct a nonmarket environmental economic analysis to explore the potential of a user-based financing management scheme, all to promote sustainable practices.

\section{Research Questions}

In order to achieve my research objectives, the following research questions were asked and the subsequent hypotheses were made: 
1- Is the current Buccoo Reef management plan ecologically effective and economically viable?

i. Hypothesis 1: The current management plans are ecologically ineffective which affects the economic viability

2- Does the current level of tourism at the Buccoo Reef exceed its carrying capacity?

ii. Hypothesis 2: The current level of tourism at the Buccoo Reef largely exceeds its carrying capacity

3- What is the potential for instituting a user-based financing system?

iii. Hypothesis 3: A user-based financing system is highly possible if adequate awareness about the Buccoo Reef and management processes are readily available

\section{Characterization of Study Area}

The Buccoo Reef/ Bon Accord Lagoon system ( $\left.11^{\circ} 10^{\prime} \mathrm{N}, 60^{\circ} 57^{\prime} \mathrm{W}\right)$, is located on the leeward coast of south western Tobago (see Figure 3), and is considered the best example of contiguous coral reef, seagrass bed and mangrove swamp in the country (Juman and Bacon, 2002). There is no riverine inflow or drainage basin, just ephemeral streams and surface drains. The fringing reef system is approximately $7 \mathrm{~km}^{2}$ in area, characterized by five insular emergent platforms to the north, a shallow sandy lagoon with a patchy distribution of coral communities, and the mangrove-fringed Bon Accord Lagoon in which a seagrass community is present (Laydoo et al., 1998).

Guided tours to the reef were initiated in the 1930s. Today, the primary activities associated with visitor use at Buccoo Reef include glass-bottom boat tours to the Outer Reef flat, the Coral Gardens, and the Nylon Pool, along with reef-walking and snorkeling 
on the shallow backreef areas of the Outer Reef flat (see Figure 6a $\&$ b, 7 and 8). Sportdiving occurs at fore-reef sites, but this activity is not common at Buccoo Reef because of the presence of higher quality dive sites at other reef localities in Tobago (Laydoo et al., 1998).

Figure 6a - Glass Bottom Boat Tour

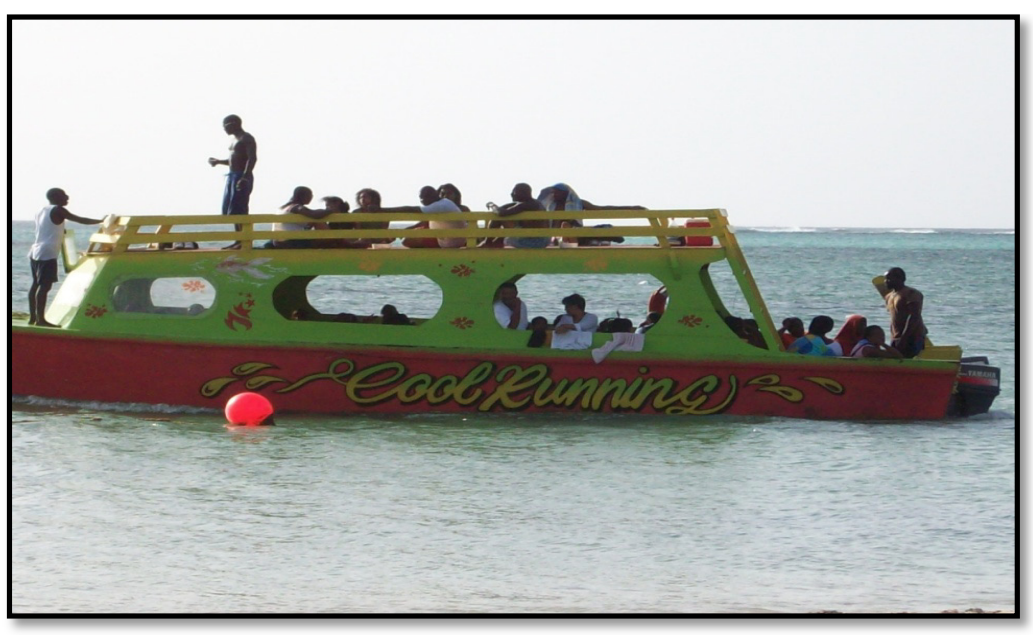

Source: Personal photograph

Figure $6 \mathrm{~b}$ - Glass bottom boat Tour



Source: Personal photograph 
Figure 7 - Glass Bottom Boat Tour - Coral Gardens



Source: Personal photograph

Figure 8- $\underline{\text { Nylon Pool }}$

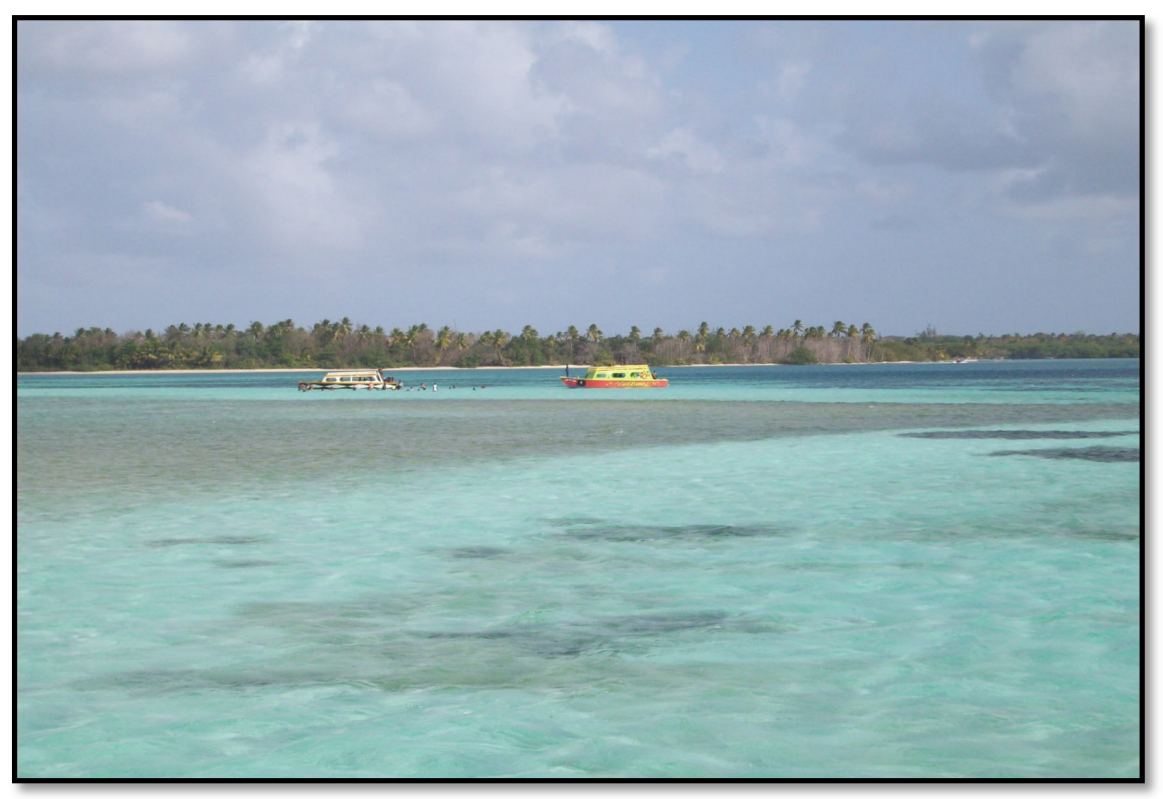

Source: Personal Photograph 


\section{Delineation of Study Site in Tobago}

On the basis of meetings with the relevant management authorities in Tobago, and personal observations, WTP surveys were conducted mostly on the two main beaches where the majority of the boat tours are undertaken: Store Bay and Pigeon Point beach (see Figure 9) as it is on these two beaches where the largest volume of visitors gather. The local resident surveys were conducted in the general Bon Accord and Crown Point area (indicated by the circle in Figure 9) as the individuals in these areas are most affected by the BRMP happenings.

\section{Figure 9 - WTP Survey Sites}



Image provided by: Google Earth 
In order to answer the aforementioned questions, the methodology was implemented in three stages:

1. Evaluate the current management plan

Firstly, the existing management plan was reviewed. Over the course of five weeks in Trinidad and Tobago, two weeks being spent in Trinidad, meeting were first held with key members of the Institute of Marine Affairs in Trinidad, where access to relevant background information was granted from the marine library regarding Buccoo Reef. With this background information in hand, three weeks were spent in Tobago where meetings were held with key members involved in the management of Buccoo Reef from the Department of Marine Resources and Fisheries, and the Buccoo Reef Trust where information was obtained regarding the management and daily goings-on of the BRMP. Supplementary tourism information was obtained though meetings with the National Tourism Board and Tobago House of Assembly (THA). All information received was then analyzed to determine what use is currently allowed, how many boat trips are allowed per day, whether boats are registered, how or if the management plan is enforced, cost of enforcement, time-line of trips and where trip funds are allocated.

Attitudes of locals and residents toward the Buccoo Reef current management plan were also assessed by conducting a survey of local residents within the Buccoo and Bon Accord Area (indicated by the circle in Figure 9). Local residents surveyed were randomly chosen adults and included those both directly and indirectly affected by the visits to the reef, inclusive of hoteliers, concession stand owners, craftsmen and vendors, beach goers, recreational personnel (jet-ski operators, boat tour operators etc.) and the general public in and amongst the Buccoo and Bon Accord region. Surveys consisted of 
17 questions that required some yes/no responses, some open-ended and some "agree/disagree/neutral" responses (see Appendix 1). Questions were set to assess the knowledge of BRMP rules and regulations, attitudes towards current protection and management plan and staff and overall satisfaction.

2. Assess the current tourism intensity in relation to the carrying capacity

The tourism trend and economic impact was estimated by informal interview of secondary sources: the Buccoo Reef Trust, the National Tourism Board and the Tobago House of Assembly. Numbers and trends of tourists for Tobago would be obtained from the National Tourism Board and numbers of visitors to the reef will be obtained from the Buccoo Reef Trust. The revenue gained via this tourism was obtained from the Tobago House of Assembly. The number of hotels available for tourists within the region of both the beaches used as entrance for the reef trips was obtained from the Board of Tourism. Boat trip operators were randomly selected and informally questioned to determine how many visitors they allow per trip and on the basis of information provided by the management plan these numbers were compared to actual observed numbers to determine whether or not there was compliance with the regulations. Following Inglis (1999), tourism carrying capacity was estimated by exploring the crowding norms of Buccoo Reef and comparing it to the crowding norms of the highly visited Great Barrier Reef. Inglis (1999) analyzed the crowding perceptions relative to the area of the marine protected area used for recreation and through survey method, determined what level of use was considered socially acceptable in a given area to ensure the best recreational 
experience. Using the information gained through the management agencies of visitor numbers and recreational area used, the social carrying capacity of BRMP was explored.

3. Economic valuation for assessing user-based financing system

The non-market approach of conducting a contingent valuation method was undertaken. As previously mentioned, the contingent valuation method (CVM) employs hypothetical questions to elicit respondents' nonuse values and subsequent maximum WTP for a specified change in an environmental amenity (Field and Field, 2006): in this case the Buccoo Reef. Because current adverse financial situations threaten efficient reef management, respondents of the survey were asked if they would be willing to pay a given amount of US\$ (which was selected at random out of 10 different amounts) for improved management and preservation of the coral reef. This was a dichotomous choice question with the choice of a YES or NO answer. The WTP Surveys were conducted to asses not only tourist perceptions, but also those of the local visitor community (domestic tourists) and was carefully designed to bring awareness to the current financial issue at hand and provided enough information to allow respondents to give informed responses. Surveys were administered to adult visitors to Buccoo Reef and were divided into five sections:

1) Purpose, motivations and activities;

2) Assessment of management knowledge;

3) Environmental attitudes; 
4) WTP where participants will indicate if they will be willing to pay a certain amount (out of 8 random amounts, with separate choices of random amounts for international versus domestic tourists due to obvious disparity of income); and 6) Demographic information.

The surveys contained a mixture of multiple choice yes/no questions, ordered-rank responses and a few open ended questions (see Appendix 2). Surveys were conducted in English and an explanation of the current reef situation was verbally discussed prior to survey taking.

\section{Statistical Model}

In order to determine the mean WTP of visitors to the BRMP a contingent valuation model was employed in this study. The conventional, single-bound CVM survey involves asking an individual if he/she would pay some given amount, A, to secure a given improvement in the environmental amenity. Following Hanemann (1991), the probably of obtaining a 'NO' or a 'YES' response can be represented by:

$$
\begin{aligned}
& P^{n}(\mathrm{~A})=\mathrm{H}(\mathrm{A} ; \Phi), \\
& P^{y}(\mathrm{~A})=1-\mathrm{H}(\mathrm{A} ; \Phi),
\end{aligned}
$$

Where $\mathrm{H}(\bullet ; \Phi)$ is some statistical distribution function with parameter vector $\Phi$. As in Hanemann (1984), this statistical model can be interpreted as a utility-maximization response within a random utility context, where $\mathrm{H}(\bullet ; \Phi)$ is the cumulative density function of the respondent's true maximum WTP as the utility maximization implies:

$$
\begin{aligned}
& \operatorname{Pr}\{\text { No to } \mathrm{A}\} \leftrightarrow \operatorname{Pr}\{\mathrm{A}>\text { maximum } \mathrm{WTP}\} \\
& \operatorname{Pr}\{\text { Yes to } \mathrm{A}\} \leftrightarrow \operatorname{Pr}\{\mathrm{A} \leq \text { maximum } \mathrm{WTP}\}
\end{aligned}
$$


Following Hanemann (1984), the probability that respondent is likely to say YES was assumed to be dependent on a variety of independent variables and was assumed to follow the logistic regression model stated below:

$$
\mathrm{P}(\mathrm{YES})=\frac{1}{1+e^{-\left(b_{0}+\beta A+X \Phi+\varepsilon\right)}}
$$

Where $e$ is the base of natural logarithms, $b_{0}$ is the intercept, $\beta$ is the coefficient of the bid variable $A, X$ is the vector of all other independent variables, and $\Phi$ is the vector of the respective slope parameters.

Following Hanemann (1984), the median WTP was subsequently calculated by using estimated parameters from (3):

$$
\mathrm{WTP}=\frac{b_{0}+\bar{X} \Phi}{\beta}
$$

Where $\bar{X}$ represents the vector of average values of the independent variables.

The single-bound CVM survey leaves a large range of potential 'true' WTP values of individuals. The statistical design for binary response $\mathrm{CV}$ surveys as a means of controlling the accuracy of the estimates of the benefits associated with the environmental good or plan has stimulated more interest as of late (Alberini, 1995). In this study, due to the disparity of income between domestic and international visitors and the subsequent different choices of the random bid amounts posed during questioning, the double-bound CVM approach is better suited for giving more accurate values of the true WTP estimates for both sets of respondents: international versus domestic. Therefore, following Hanemann and Carson (1985), the respondent was engaged in two rounds of 
bidding to obtain statistical efficiency of the dichotomous CVM. Participants respond to a first dollar amount and then face a second question involving another dollar amount, higher or lower depending on the response to the first question (Hanemann et al., 1991). The level of the second bid is contingent upon the response to the first bid where if the individual responds 'YES' to the first bid, the second bid (represented by $A_{i}^{h}$ ) is some amount greater (in this case twice the amount) than the first bid $\left(A_{i}<A_{i}^{h}\right)$; and if the first response is 'NO' the second bid $\left(A_{i}^{l}\right)$ is some amount (in this case half) smaller than the first bid $\left(A_{i}^{l}<A_{i}\right)$. This therefore gives four possible outcomes with either (a) both answers being 'yes'; (b) both answers being 'no'; (c) a 'yes' followed by a 'no' and (d) a 'no' followed by a 'yes' (Hanemann et al., 1991). Following Hanemann (1991), the likelihoods of these outcomes are $P^{y y}, P^{n n}, P^{y n}$, and $P^{n y}$ respectively. The formulas for these likelihoods, under the assumption of a utility-maximizing respondent, are as follows:

$$
\begin{gathered}
P^{y y}\left(A_{i}, A_{i}^{h}\right)=\operatorname{Pr}\left\{A_{i} \leq \max \mathrm{WTP} \text { and } A_{i}^{h} \leq \max \mathrm{WTP}\right\} \\
=\operatorname{Pr}\left\{A_{i} \leq \max \mathrm{WTP} \mid A_{i}^{h} \leq \max \mathrm{WTP}\right\} \operatorname{Pr}\left\{A_{i}^{h} \leq \max \right. \\
\operatorname{WTP}\} \\
=\operatorname{Pr}\left\{A_{i}^{h} \leq \max \mathrm{WTP}\right\}=1-\mathrm{H}\left(A_{i}^{h} ; \Phi\right), \\
P^{n n}\left(A_{i}, A_{i}^{l}\right)=\operatorname{Pr}\left\{A_{i}>\max \mathrm{WTP} \text { and } A_{i}^{l}>\max \mathrm{WTP}\right\}=\mathrm{H}\left(A_{i}^{l}, \Phi\right), \\
P^{y n}\left(A_{i}, A_{i}^{h}\right)=\operatorname{Pr}\left\{A_{i} \leq \max \mathrm{WTP} \leq A_{i}^{h}\right\}=\mathrm{H}\left(A_{i}^{h} ; \Phi\right)-\mathrm{H}\left(A_{i} ; \Phi\right), \\
P^{n y}\left(A_{i}, A_{i}^{l}\right)=\operatorname{Pr}\left\{A_{i} \geq \max \mathrm{WTP} \geq A_{i}^{l}\right\}=\mathrm{H}\left(A_{i} ; \Phi\right)-\mathrm{H}\left(A_{i}^{l}, \Phi\right) .
\end{gathered}
$$

Unlike the single-bound approach, the double-bound method allows the researcher to narrow down the range of potential true WTP values. In (7) and (8) for 
example, the second bid places both and upper and lower bound on the respondents unobserved true WTP, while in (4) and (5), the second bid sharpens the value by raising the lower bound or lowering the upper bound. Hanemann et al. (1991) have demonstrated that adding a follow-up bid to a conventional, dichotomous choice CV survey substantially improves the statistical information provided by the data.

Given a sample of $N$ respondents, where $A_{i}, A_{i}^{h}$ and $A_{i}^{l}$ are the bids used for the $i$ th respondent, the log-likelihood function would take the following form:

$$
\text { (9) } \begin{aligned}
\ln L^{D}(\Phi)= & \sum_{i=1}^{N}\left\{d_{i}^{y y} \ln P^{y y}\left(A_{i}, A_{i}^{h}\right)\right. \\
& +d_{i}^{n n} \ln P^{n n}\left(A_{i}, A_{i}^{l}\right) \\
& +d_{i}^{y n} \ln P^{y n}\left(A_{i}, A_{i}^{h}\right) \\
& \left.+d_{i}^{n y} \ln P^{n y}\left(A_{i}, A_{i}^{l}\right)\right\}
\end{aligned}
$$

Where $d_{i}^{y y}, d_{i}^{n n}, d_{i}^{y n}$, and $d_{i}^{n y}$ are binary-valued indicator variables and the formulas for the corresponding probabilities are given by (5) - (8).

Following, Effron's measure for binary dependent variables, a modified $\mathrm{R}^{2}$ was calculated by:

$$
\mathrm{R}^{2}=1-\frac{n}{n_{1 n_{2}}} \sum_{i=1}^{n}\left(y_{i}-\hat{y}_{i}\right)^{2}
$$

Where $\left(y_{i}-\hat{y}_{i}\right)^{2}$ is the squared error, and $\mathrm{n}$ is the total sample size, $n_{1}$ is the number of domestic respondents, and $n_{2}$ is the number of international respondents (Effron, 1978). 


\section{Model Variables}

Table 1 shows the definition of the variables used in the model. It was hypothesized that the probability of a respondent saying "YES" to the bid amount is based on the following independent variables; the bid amount, either first level or second level (BIDFL or BIDSL), gender (GEN), education level (EDNLVL), per capita income (PRPIN), visitor origination, either domestic or international (INTER), the knowledge that BRMP is a protected area (KNWBRMP), the recreational activities undertaken while on the BRMP tour (RECRTN), and the current satisfaction (CURSATIS). Through trial and error of testing other independent variables in the bivariate probit model, it helped determine that the aforementioned independent variables would most likely influence the decision of the visitors' willingness to pay for improved conservation and preservation of Buccoo Reef Marine Park. These variables allowed for the most suitable and accurate model for predicting visitors' willingness to pay in this study.

\section{$\underline{\text { Table 1- Model Variables }}$}

\begin{tabular}{|c|c|}
\hline DIST & Travel Distance to Tobago (miles) \\
\hline INTER & International (if DIST $>19$ miles INTER $=1$ ) \\
\hline CURSATIS & $\begin{array}{l}\text { Current level of satisfaction: } 0=\text { neutral, } 1=\text { very satisfied, } 2=\text { satisfied, } \\
3=\text { disappointed, } 4=\text { very disappointed }\end{array}$ \\
\hline KNWBRMP & Knowledge that BRMP is a protected area $1=$ yes, $0=$ no \\
\hline BIDAMT & $\begin{array}{l}\text { Additional amt. visitor is asked to pay US } \$ \\
(5,10,15,20,30,50,75,100=\text { Foreign } \quad 1,2,5,10,15,20=\text { Domestic })\end{array}$ \\
\hline GEN & Gender $-0=$ male, $1=$ female \\
\hline EDNLVL & $\begin{array}{l}\text { Education level : } 0=\text { no formal education, } 1=\text { elementary, } 2=\text { high } \\
\text { school, } 3=\text { college, } 4=\text { vocational }\end{array}$ \\
\hline NUMPH & Number of people per household \\
\hline HSINC & old income \\
\hline PRPIN & per capita income (HSINC/NUMPH) \\
\hline BIDFL & Bid amount first level \\
\hline BIDSL & Bid amount second level \\
\hline RECRTN & ecreation undertaken : $0=$ glass-bottom boat riding, $1=$ Snorkeling \\
\hline
\end{tabular}




\section{Data Collection}

Data collected:

1. Obtained background material on Buccoo Reef Marine Park inclusive of a detailed description of the geography of Buccoo Reef (indicated in Chapter 1), management plan supplied by the IMA, budget delineation for management of the BRMP supplied by the Department of Marine Resources and Fisheries and estimations of the area used for snorkeling on the reef

2. Obtained a key informant Interview from the Program Coordinator of the Buccoo Reef Trust

3. Interviewed local residents within the Buccoo region: inclusive of hoteliers, craftsmen, general local villagers, concession stand owners, and businesses directly and indirectly affected by tourism from the BRMP

4. Interviewed tourists/visitors to the BRMP with WTP surveys

5. Obtained tourism information from the Tobago House of Assembly and the Tourism Board to determine the influx of tourists, both domestic and international to Tobago

The data were collected during the summer of 2009. They were summarized in excel tables and used to create graphs and charts that summarized the information provided by visitors to the reef. A total of 200 tourist WTP surveys were administered, including both international and domestic visitors to the BRMP, along with 80 local resident perception surveys. Not all the surveys were useable because some individuals did not respond to pertinent questions during the interview process and thus only 164 
WTP surveys and 50 local resident surveys were able to be analyzed. Due to conducting both the WTP and local resident surveys myself, the sample size was a lot smaller than anticipated, as each WTP survey took about 20-30minutes to conduct and respondents were interviewed immediately after disembarking from the boat tour, therefore battling against respondents' fatigue and hunger. Using the survey data, the double-bound WTP model was estimated using the binary logit estimation technique. The LIMDEP software was used to estimate this model. 


\section{Chapter IV}

\section{$\underline{\text { Results and Discussion }}$}

This chapter is arranged into sections: firstly an analysis of the Buccoo Reef Marine Park Management plan would be undertaken with an analysis of the policy and presentation of the findings of the key informant and local resident perception of BRMP and its management. The findings regarding the tourism sector in Tobago will then be presented, followed by the social carrying capacity estimates and subsequent recommendations. Finally, the results to the Willingness to Pay valuation will be states and the possibility for user-based financing would be discussed.

The Analysis of Bucoo Reef Marine Park Management Plan

In order to understand how effective the BRMP management has been, one must critically look at the following management aspects: (a) goals and objectives of the BRMP plan, (b) institutional framework, (c) implementation and enforcement, (d) stakeholders' participation and their perception and (e) funding.

\section{Management Goals \& Objectives}

Firstly, the goal of BRMP as stated in the management plan is to ensure that BRMP yields "the greatest benefits to the present generation, while maintain its optimum potential to meet the needs and aspirations of the future generations" (BRMP Management Plan, 1996). Within the contest of establishing BRMP as a tourist attraction, the maintenance of the quality of the reef is said to be of paramount importance (BRMP 
Management Plan, 1996). In order to achieve this goal with the focus of maintaining a healthy environment, the BRMP management plan has outlined the following objectives:

(a) To protect and maintain the quality of the Buccoo reef environment, particularly with respect to its ecology and water quality;

(b) To ensure that the users of the BRMP exploit this natural resource in a sustainable manner;

(c) To provide for the proper management of the BRMP through the appropriate legal and institutional framework; and

(d) To provide the information to the general public necessary for their understanding and appreciation of coral reefs as a natural resource, and their role in facilitating effective resource management

It is evident from the above objectives that the BRMP Plan strives to achieve long-term sustainability of the reef environment while allowing for a sustainable use of its resources. In order to achieve these goals, the plan recognizes that a proper legal and institutional structure is necessary and that people's appreciation and participation are critical.

\section{Institutional Framework}

In order to undertake the aforementioned objectives, the management plan suggests a particular action framework that indicates the order of authorities involved in the management of BRMP (see Figure 10). The management agencies involved are as follows: The Environmental Management Authority (EMA) and other governmental agencies inclusive of the Department of Marine Resources and Fisheries, The Institute of 
Marine Affairs (IMA), Tourism and Industrial Development Company (TIDCO), and the Ministry of Planning and development are to provide advice to the Tobago house of Assembly (THA), the main governing body in Tobago. The THA appoints the NGO, the Buccoo Reef Marine Park Trust with the duty of managing the daily goings-on of the BRMP while undertaking scientific research projects and educational outreach to ensure the sustainability of the resource. The BRMP Trust, as stated in the BRMP management plan, is to make decisions based on the suggestions of a local advisory committee and a technical advisory committee. The local advisory committee is to consist of individuals representing different interest groups of Tobago, especially southwest Tobago and should be made up of representatives from (but not limited to) the following groups: fishermen, hoteliers, developers, property owners, dive operators, concessionaries, Buccoo Reef Operators Co-Operative Society and the resident community (BRMP Management Plan, 1996). The management plan further states that the BRMP Trust should have the duty of appointing a marine park manager along with a marine park staff.

Upon further investigation of the management plan of BRMP and complemented by information gained through meetings with the management authority of the Department of Marine Resources and Fisheries and a key informant of the BRMP Trust, it became overtly clear that not only have the proposed objectives not been realized, but there is gross mismanagement when it comes to the daily goings-on of the marine park. According to a key informant, not only has the intended institutional framework had not been realized, but rather what has resulted is a convoluted management framework (see Figure 11) that involves input from too many agencies causing conflict and inefficiencies. 
There is the IMA which along with the EMA (Environmental Management Authority) drafted the one and only management plan (drafted 1996). The Department of Marine Resources and Fisheries is responsible for overseeing and monitoring the BRMP. The Department of Marine Services (located on the island of Trinidad) is dealing with the boat registration and capacity allowances for the reef tour operators. The BRMC and the BRMP Trust are largely in charge of conducting research activities and overseeing education awareness outreach, and there is the THA for supplying the management budget. Then there are the obvious main users, the boat tour operators who seem to run their own show.

Figure 10 - Proposed Management Structure for BRMP



Source: Modified from BRMP Management Plan 
Figure 11 - Actual/Observed Management of BRMP and affected stakeholders

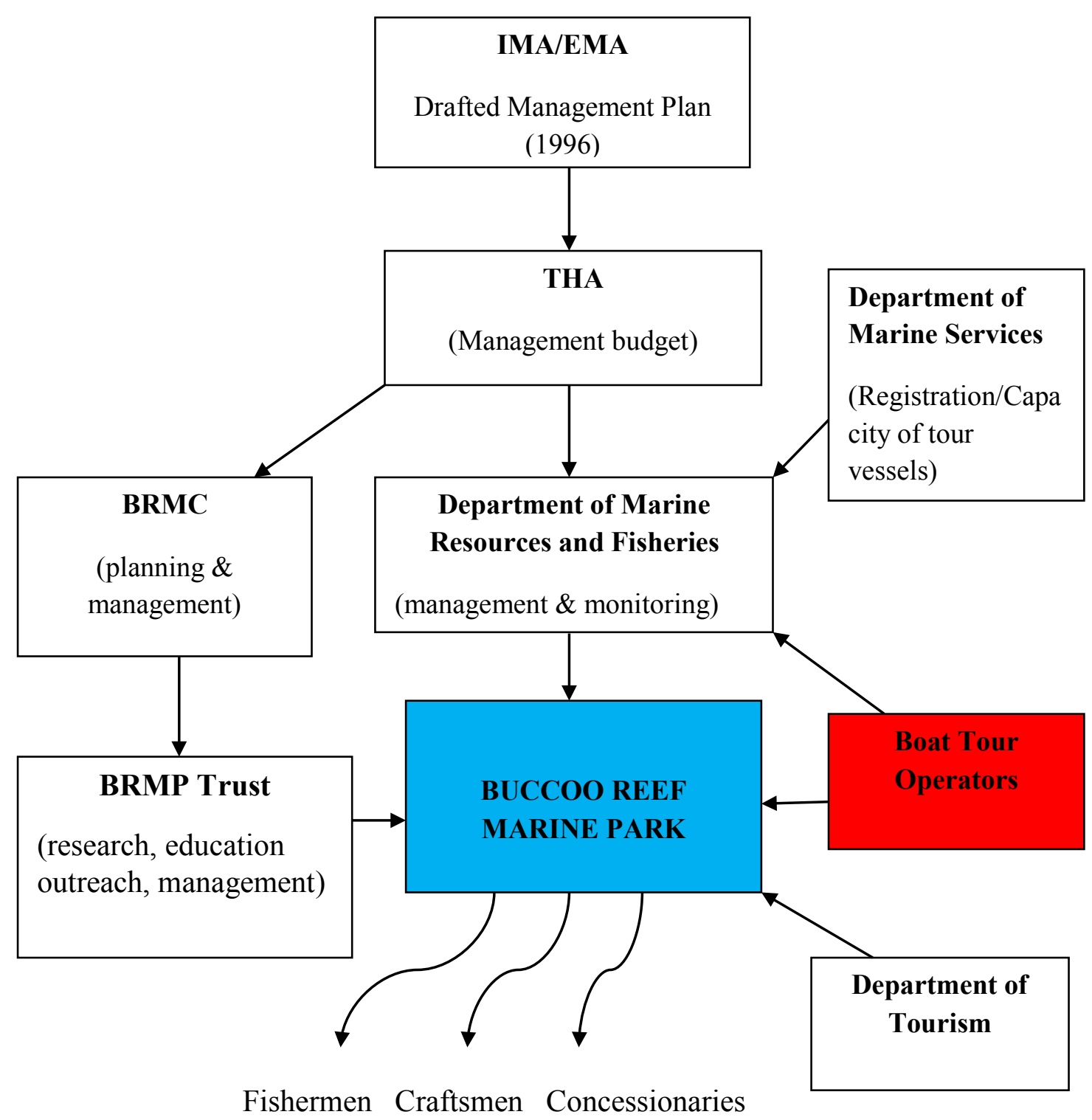




\section{Implementation and Enforcement}

Upon completion of the key informant interview, it was noted that not only has the intended framework not been implemented, but the existing framework lacks organization which has resulted in a lack of monitoring and enforcement of rules. The Department of Marine Reserves and Fisheries, responsible for providing boat patrol officers is understaffed resulting in half of the patrol positions currently being vacant. Apart from inadequate staffing, there are inadequate salaries, which in most cases affects the performance of the monitoring and enforcement personnel. Infrastructure is also lacking, thus also contributing to inefficiencies. According to the key informant, a major hindrance in successful implementation and enforcement arises because with the many agencies involved, frustration arises as persons at the top are very difficult to work with as not everyone holds the BRMP in the priority bracket resulting in many cases where new ideas are suggested, but no follow through occurs.

\section{Stakeholder Participation \& Local Perception}

Though the BRMP Management Plan indicates the need for inclusion of the public, when a key informant was asked about the process regarding public meetings, it was surprising to find out that no public meetings have been held and any meetings that do occur solely involve those considered as key stakeholders, such as the managing agencies and the reef tour operators (who most times do not even show up). What results therefore is a meeting that does not include many other stakeholders affected by the daily operations, and thus cannot voice any possible concerns or disagreements that may arise that can potentially affect them directly or indirectly based on the decisions made. To 
asses this issue, a survey study was undertaken in Tobago of a small sample size of 50 people to access local resident perception of the Buccoo Reef Marine Park and its management (see Appendix 1). The residents responded to a set of 17 questions, on issues ranging from how they felt about BRMP, its rules and regulations, trust in government, to their observations of the environmental changes since BRMP was designated a protected area. The responses to the following questions in Table 2 with 'yes/no' and 'agree/disagree/ neutral' choices were tabulated and presented in Figure 12 below.

Table 2 - Questions used in Local Resident Survey for graphical analysis

\begin{tabular}{|c|c|c|c|c|}
\hline $\begin{array}{l}\text { Question } \\
\#\end{array}$ & Question & $\%$ YES & $\%$ NO & $\%$ Neutral \\
\hline 1 & Are you aware that Buccoo Reef is a protected area? & 80 & 20 & 0 \\
\hline 2 & $\begin{array}{l}\text { Are you familiar with the management rules of } \\
\text { BRMP? }\end{array}$ & 70 & 30 & 0 \\
\hline 6 & $\begin{array}{l}\text { Have you or any family members ever been fined or } \\
\text { reprimanded for any violation of the rules in BRMP? }\end{array}$ & 0 & 100 & 0 \\
\hline 8 & $\begin{array}{l}\text { Do you agree with Buccoo Reef becoming a protected } \\
\text { marine park? }\end{array}$ & 90 & 10 & 0 \\
\hline 10a & $\begin{array}{l}\text { I like the fact that Bucoo Reef was designated a } \\
\text { protected marine park? }\end{array}$ & 90 & 10 & 0 \\
\hline $10 \mathrm{~b}$ & The BRMP has increased job opportunities? & 50 & 24 & 26 \\
\hline $10 \mathrm{c}$ & The staff of BRMP is professional and courteous? & 14 & 10 & 76 \\
\hline $10 d$ & In general, BRMP is well managed? & 4 & 88 & 8 \\
\hline 13 & $\begin{array}{l}\text { Have you ever attended a public meeting concerning } \\
\text { the marine park? }\end{array}$ & 12 & 88 & 0 \\
\hline 14 & $\begin{array}{l}\text { If yes, was the experience positive/ negative/do not } \\
\text { know? }\end{array}$ & 4 & 8 & 88 \\
\hline $16 a$ & $\begin{array}{l}\text { The corals are better protected with the } \\
\text { implementation of BRMP? }\end{array}$ & 20 & 56 & 24 \\
\hline $16 b$ & Fish numbers are increasing in BRMP? & 6 & 76 & 18 \\
\hline $16 \mathrm{c}$ & The current rules are adequate? & 32 & 54 & 14 \\
\hline $16 \mathrm{~d}$ & Tourism is properly managed in BRMP? & 6 & 74 & 20 \\
\hline $16 e$ & $\begin{array}{l}\text { Overall I am glad that Buccoo Reef was designated a } \\
\text { marine park? }\end{array}$ & 90 & 6 & 4 \\
\hline
\end{tabular}


Figure 12 - Local Respondent Survey

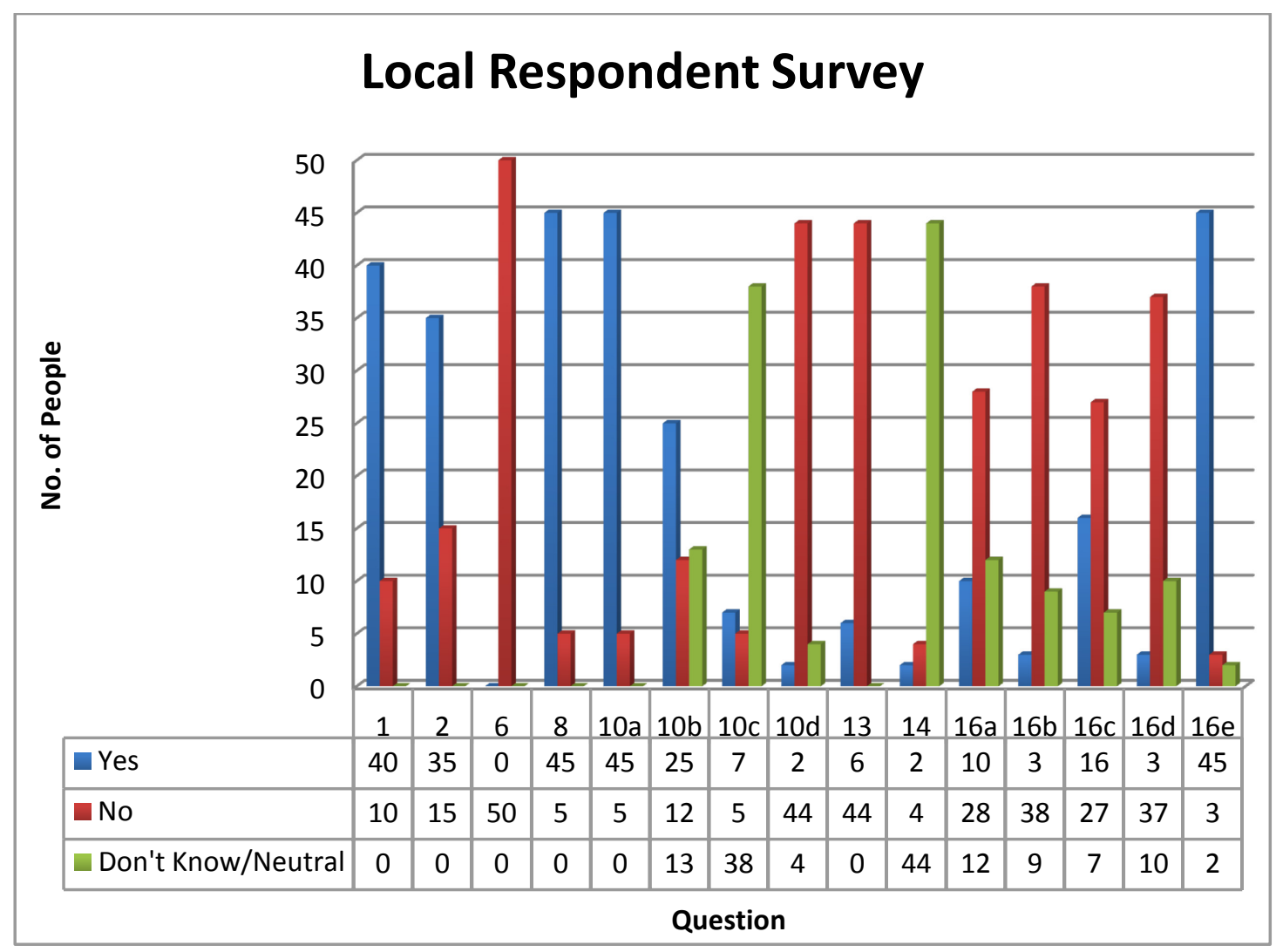

Eighty percent of people interviewed at least know that Buccoo Reef is a protected area and a large percent $(90 \%)$ also agree that it should be protected. However, approximately $76 \%$ responded that they did not know even know who the management staff was, while $88 \%$ state that the park is not well managed. Eighty eight percent also indicated that they never attended a meeting, and in the open-ended question following (not indicated here - please see Appendix 1) most people's reasons were because they never heard of any interest meetings, proving that communication is lacking. When questioned about the job opportunities provided by the marine park, the responses do not seem to be positive hence this is an area that management should look into in order to 
provide incentives for the community to increase interest in aiding in protection of the area.

Even though most respondents think that Buccoo Reef should be a protected area, and are glad that is, they do not think that designation has significantly improved reef conditions, in terms of coral protection and fish numbers. Many respondents stated that the rules are not enforced thus contributing to unsustainable practices. Though the results clearly tell us something about the management of Buccoo Reef, it is important to note that this is a very small sample size and further studies have to be conducted to more accurately represent the community's perception. However, though a rough estimation, these results seem to coordinate with those of the key informant survey that was undertaken.

In all countries, strengthening the relationship between conservation actions and human welfare is necessary (Camargo et al., 2009), and thus Buccoo Reef Marine Park is no different. Judging from this study, it is overtly clear that there is not only a significant need for community awareness, involvement and education, but also a need to improve communication amongst managers. Having personally conducted the surveys, it was noted that the social capital of local residents is severely bruised. As in many developing countries, there is political turmoil that disenfranchises the local community and results in lack of trust in the government. Through discussion with key informants and residents, it was observed that the local community, especially those indigenous to Buccoo Village feel disrespected by the lack of communication as they feel their opinions should be valued regardless of education level. Some local residents feel that they know more about the reef and its decline than hired scientists, as they are descendants of generations or 
fishermen and divers. Fishermen that may know of information sessions, or meetings do not even attend because in their opinions, their concerns are not heard and their suggestions fall on deaf ears or are not supported because of their lack of higher education. The lack of communication and support of community involvement in Buccoo Reef has led to a community that is somewhat rebellious and uninterested in contributing to protection.

\section{Funding}

With regards to funding, the BRMP plan states that "the governmental authority (THA) should provide a budget for management, however because of other more highly prioritized obligations of the national budget and the possible inability of the government to provide adequate funding on an ongoing basis for protected area management, the managing agencies should examine alternative funding sources, such as donor contributions, permits, licensing fees, royalties and/or user fees." It is also indicated that all revenues earned by the park should be retained to offset operational and maintenance costs and any additional revenues should be placed in an endowment for the continued management and development of parks in Trinidad and Tobago.

The proposed management strategy as stated by the BRMP management plan has not been realized, leaving the Department of Marine Resources and Fisheries (DMRF) with the burden of overseeing the majority of the BRMP management. The DMRF is responsible for the sustainable management of the island's marine resources and fisheries, and the economic, educational, scientific and recreational use of Tobago's marine resources and marine areas. The resources allocated to the management of the 
Buccoo Reef include: (1) one park manager, a position which is currently vacant and has been vacant for the past 10 years or more, (2) eight reef patrol men, of which 4 positions are currently vacant, (3) one reef patrol supervisor, a position also currently vacant and, (4) two patrol vessels. The budget provided by the THA to cover these resources as of 2009/2010 has been set at \$140,000 TTD (approximately US\$23,000). The budget is directly related to the day to day management of the reef and includes the payment of salaries, maintenance and upkeep of vessels, vehicles and other facilities.

The THA also has the responsibility of providing financial support to the Buccoo Reef Management Committee (BRMC), a stakeholder management committee set up in accordance with the ESA (Environmentally Sensitive Areas) Rules 2001 to assist in the planning and management of the BRMP. The BRMC develops an annual work plan which includes various activities such as: installation of BRMP signs, installation of mooring buoys in BRMP, demarcating the boundaries of the BRMP, compilation of research projects on the reef, documentation of the history of the BRMP, sea grass removal of the Nylon pool, detection analysis for the Bon Accord mangrove system, training and certification of reef tour operators, website development, and capacity building sessions for the BRMC inclusive of training. The BRMP Trust is a major contributor of this committee and generally hold meetings along with other members to discuss the actions required in order to achieve the above mentioned work plan. As previously mentioned, the financial support for undertaking these activities is primarily obtained from the THA and as of 2009/2010 the budget designated to see these activities through was set at $\$ 200,000$ TTD (approximately US\$33,000). The total annual budget therefore set aside by the governmental authority for the managing of the BRMP is 
$\$ 340,000$ TTD (approximately US $\$ 56,000$ ), which when compared to protected areas in the United States for example where budgets are in the hundreds of thousands, is severely underfunded, an opinion also voiced by a key informant. Other funding is sometimes awarded to BRMP Trust from international donor agencies, and funding for specific research projects, both of which are not guaranteed and are subject to fluctuations. The main financier of the BRMP Trust, CL Financial was subject recently subject to bankruptcy thus putting necessary activities such as mass education awareness and outreach, conservation programs, monitoring activities and needed research projects in jeopardy. According to a key informant, it is therefore imperative that a more reliable funding source of revenue be sourced. Currently there are registration and licensing fees collected for the vessels of the boat tour operators, but many licenses have expired and lack of monitoring have resulted in a fee system that is inconsistent. Though the management plan states that all revenues made by visiting the BRMP should be funneled back into management, in reality what has taken place is the reef tour operators retain all revenues earned from the boat tours. It has been suggested in the BRMP plan that the boat tour operator's earnings should be taxed on the basis of the volume of revenue, but what has resulted is a system where tour operators become dishonest in reporting their numbers and earnings in order to not be subjected to higher taxes. Though a user fee system has been suggested by the management plan, thus far no such financing scheme has been successfully implemented.

It was suggested by a key informant, that for management of the reef to be improved, there needs to be an increase in funding, staff, enforcement of regulations and more education awareness. However, though many obstacles are affecting the potential of 
effective management, the individuals involved seem to have not lost all hope, and are willing to consider change and try to achieve it. Thus far, one such accomplishment is the recent cessation of reef walking.

\section{Growth of Tourism in Trinidad and Tobago}

In order to investigate whether the current tourism has exceeded the capacity, the recent trend in the tourism industry was analyzed. According to the Central Statistical Office (CSO), Trinidad and Tobago received 442,555 air arrivals in 2004, an 8.2\% increase over 2003. Of these $86 \%(352,926)$ visited Trinidad and 14\% (56 143) visited Tobago. $65 \%$ of air arrivals in 2004 visited the destination for leisure purposes. A further $18 \%$ visited for business reasons (primarily to Trinidad), whilst the balance (17\%) visited for other reasons (CSO). A study published by World Travel and Tourism Council estimated that: TT $\$ 2.3$ billion (approximately US $\$ 370$ million) would be spent by tourists to Trinidad and Tobago in 2005 (CSO). In Trinidad and Tobago, about $8 \%$ or one in 12 persons is estimated to be employed in the tourism industry. In Tobago, the number is significantly higher with more than one out of every two employed persons working in the visitor economy and with more than 50\% of Tobago's workforce depending upon visitor spending for their employment (Tourism Development Company Limited).The tourism industry overall generates about $14 \%$ of the country's income, more than agriculture, more than manufacturing, and more than construction (CSO). While there is great potential for the industry, there is also great need to improve the quality of the local tourism product and to ensure long-term sustainability. 
In terms of visitor numbers, the following figures were obtained from the Central Statistical Office of Trinidad and Tobago: Tobago received 53,667 international stayover arrivals in 2000. Between 2000 and 2001, Tobago experienced a severe drop of 7\% in arrivals following the terrorist attacks of September 11, 2001. The industry, however, recovered and arrivals continued to grow at a steady pace between 2001 and 2005, when arrivals peaked at 87,796 in 2005 (see Figure 13). The average growth rate for the 20012005 period was 15.3 percent. Since 2005 , however, arrivals declined. The average annual growth rate between 2005 and 2007 was negative 13.1 percent. The average growth rate for stay-over arrivals to Tobago was recorded at 3.1 percent per annum.

Figure 13 - Visitor Air and Cruise Arrivals to Tobago 2000 - 2007

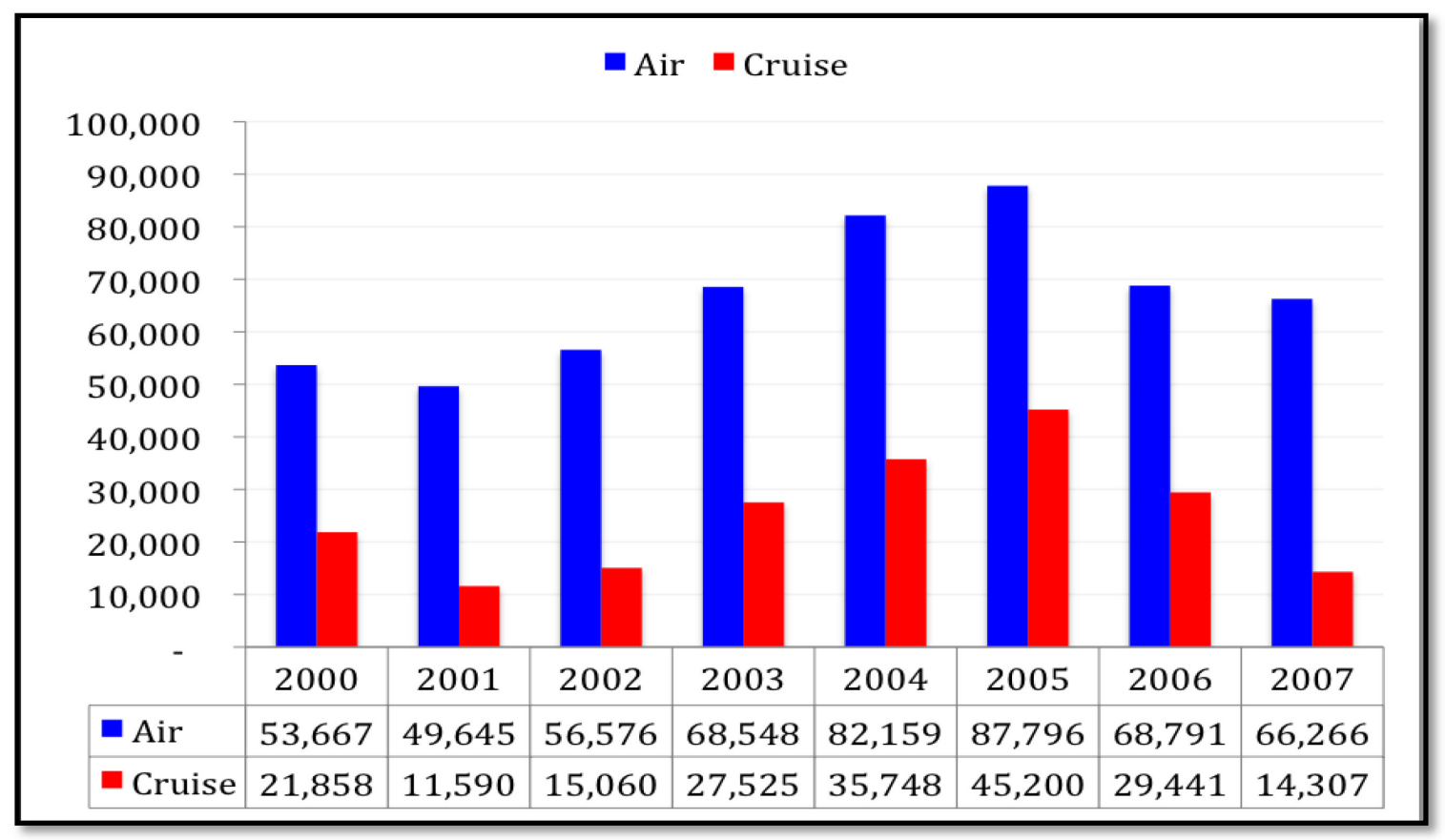

Source: Central Statistical Office, 2009

Domestic tourism is a significant contributor to the tourism sector in Tobago. Many people from Trinidad frequent the island of Tobago for different reasons, either 
business and pleasure, and this is mainly as a result of convenient transportation as the domestic market in Tobago is supported by ferry and air services. As a result of affordable coasts, arrivals by ferry are substantial and the THA reported that ferry arrivals accounted for three fifths of domestic arrivals to Tobago in 2008, while arrivals from Trinidad by air accounted for the other two fifths (see Figure 14). Domestic ferry arrivals from Trinidad to Tobago grew by $165 \%$ from 181,000 arrivals in 2001 to 480,000 in 2008 , reflecting benefits of new ferry purchases and the commitment of the Government to provide reliable air and sea connections between the two islands. The average annual growth rate over the same period was 15 percent (CSO). Domestic air arrivals to Tobago grew from 207,000 in 2001 to 331,000 in 2008 an overall increase of $60 \%$, representing an average annual rate of growth of seven percent. In 2007 there were a total of 758,734 domestic arrivals to Tobago, which was 11.4 times larger than international stay-over arrivals, demonstrating the critical importance of the domestic market to the development of tourism in Tobago, according to the THA Division of Tourism and Transportation (THA).

\section{Accommodation}

Trinidad and Tobago are characterized by small and medium establishments. The average size of the accommodation properties in Trinidad is just over 50 rooms, while in Tobago it is just under 7 rooms (TDC). In Tobago there are almost 4,300 tourism accommodation rooms. The majority of tourism accommodation is made up of small establishments such as guest houses, apartments, condos, bed and breakfast accommodation and villa properties (see Table 3). These collectively account for over 
two thirds (69\%) of the room stock in Tobago, according to the THA Division of Tourism and Transportation. There are no internationally branded hotels in Tobago.

Figure 14 - Domestic Arrivals to Tobago by Mode of Transport

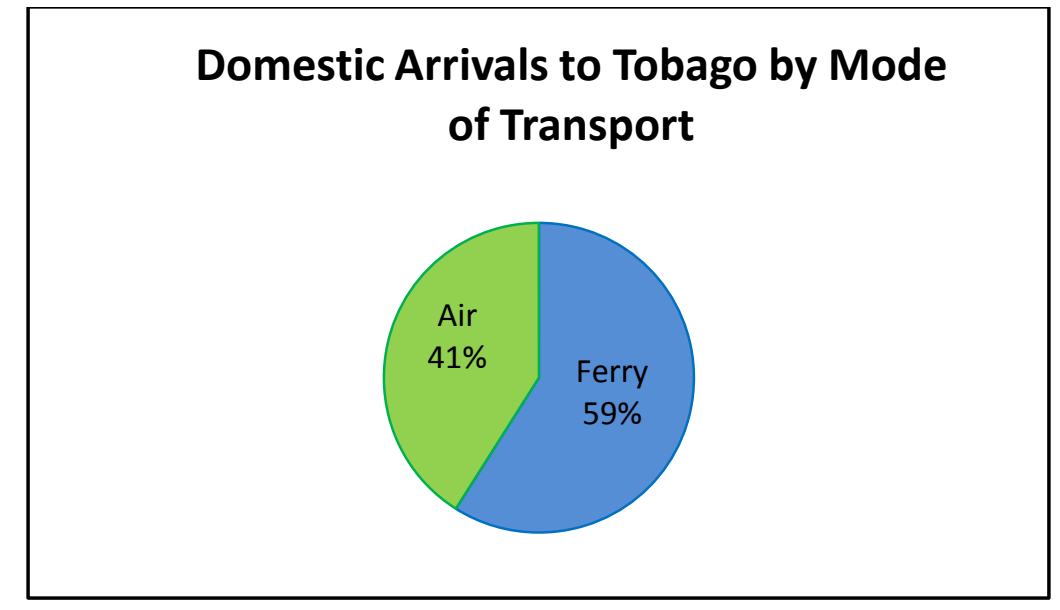

Source: Modified from Division of Tourism and Transportation, Tobago House of Assembly, 2009

Table 3 - Accommodation Availability in Tobago

\begin{tabular}{|l|l|l|l|}
\hline $\begin{array}{l}\text { Breakdown of } \\
\text { Room Stock in } \\
\text { Tobago, 2009 } \\
\text { Type of Property }\end{array}$ & $\begin{array}{l}\text { Total No. of } \\
\text { Properties }\end{array}$ & $\begin{array}{l}\text { Total No. of } \\
\text { Rooms }\end{array}$ & $\begin{array}{l}\text { \% Share of } \\
\text { Tobago } \\
\text { Accommodation } \\
\text { Sector (by Rooms) }\end{array}$ \\
\hline $\begin{array}{l}\text { Apartment } \\
\text { Bed \& Breakfast }\end{array}$ & 162 & 976 & $23 \%$ \\
Guesthouse & 199 & 273 & $6 \%$ \\
Hotel & 39 & 983 & $23 \%$ \\
Villa & 171 & 1,340 & $31 \%$ \\
Condo & 2 & 692 & $16 \%$ \\
Total & 655 & 6 & $0.1 \%$ \\
\hline
\end{tabular}

Source: Division of Tourism and Transportation, Tobago House of Assembly, 2009 


\section{Tourism Carrying Capacity Estimates}

In an effort to analyze the carrying capacity the following information was obtained. Currently there are 16 registered and licensed tour boats legally allowed to operate tourist trips. Each boat has an average capacity of 35 people and can make a maximum of three trips daily. The Department of Marine Resources and Fisheries, has the responsibility for deploying reef patrol officers to ensure the legal trip requirement. These patrol vessels however work solely on weekdays as a result of vacant positions, can only work very sporadically resulting in potentially inaccurate recordings. The maximum allowable daily rate of visitation to the reef based on the number of registered boats and their capacity was calculated to be 1680 people ( 16 boats * 35 people * 3 times/day). Minimum number of visitors to the reef, if boat tour operators are conservative in their use operating two trips per day, will equate to an allowable number of visitors at 1120 people per day. Because of the fact that patrol vessels only operate on weekdays and in limited numbers, tour operators tend to crowd their boats, exceeding the carrying capacity by as much as 10 or 15 extra in an effort to maximize funds. This will cause a hike in visitor numbers from the allowable 1680 to 2160 or sometimes even 2400 people going to the reef per day if boat tour operators crowd their boats by 10 or 15 people respectively. The number of actual visitors recorded by boat tour patrol officers in 2009 to BRMP was 16,977 which is an extremely conservative figure as this would not include the tabulation of weekend trips to the reef. Numbers may sometimes be recorded by tour operators, but that is subject to question as well as operators may not willingly report their indiscretions. If 16,977 visitors were recorded for 2009, an average number of actual visitors recorded would approximately be 65 people per day in 2009 , about $4 \%$ of 
the total allowable number as implied from the management team. Monthly visitor numbers for the period of July 2008 to June 2009 as reported by the Department of Marine Resources and Fisheries were obtained and presented in Figure 15 below.

Figure 15 - Monthly Record of Visitors to BRMP 08-09

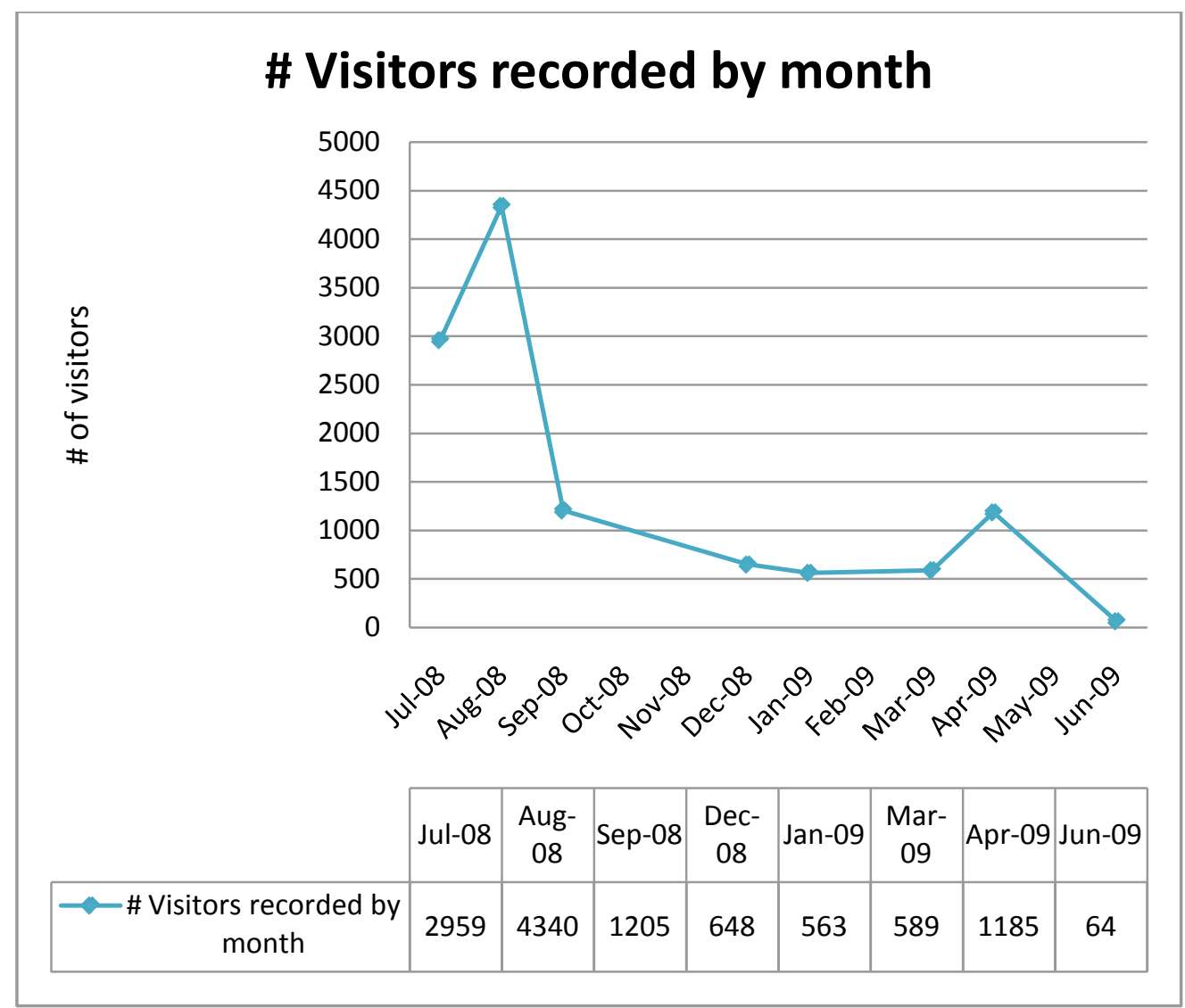

Source: Department of Marine Resources and Fisheries

The total area of Buccoo Reef Marine Park is $6.5 \times 10^{6} \mathrm{~m}^{2}$. The entire area of the reef is open access, but of this area, approximately $836 \mathrm{~m}^{2}$ to $1022 \mathrm{~m}^{2}$ is utilized by the reef tour operators for snorkeling and glass-bottom boat tours. Based on reported numbers therefore, an average of 65 visitors utilizes a total of about $836 \mathrm{~m}^{2}$ to $1022 \mathrm{~m}^{2}$ daily. In order to estimate biological thresholds, detailed data from the distant past to 
present regarding the gradual ecological changes in comparison to visitor numbers is essential for estimating what the acceptable numbers of visitors should be for minimal impact. However, such data were not available for BRMP, and thus estimating crowding norms and perceptions seem to be a plausible path.

Inglis (1999) conducted a crowding study to assess the acceptable social carrying capacity of snorkeling of an area of $1728 \mathrm{~m}^{2}$ of the Great Barrier Reef. Through surveys, it was determined that most respondents found between 0 to 22 snorkelers acceptable in above-water scenarios, and fewer than 6 snorkelers acceptable in below-water scenes (Inglis, 1999), with more experienced snorkelers preferring less people than less experienced snorkelers. Following Inglis (1999), assume that 22 snorkelers are considered acceptable for an area of reef of $1728 \mathrm{~m}^{2}$. For the minimum area used by snorkelers at BRMP of approximately $836 \mathrm{~m}^{2}$ it would follow that the acceptable number would be approximately 11 snorkelers at one time. If the maximum area of approximately $1022 \mathrm{~m}^{2}$ was utilized it would equate to approximately 13 snorkelers as being considered acceptable on each trip. Extrapolation of these estimates to three allowed trips per day in BRMP, the total number of acceptable persons per day amounts to about 33 and 39 for areas $836 \mathrm{~m}^{2}$ and $1022 \mathrm{~m}^{2}$ respectively. Compare these estimates to the 2009 estimated number of 65 people reported per day. This shows that the actual crowding intensity of snorkelers using the reef (just based on Monday to Friday reporting), was approximately a $67-97 \%$ over the socially acceptable crowding norm for the study area. Needless to mention that the total daily visitation rate of people as allowed by the 1996 management plan is clearly beyond what is socially and aesthetically acceptable to people. It is important to note however that this comparison calculation is a very rough estimate, as 
the Inglis (1999) study may be culturally sensitive and may depend of a variety of other external factors.

\author{
Contingent Economic Valuation of Reef Use \\ Sample Characteristics
}

Of 164 usable surveys, all respondents had at least some form of formal education, with $1.2 \%$ having elementary education, $32.5 \%$ completing the high school level, $61.4 \%$ having college education and $4.8 \%$ with vocational education. About one third of the respondents were international visitors (31.9\%), while the remaining two thirds (68.1\%) were domestic visitors from the island of Trinidad. Of the $31.9 \%$ of international respondents, $37.7 \%$ were from the United Kingdom, $5 \%$ from Brussels and 5\% from Paris, France. About 18.9\% of international respondents were from Germany, and another $37.7 \%$ were from the USA. Only $5.7 \%$ of the international respondents were from other Caribbean Islands. Of the domestic respondents, about three quarters (75.2\%) reported an average household income of US\$10-20,000, with less than a quarter (20.4\%) reporting earnings of US\$25-40,000 annually while only a mere $4.4 \%$ stated average household income as being over US\$40,000. The distribution of income was vastly different for international visitors with as much as over two thirds of the respondents (67.9\%) reporting average household income of over US\$40,000 annually, about one fifth (20.8\%) stated earnings of US $\$ 25-40,000$ and $11.3 \%$ reported between US $\$ 10-20,000$. The entire sample was comprised of $48.2 \%$ males and $51.8 \%$ females, with a sample mean age of 37 years old. 


\section{Willingness to Pay for Reef}

The sample of tourists were asked if they would be willing to pay a certain additional entrance fee or bid amount, toward a program that would improve the quality of their travel experience by enhancing protection and conservation. Over half of the respondents $(57.8 \%)$ were willing to pay the first level bid amount randomly picked for their specific survey. Of this $57.8 \%$ willing to pay, $46.9 \%$ of them also said YES to the second level bid which was set at twice times the first level bid if the initial response was YES. Of the $42.2 \%$ saying NO to the first level bid, $41.4 \%$ of them said YES to the second level bid which was half the first level bid if the initial response was NO. The bid amount frequency and distribution in US\$ is represented below (see table 4) with a graphical analysis (see figure 16).

Table 4 - Frequency of Bid Amounts and Percent Saying 'YES'

\begin{tabular}{|r|r|r|}
\hline $\begin{array}{c}\text { Bid } \\
\text { Amount US\$ }\end{array}$ & Frequency & \% saying YES \\
\hline 1 & 17 & 88.2 \\
\hline 2 & 26 & 88.9 \\
\hline 5 & 37 & 64.9 \\
\hline 10 & 41 & 43.9 \\
\hline 15 & 18 & 33.3 \\
\hline 20 & 20 & 35 \\
\hline 30 & 6 & 33.3 \\
\hline
\end{tabular}


Figure 16 - Percentage Distribution of Respondents Saying 'YES' to Bid Amounts



Bivariate logit regression was undertaken using LIMDEP 7.0 to model the relationship of the binary dependent variable (WTP) to the independent variables. A description of the variables used in the model was presented in table 1 (p. 53). Of the eight variables used in the model, five were significant predictors of WTP in the model: the bid amount, per capita income, nationality (international or domestic), knowledge that BRMP is a protected area and current satisfaction (see table 5). The negative signs of the bid amount and current satisfaction indicated that the higher the bid amount or the greater the dissatisfaction level, the lower the probability of willingness to pay. The median WTP for those who were very satisfied versus those very disappointed were estimated at US\$19.44 and US\$5.01 respectively. As expected per capita income was very significant with respondents who reported income over US $\$ 40,000$ were willing to pay an amount of almost 3 times higher than those who reported incomes of between US\$10-20,000. 
Gender, education level and recreation undertaken, were not significant in determining the respondents willingness to pay.

Using the above model parameter estimates and sample mean values of various independent variables and the formula given in equation (2) of Chapter 3, the median WTP for the entire sample was calculated to be approximately US\$11.72. Because of obvious disparities in annual income between international and domestic tourists, median willingness to pay estimates varied. There was a noticeable difference between the median WTP of international visitors (US\$18.70) and the median WTP of domestic visitors (US\$5.91). Based on equation (3) [pg.55] in Chapter 3, a probability distribution of a range of bid amounts in increments of US $\$ 0.50$ was calculated and presented graphically (see Figure 17, 18 \& 19). Actual value amounts can be found in Appendix 3. The probability distribution for different bid amounts is important as it can aid management in determining how widely acceptable a specific fee hike will be, therefore gearing towards satisfaction of the masses.

Table 5 - Double-Bound Logit Regression Model of WTP for Improving BRMP

\begin{tabular}{|lrrrr|}
\hline Variables & \multicolumn{1}{c}{ Coefficient } & \multicolumn{1}{c}{ Std. Error } & \multicolumn{1}{c|}{ t-ratio } & \multicolumn{1}{c|}{ P[|Z|>z] } \\
\hline Constant & 0.452936 & 0.473799 & 0.955967 & 0.339089 \\
BIDAMT & -0.0875619 & 0.0113528 & -7.71281 & $\mathbf{1 . 2 2 E - 1 4}$ \\
GEN & 0.180338 & 0.165295 & 1.09101 & 0.275269 \\
EDNLVL & 0.127483 & 0.125213 & 1.01813 & 0.308615 \\
PRPIN & 0.0157768 & 0.00751478 & 2.09943 & $\mathbf{0 . 0 3 5 7 7 8 9}$ \\
INTER & 0.679252 & 0.295437 & 2.29914 & $\mathbf{0 . 0 2 1 4 9 6 9}$ \\
KNWBRMP & 0.342568 & 0.190671 & 1.79665 & $\mathbf{0 . 0 7 2 3 9 1 7}$ \\
RECRTN & -0.269924 & 0.169931 & -1.58843 & 0.112189 \\
CURSATIS & -0.193454 & 0.0994282 & -1.94567 & $\mathbf{0 . 0 5 1 6 9 4 4}$ \\
RHO(1,2) & 0 & 0 & $1.00 \mathrm{E}+10$ & \\
\hline Log Likelihood: -187.54 & & & \\
R $^{2}: 0.66$ & & & & \\
\hline
\end{tabular}


Figure 17 - Probability Distribution of Bid Amounts (Entire Sample)



Figure 18 - Probability Distribution of Bid Amounts (Domestic)

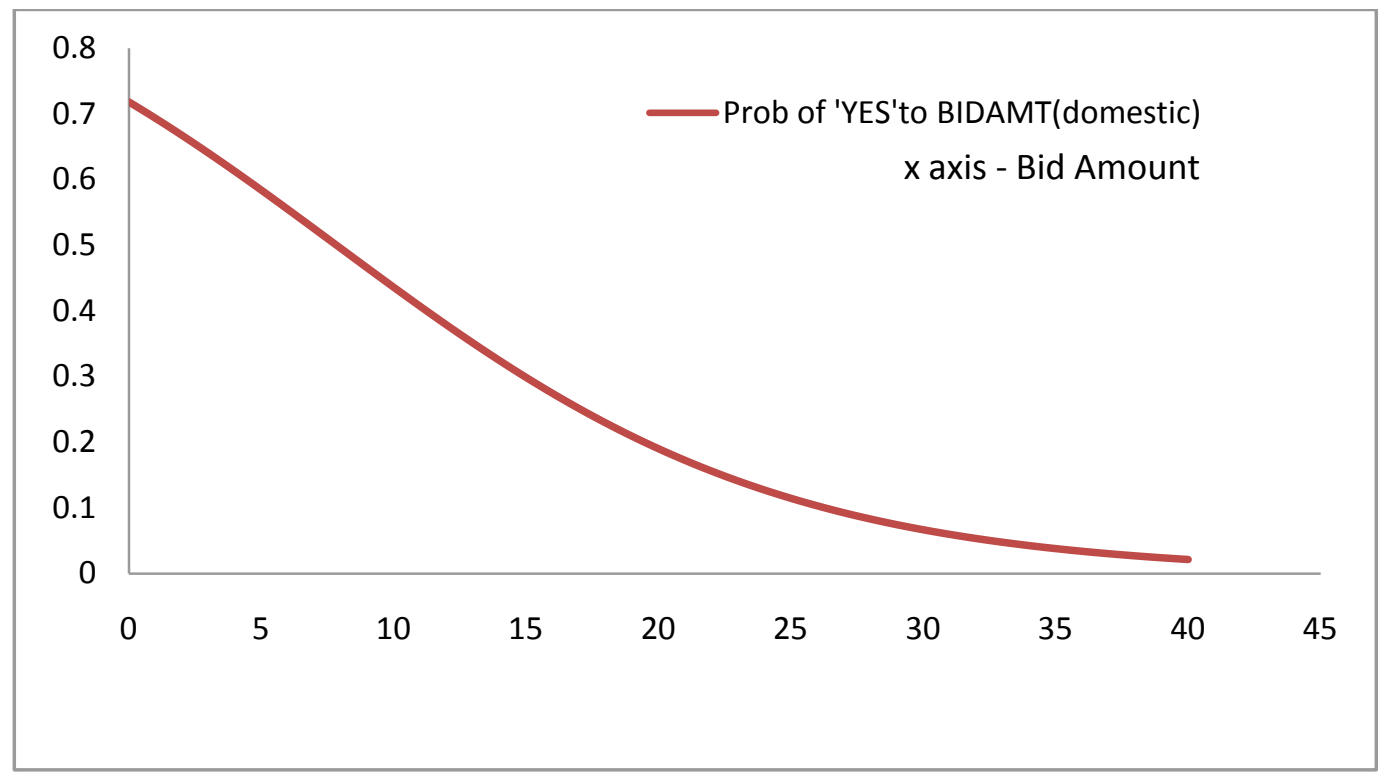


Figure 19 - Probability Distribution of Bid Amounts (International)

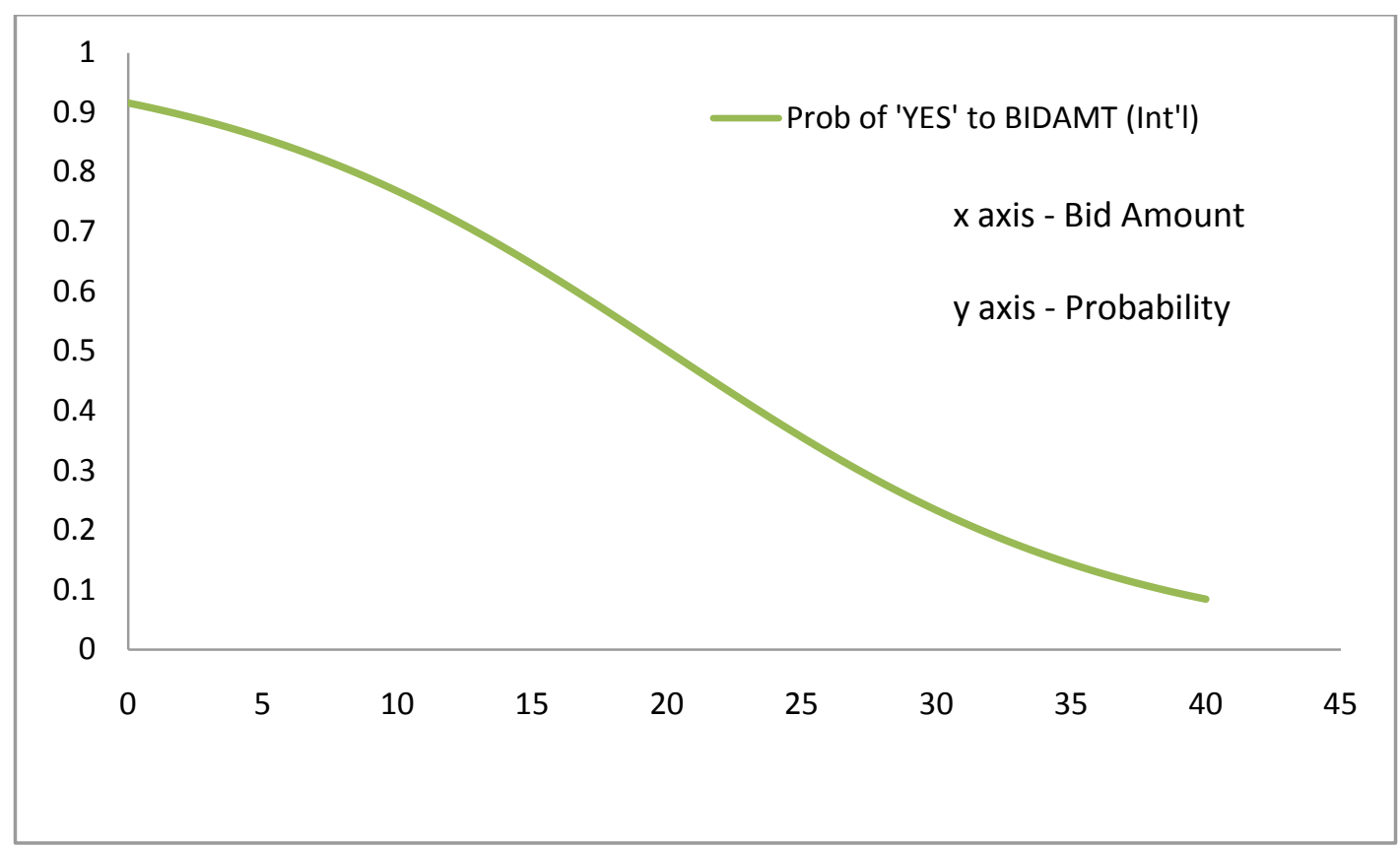

Reasons for Willingness to Pay

A description of the reasons for WTP, either YES or NO is given in Table 6. Numbers 1 through 6 are the reasons for saying YES, and 6 through 10 are reasons for saying NO. The percent distribution of these reasons for the entire sample, domestic and international respectively, is shown in figures 20 through 25. 
Table 6 - Reasons and Percentage Distribution of Responses

\begin{tabular}{|l|l|l|l|l|}
\hline $\begin{array}{l}\text { Reasons } \\
\text { (Yes) }\end{array}$ & Description & $\begin{array}{l}\% \\
\text { (ALL) }\end{array}$ & $\begin{array}{l}\text { \% } \\
\text { (Int'I) }\end{array}$ & \%(Dom) \\
\hline 1 & $\begin{array}{l}\text { I deeply care about marine environment } \\
\text { protection }\end{array}$ & 7.83 & 16.98 & 3.54 \\
\hline 2 & $\begin{array}{l}\text { I feel or know that Buccoo Reef coral reef, fish } \\
\text { and water quality have declined over the years }\end{array}$ & 31.33 & 20.75 & 36.28 \\
\hline 3 & $\begin{array}{l}\text { As a tourist coming from outside, it gives me a } \\
\text { higher satisfaction }\end{array}$ & 13.25 & 41.51 & 0 \\
\hline 4 & $\begin{array}{l}\text { I believe that coral reefs are important and should } \\
\text { be conserved and protected }\end{array}$ & 54.82 & 66.04 & 49.56 \\
\hline 5 & $\begin{array}{l}\text { I believe it is important to preserve our } \\
\text { environment for future generations }\end{array}$ & 28.31 & 22.64 & 30.97 \\
\hline $\begin{array}{l}\text { Reasons } \\
\text { (No) }\end{array}$ & $\begin{array}{l}\text { I/we cannot trust a public/private agency with } \\
\text { additional money }\end{array}$ & 23.49 & 9.43 & 30.09 \\
\hline 6 & the new system will not work & 16.27 & 3.77 & 22.12 \\
\hline 7 & the fee proposed is too high & 22.29 & 26.42 & 20.35 \\
\hline 8 & we are happy with the current coral reef quality & 6.63 & 1.89 & 8.85 \\
\hline 9 & It is not fair to increase the price on tourists & 3.61 & 5.66 & 0 \\
\hline 10 & & & \\
\hline
\end{tabular}

Figure 20 - Percent Distribution of Reasons for 'YES' (entire sample)

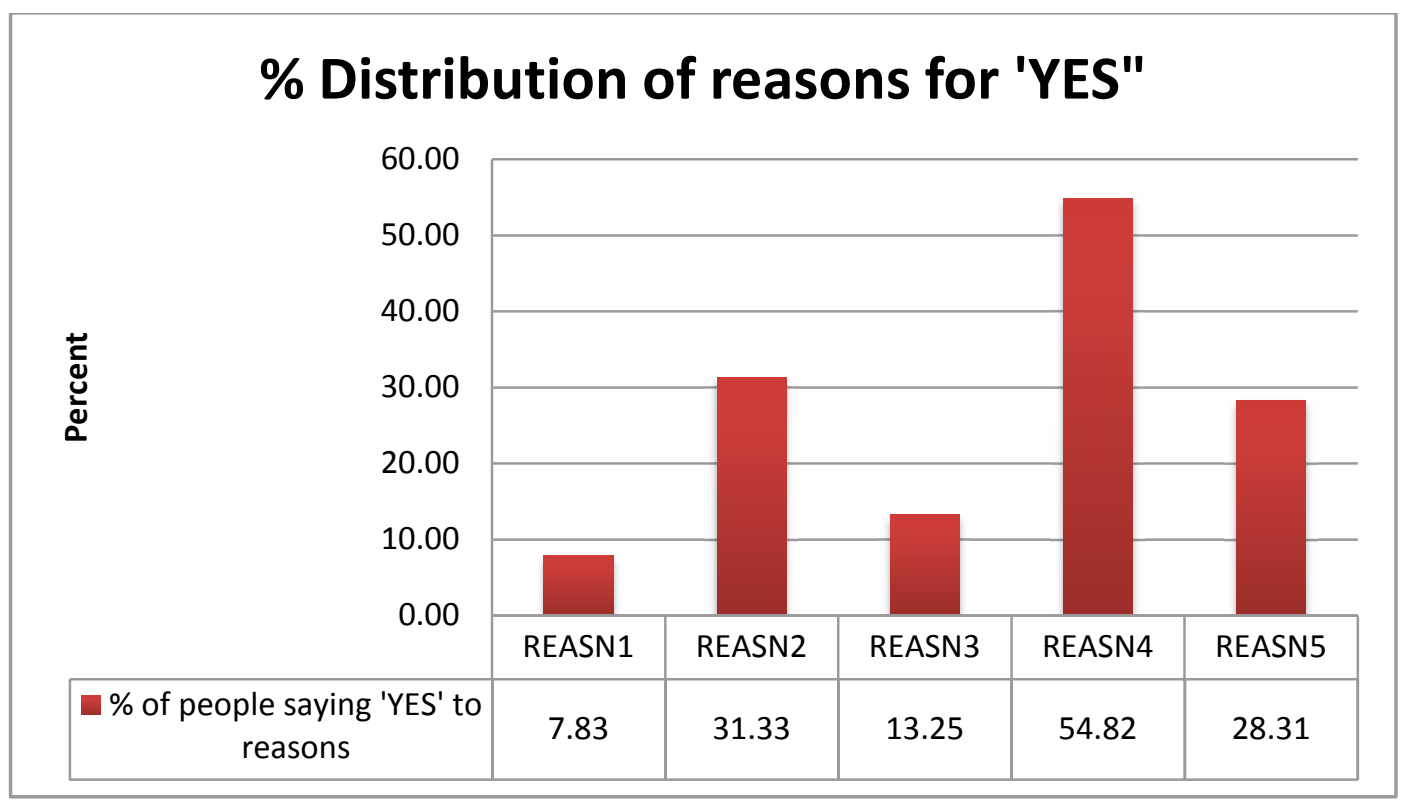


Figure 21 - Percent of Reasons for 'NO' (entire sample)

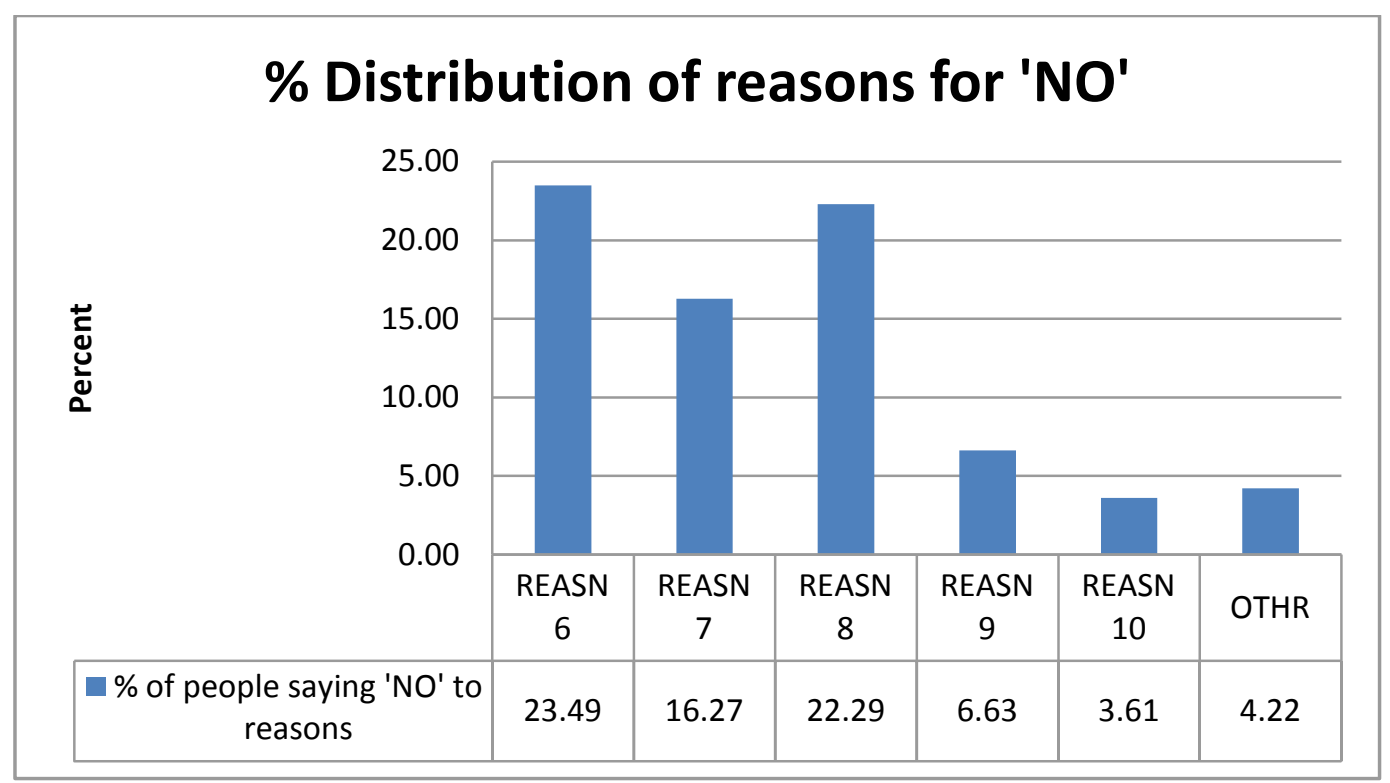

Over half the entire sample (54.82\%) was willing to pay because of reason 4 "I believe that coral reefs are important and should be conserved and protected." This shows that the many visitors to the BRMP are somewhat environmentally conscious and would be interested in contributing to its continued protection. Similarly, just under a third (28.31\%) chose reason 5 "I believe it is important to preserve our environment for future generations," showing that management can find ways to tap into the environmental conscience of visitors, stimulating more interest in protection and conservation (see Figure 20).

The majority of persons saying 'NO' chose reasons 6 and 8 for their decision not to pay. Just under a quarter of persons saying 'NO' (22.29\%) of persons saying 'NO' thought that the fee proposed was too high with another $23.49 \%$ saying 'NO' because they believe that the system would not be trustworthy and are not willing to risk paying additional monies (see Figure 21). 
Figure 22 - Percent Distribution of Reasons for 'YES' (domestic)

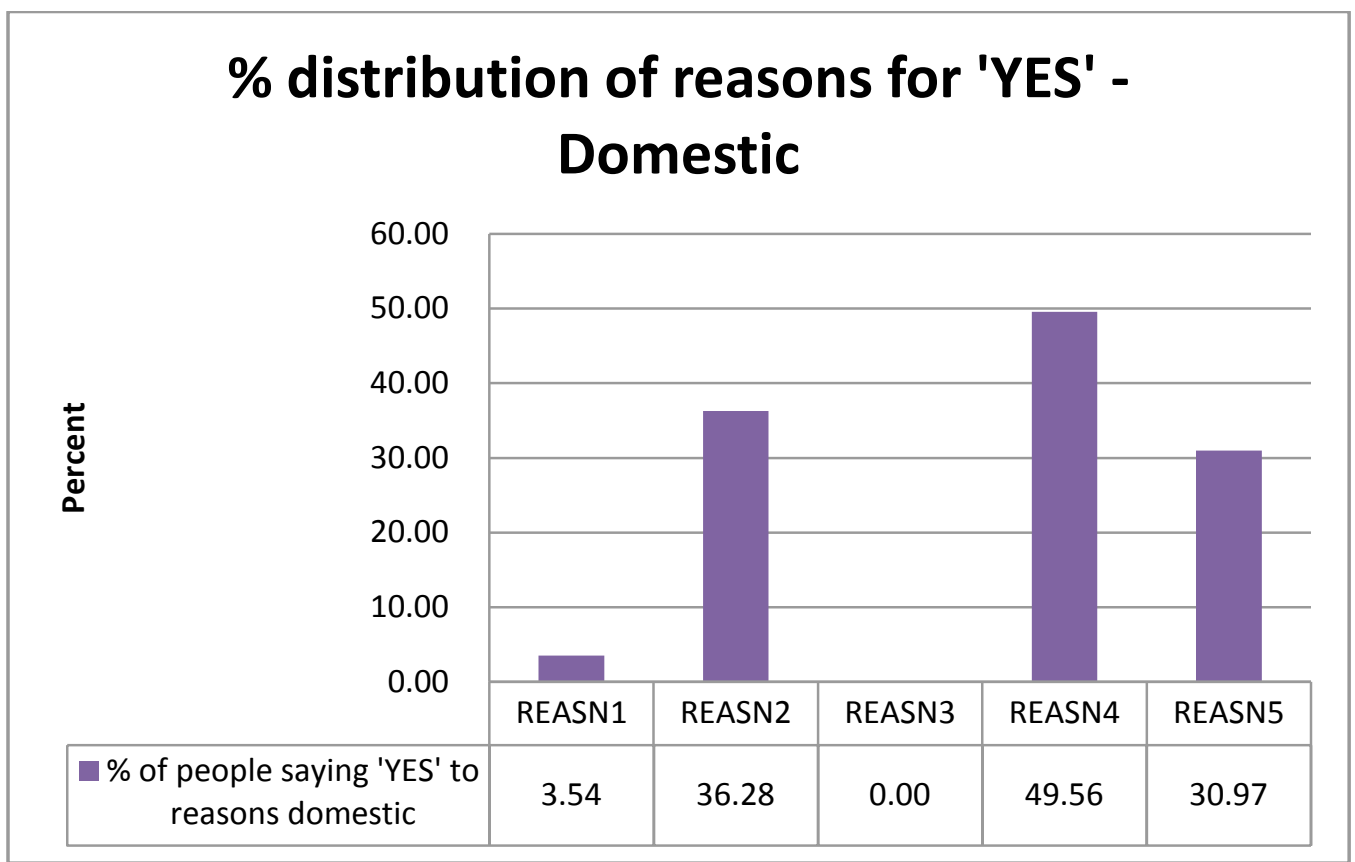

Figure 23 - Percent Distribution of Reasons for 'NO' (domestic)

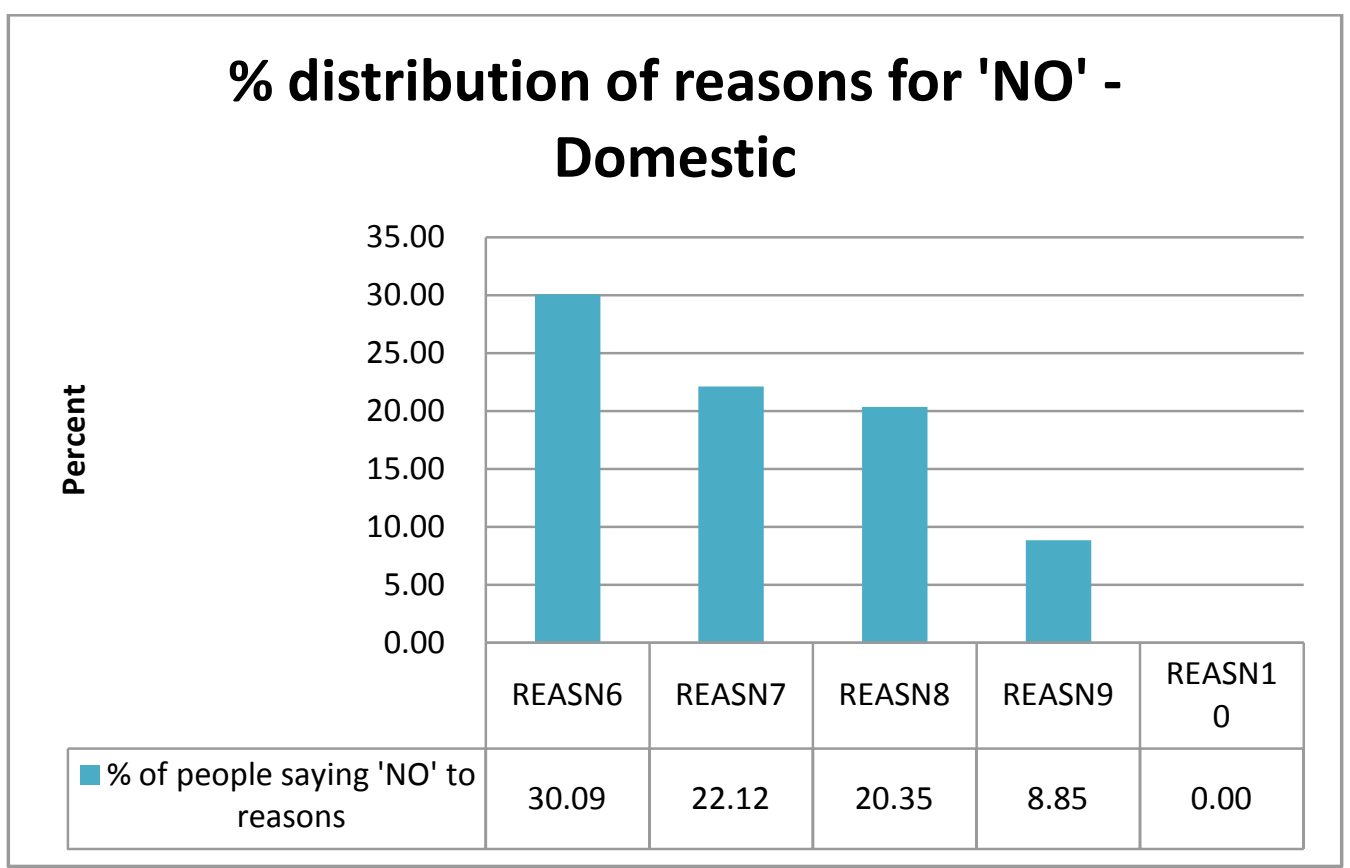


It is evident from Figure 22 that a significant percent of domestic tourists (31.33\%) were willing to pay because of reason 2 "I feel or know that Buccoo Reef coral reef, fish and water quality, have declined over the years." In order for them to state this reason, they should have been visiting the BRMP for quite some years. That is, respondents' age must be closely associated with those citing reason 2 . Age being a factor was further confirmed by the fact that of the 41 people who responded to reason 2 approximately $47 \%$ of people were over 40 . In Figure 23, the largest percent of domestic visitors who were not willing to pay any additional fee chose reason 6: "I/we cannot trust a public/private agency with additional money," thus speaking volumes about the social capital of the region and their trust, or lack thereof, in the government or managing agencies.

Just as with the domestic sample, the most frequently selected reason for choosing YES to the WTP in the international sample was reason 4: "I believe that coral reefs are important and should be conserved and protected", with approximately two thirds of the people saying yes choosing this option (see figure 24).

Figure 24 - Percent Distribution of Reasons for 'YES' (International)

\begin{tabular}{|c|c|c|c|c|c|c|}
\hline \multicolumn{7}{|c|}{$\begin{array}{l}\text { \% distribution of reasons for 'YES' - } \\
\text { International }\end{array}$} \\
\hline \multirow{4}{*}{ 菍 } & \multirow{4}{*}{$\begin{array}{r}70.00 \\
60.00 \\
50.00 \\
40.00 \\
30.00 \\
20.00 \\
10.00 \\
0.00\end{array}$} & \multirow{3}{*}{\multicolumn{3}{|c|}{ 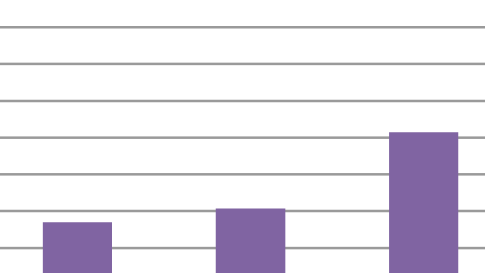 }} & \multirow{3}{*}{  } & \\
\hline & & & & & & \\
\hline & & & & & & \\
\hline & & REASN1 & REASN2 & REASN3 & REASN4 & REASN5 \\
\hline \multicolumn{2}{|c|}{$\begin{array}{c}\text { \% of people saying 'YES' to } \\
\text { reasons (int'I) }\end{array}$} & 16.98 & 20.75 & 41.51 & 66.04 & 22.64 \\
\hline
\end{tabular}


Figure 25 - Percent Distribution of Reasons for 'NO' (International)



The second most selected reason for saying YES for international visitors was reason 3:

"As a tourist coming from outside, it gives me a higher satisfaction," with about $42 \%$ selecting this option. The majority of international respondents (approximately $26 \%$ ) stated reason 6 (the fee proposed is too high) as why they would not be willing to pay an additional fee (see Figure 25).

\section{Analysis of User Fees}

Based on average visitor numbers provided by the Department of Tourism for 2007 to 2009, it was estimated the proportion of international visitors to domestic visitors was approximately one third. The estimation is similar to the proportion of international visitors to domestic visitors in this study sample. In 2009 the reported number of visitors to the BRMP was 16,977 amounting to an average of 65.30 persons per day. This 
visitation level however is based on the reporting by patrol officers who only work from Monday to Friday. Based on information provided by the CVM surveys, patrons observed an average of 4.214 boats out on the reef during their trip on a weekday, and an average of 6.933 boats during the weekend trips. The ratio of boats observed on weekday versus weekend was therefore 4.214/6.933. This ratio of weekday to weekend observed boats was then applied to the reported number of weekday visitors in 2009 of 16,977 persons, in order to extrapolate an annual average number of visitors to the reef for an entire week inclusive of weekends. Applying this ration, it was estimated that there are approximately 107.43 people observed per day on a weekend, amounting to $11,172.43$ people annually visiting this reef on weekends. This weekend estimation was then added to the weekday reported number of 16,977 , giving an estimation of $28,149.43$ people currently visiting Buccoo Reef per year inclusive of weekends. Applying the proportion of international visitors to domestic visitors $(1 / 3)$ to this annual estimation, there are about 8,933.65 international visitors and 19,215.78 domestic visitors coming to BRMP annually. From these annual visitation numbers, one can estimate potential revenues, which can be made if the proposed user fee system is implemented. The results are presented in Table 7.

As reported above, the median WTP differed between international and domestic visitors. Median WTP for international visitors was about 3.2 times higher than that of domestic visitors. Table 7 below shows different scenarios of various proposed fees and the subsequent economic potential based on the current usage. The probability values of the 'expected YES' column were determined by the econometric model [equation (3)] presented in Chapter 3 for calculating the $\mathrm{P}(\mathrm{YES})$ of each of the dollar amounts presented 
in table 7. To determine the probability of YES for international visitors, the dollar amount in the 'proposed fee' column was multiplied by three to represent the approximate difference in international visitors WTP, and the subsequent probability value for that amount was recorded (see Appendix 3).

Currently, the only fee imposed on visitors to BRMP is a US\$10 for domestic and US\$15 for foreign visitors, to partake in the BRMP reef tour, and no portion of these revenues is filtered back to the management agencies. As previously mentioned, the current budget allotted for management of this reef is set at $\$ 340,000 \mathrm{TTD}$ (approximately US\$57,000). Consider the figures in Table 7: If a separate user fee was implemented of just US $\$ 1$, approximately $70 \%$ of domestic visitors and over $80 \%$ of internationals would be expected to pay. This increase would be a $10 \%$ and $20 \%$ increase in the current fee charged to domestic and international visitors, respectively, and can result in a total potential income of about US $\$ 47,480.86$. The potential income represents almost a $80 \%$ of the current budget. Similarly, if a user fee of just US\$3 is implemented, of which over $60 \%$ of visitors, both international and domestic would be in agreement, potential revenues at the current use level can soar to US $\$ 142,442.57$, which is as much as over a $150 \%$ increase of the budget currently set for management. Consider Table 8 , if the current use of about 65 people per day was decreased to almost half, to the proposed capacity of about 33 people per day (based on the crowding estimates), the potential revenues that can be made if just US\$4 was implemented, an amount of which about $60 \%$ and $70 \%$ of domestic and international visitors respectively would be anticipated to agree to, can surmount to a potential total income of approximately US $\$ 81,267.28$ annually, 
which is still over about a $40 \%$ increase of the annual budget of US\$57,000. The potential for a successful user fee system is therefore extremely plausible.

It is vital to not however, that if visitation rates were halved, tourism revenue will inevitably decrease. Based on investigations made my McLeod and Airey (200x), average expenditure of international tourists coming to Tobago for leisure in 2002 was estimated to be US\$530 per day. Average expenditure for domestic visitors is significantly less because of the fact that domestic visitors can bring across cars, and food via the ferry from Trinidad and tend to have cheaper accommodations and stay for shorter periods of time. Based on information provided in the CVM surveys, domestic visitors tend to spend an average of about $10 \%$ less per day than international visitors. Applying this $10 \%$ to the 2002 international visitor expenditure of US\$530, domestic visitors therefore spend on average US\$53 per day in Tobago. Applying these expenditure averages to the current visitation of Buccoo Reef of 8,933.65 international visitors and 19,215.78 domestic visitors, we can estimate that the current annual expenditure of visitors to the reef is US\$4,734,835.18 and US\$1,018,436.23 for international and domestic visitors respectively, giving a total annual expenditure for Buccoo Reef related tourism activities of US\$5,753,271.35. If the proposed halving of visitors to the reef was implemented of about 33 people per day (12,045 people per year) based on the crowding study analysis, annual expenditure of visitors will significantly decrease. With the proposed suggestion of 12,045 people per year, amounting to approximately 3,828 international visitors and 8,222 domestic visitors, this results in a decline in visitor expenditure to US\$2,026,012.28 and US $\$ 435,783.77$ for international and domestic 
visitors respectfully, amounting to US\$2,461,796.05 total annual expenditure, which is about a $42.8 \%$ decrease of the current estimated expenditure. 
Table 7 - User Fee Analysis (Based on Current Usage)

\begin{tabular}{|ccccccccc|}
\hline $\begin{array}{c}\text { Proposed } \\
\text { fee(US\$) }\end{array}$ & $\begin{array}{c}\text { Expected } \\
\text { "YES" } \\
\text { (Domestic) }\end{array}$ & $\begin{array}{c}\text { Expected } \\
\text { "YES" } \\
\text { (Int'I) }\end{array}$ & $\begin{array}{c}\text { Percent Inc. } \\
\text { over current } \\
\text { fee } \\
\text { (Domestic) }\end{array}$ & $\begin{array}{c}\text { Percent Inc. } \\
\text { over current } \\
\text { fee (Int'l) }\end{array}$ & $\begin{array}{c}\text { Potential } \\
\text { annual } \\
\text { income(Int'l) }\end{array}$ & $\begin{array}{c}\text { Potential } \\
\text { annual } \\
\text { Income } \\
\text { (Domestic) }\end{array}$ & $\begin{array}{c}\text { Total } \\
\text { Potential } \\
\text { Income }\end{array}$ & $\begin{array}{c}\text { Percentof } \\
\text { current } \\
\text { budget }\end{array}$ \\
\hline 1 & 0.693 & 0.884 & 10 & 20 & 28265.08 & 19215.78 & 47480.86 & 83.79 \\
2 & 0.667 & 0.842 & 20 & 40 & 56530.15 & 38431.56 & 94961.71 & 167.58 \\
3 & 0.64 & 0.789 & 30 & 60 & 84795.23 & 57647.33 & 142442.57 & 251.37 \\
4 & 0.612 & 0.723 & 40 & 80 & 113060.31 & 76863.11 & 189923.42 & 335.16 \\
5 & 0.583 & 0.646 & 50 & 100 & 141325.39 & 96078.89 & 237404.28 & 418.95 \\
6 & 0.554 & 0.56 & 60 & 120 & 169590.46 & 115294.67 & 284885.13 & 502.74 \\
7 & 0.525 & 0.471 & 70 & 140 & 197855.54 & 134510.45 & 332365.99 & 586.53 \\
8 & 0.495 & 0.384 & 80 & 160 & 226120.62 & 153726.22 & 379846.84 & 670.32 \\
\hline
\end{tabular}


Table 8 - User fee Analysis (Based on Proposed Carrying Capacity)

\begin{tabular}{|ccccccccc|}
\hline $\begin{array}{c}\text { Proposed } \\
\text { fee(US\$) }\end{array}$ & $\begin{array}{c}\text { Expected } \\
\text { "YES" } \\
\text { (Domestic) }\end{array}$ & $\begin{array}{c}\text { Expected } \\
\text { "YES" } \\
\text { (Int'I) }\end{array}$ & $\begin{array}{c}\text { Percent Inc. } \\
\text { over current } \\
\text { fee } \\
\text { (Domestic) }\end{array}$ & $\begin{array}{c}\text { Percent } \\
\text { Inc. over } \\
\text { current fee } \\
\text { (Int'l) }\end{array}$ & $\begin{array}{c}\text { Potential } \\
\text { annual } \\
\text { income(Int'l) }\end{array}$ & $\begin{array}{c}\text { Potential } \\
\text { annual } \\
\text { Income } \\
\text { (Domestic) }\end{array}$ & $\begin{array}{c}\text { Total } \\
\text { Potential } \\
\text { Income }\end{array}$ & $\begin{array}{c}\text { Percent } \\
\text { of } \\
\text { current } \\
\text { budget }\end{array}$ \\
\hline 1 & 0.693 & 0.884 & 10 & 20 & 12094.49 & 8222.34 & 20316.82 & 35.85 \\
2 & 0.667 & 0.842 & 20 & 40 & 24188.97 & 16444.67 & 40633.64 & 71.71 \\
3 & 0.64 & 0.789 & 30 & 60 & 36283.46 & 24667.01 & 60950.46 & 107.56 \\
4 & 0.612 & 0.723 & 40 & 80 & 48377.94 & 32889.34 & 81267.28 & 143.41 \\
5 & 0.583 & 0.646 & 50 & 100 & 60472.43 & 41111.68 & 101584.10 & 179.27 \\
6 & 0.554 & 0.56 & 60 & 120 & 72566.91 & 49334.01 & 121900.92 & 215.12 \\
7 & 0.525 & 0.471 & 70 & 140 & 84661.40 & 57556.35 & 142217.74 & 250.97 \\
8 & 0.495 & 0.384 & 80 & 160 & 96755.88 & 65778.68 & 162534.57 & 286.83 \\
\hline
\end{tabular}




\section{Chapter V}

\section{$\underline{\text { Policy Implications and Conclusion }}$}

Buccoo Reef Marine Park under the present management scheme is highly mismanaged and ineffective in achieving its goal as the facts and figures in Chapter 4 show. The severely outdated management plan and the subsequent gaps and disconnects amongst management agencies and the local community has resulted in a protected area that is improperly managed, undervalued and unsustainably used. On the basis of the findings in this study, the management plan needs to be seriously reevaluated since one cannot manage in a park in 2010 with a 1996 plan as issues and problems regarding the MPA in question may change over time. The health of this reef system is in jeopardy and should be cause for alarm and immediate assessment.

On the basis of the findings of this study from key informants and local residents, it is evident that there is severe lack of communication which seems to be a major contributor to the management inefficiencies of this reef. With the number of agencies involved, inter-agency communication and coordination proves to be a challenge as there are many individuals with differing interests and priority of concerns regarding the management of Buccoo Reef. Considering the local resident survey, it is clear that communication must not only improve amongst managing agencies, but to the general public as well and this is an avenue that must be reevaluated. There is significant need for increased community awareness, involvement and education to ensure that the goals set out by management are achieved. 
Though the current plan indicates the need for sustainable visitation to the reef, no methods have been specified. As a result of potential disparities in the tourism numbers reported and lack of sufficient scientific data, it is very difficult to make firm suggestions about what use can be deemed as acceptable or sustainable. It is fair to say however, that the maximum possible allowable number as implied by the management agencies of 1680 per day should be reevaluated as this number seems to be too large not to in an increase of environmental damage. Management should consider other options such as, lowering the maximum possible numbers of trips per day as well as the capacity of the boats. However this can most likely lead to significant disapproval from boat tour operators and other business owners as their main source of income may be jeopardized. Alternate avenues of earning income should be explored for directly affected persons in the event of significantly decreased income. These can include, conducting education awareness programs or jobs within the management agencies, such as patrol officers or reef supervisors.

Management should also consider the implementation of a zonation plan whereby different areas of the reef are sectioned. This can have a positive effect on the carrying capacity as different areas can be designated for specific usage at differing levels of protection. This is a method readily accepted in most protected area management and has been successfully implemented in areas of the Meso-American reef bordering Mexico where management has designated the most populous portion of the reef in Cancún affected by high volumes of tourism, as the "sacrificial reef" allowing higher volumes of tourism activity, and in the less visited portion of the reef in Puerto Morelos being under stricter regulations with limited visitation numbers. However, considering the current 
atmosphere of the environmental issues and lack of political will within the country, fostering willingness to accept change may prove to be a huge obstacle.

The current plan also indicates the need for exploration of a user fee system, but this too has yet to be implemented. Based on the findings of this study it is clear that a user fee system is a very plausible option which can lead to significant revenue for the management of the BRMP. Even if visitation rates were halved, the fact that over $50 \%$ of visitors interviewed said that they would be willing to pay an additional fee with a median amount of approximately US $\$ 12$ shows that there can be significant additional revenues generated through this method. Revenue gained can not only cover management costs, but can also filter back into the community and be used for other purposes of much needed community upliftment. The means by which funds will be collected needs to be ascertained. The payment system could be implemented in such a way where a stall or booth is set up where patrons can pay the user fee and then be assigned to a specific boat where he/she can then pay the tour operator for the trip. This suggested payment system may be welcomed since visitors are currently being badgered by boat tour operators upon entering the beach areas, but this plan will probably receive major objections from the boat tour operators as there is serious competition amongst them to fill boats, hence the visitor badgering. The user fee booth idea can be successful in eliminating confusion or misappropriations of user fee funds with boat tour operator fees. Though the user fee system proves to be widely accepted amongst both international and domestic visitors, fallout may occur with boat tour operators as most are very stubborn and set in the way they currently operate. 
Though the need for much improvement is clear, it must be noted that many of these problems seem to be a worldwide issue in MPA management, especially in developing countries. A combination of bottom-up and top-down management strategies generally works best in protected area management (MPA Connections, 2004), but considering the years of distrust in the local government in Trinidad and Tobago, this method may not be readily possible. Unfortunately the future for Buccoo Reef Marine Park seems very grim, however all hope should not be lost. If the community members were respected and their opinions were valued their mindsets may change and this can be the focus for the short term. That stakeholders unite and tackle the problems plaguing BRMP collectively, is the key to its successful future.

Long terms goals however are much more complex and require a change in government authorities and priorities, and a revamping of the entire management system. There needs to be a development of top-down control where government can effectively formulate committees of various stakeholder groups that will undertake official duties and that are required to have effective communication through mandatory meetings. A successful management scheme should involve a cohesive approach to management, inclusive of stakeholders such as fishermen, boat tour operators, community representatives, NGOs and governmental personnel. The local community can therefore begin to build the needed trust in government if they can recognize governmental efforts to bettering the management of the park that ultimately affects their livelihoods. 


\section{REFERENCES}

Adams,C., Seroa da Motta,R., Ortiz, R.A., Reid, J., Aznar,C.E. and Antonio de Almeida Sinisgalli,P. "The use of contingent valuation for evaluating protected areas in the developing world: Econimic valuation of Morro do Diabo State Park, Atlantic Rainforest, São Paulo State (Brazil).” Ecological Economics 66 (2008) 359-370

Adams, W. and Hulme D. "Conservation and Community: Changing narratives, policies and practices in African conservation." African Wildlife and livelihoods: The promise and performance of community conservation. Oxford UK. James Currey (2001) 9-23

Agardy, T. et al. "Dangerous targets? Unresolved issues and ideological clashes around marine protected areas" Aquatic Conservation: Marine and Freshwater Ecosystems 13 (2003) 1-15

Ahmed, M., Umali,G.M., Chong, C.K., Rill, M, F. and Garcia, M.C. "Valuing recreational and conservation benefits of coral reefs - The case of Bolinao, Phillipines." Ocean \& Coastal Management 50 (2007) 103-118

Alberini, A. "Optimal Designs for Discrete Choice Contingent Valuation Surveys: Single-Bound, Double-Bound, and Bivariate Models.” Journal of Environmental Economics and Management 28 (1995) 287-306

Arin, T. and Kramer, R.A. 'Divers' willingness to pay to visit marine sanctuaries: an exploratory study" Ocean and Coastal Management 45 (2002) 171-183

Aronson, R.B. and Precht, W.F. "Conservation, precaution, and Caribbean reefs.” Coral Reefs 25 (2006) 441-450

Arrow et al., "Report of NOAA panel on contingent valuation." Federal Register 58 (1993) 4602-4614

Badalamenti, F., Ramos, A.A., Voultsiadou,E., Sánchez Lizaso, J.L., D’Anna,G., Pipitone, C., Mas, J., Ruiz Fernandez, J.A., Whitmarsh,D. and Riggio, S. " Cultural and socio-economic impacts of Mediterranean marine protected areas." Environmental Conservation 27 (2000) 110-125

Bajracharya, S.B., Furley, P.A. and Newton, A.C. "Effectivness of communityinvolvement in delivering conservation benefits to the Annapurna Conservation Area, Nepal.” Environmental Conservation 32 (2005) 239-247

Bajracharya, S.B., Furley, P.A. and Newton, A.C. "Impacts of community-based conservation on local communities in the Annapurna Conservation Area." Biodiversity and Conservation 15 (2006) 2765-2786

Balistreri,E., McClelland, G., Poe,G. and Schulze,W. "Can Hypothetical Questions Reveal True Values? A Laboratory Comparison of Dichotomous Choice and Open-Ended 
Contingent Values with Auction Values." Environmental and Resource Economics 18 (2001) 275-292

Ban, N.C., Hansen, G.J.A., Jones,M. and Vincent, A.C.J. "Systematic marine conservation planning in data-poor regions: Socioeconomic data essential." Marine Policy 33 (2009) 794-800

Ban, N.C., Picard, C.R. and Vincent, A.C.J. "Comparing and Integrating CommunityBased and Science-Based Approaches to Prioritizing Marine Areas for Protection." Conservation Biology 23 (2009) 899-910

Baral,N., Gautam,R., Timilsina,N. and Bhat,M.G. "Conservation implication of contingent valuation of critically endangered white-rumped vulture Gyps bengalensis in South Asia." International Journal of Biodiversity Science and Management 2 (2007) $145-156$

Baral,N., Stern,M.J. and Bhattarai,R. "Contingent valuation of ecotourism in Annapurna conservation area, Nepal: Implications for sustainable park finance and local development." Ecological Economics 10 (2008) 1-10

Beaumont, N.J., Austen,M.C., Mangi, S.C. and Townsend,M. "Economic valuation for the conservation of marine biodiversity." Marine Pollution Bulletin. 56 (2008) 386-396.

Bhat, M.G. Application of non-market valuation to Florida Keys marine reserve management.” Journal of Environmental Management. 67 (2003) 315-325.

Bingham, G. et al. "Issues in ecosystem valuation: improving information for decision making.” Ecological Economics. 14 (1995) 73-90.

Blakemore,F. and Williams, A. "British Tourist's valuation of Turkish Beach Using Contingent Valuation and Travel Cost Methods." Journal of Coastal Research. 24 (2008) $1469-1480$

Boersma, P. D. and Parrish, J.K. "Limiting abuse: marine protected areas, a limited solution.” Ecological Economics 31 (1999) 287-304

Boyle, K. (2003). "Contingent Valuation in Practice." In: A Primer on nonmarket Valuation, P.A. Champ, K. J. Boyle, and T. C. Brown, eds., Kluwer Academic Publishers, The Netherlands, 111-169

Briggs, J.C. "Coral reefs: Conserving the evolutionary sources." Biological Conservation. 126 (2005) 297-305.

Brody, S.D. "Measuring the Effects of Stakeholder Participation on the Quality of Local Plans Based on Principles of Collaborative Ecosystem Management." Journal of Planning Education \& Research 22 (2003) 407-419 
Bryant, D., Burke,L., MaManus,J. and Spalding,M. "Reefs as Risk - A Map-Based Indicator of the Threats to the World's Coral Reefs." World Resources Institute (WRI) Washington, D.C., 1998

Bunce,L., Gustavson, K., Williams, J. and Miller,M. "The human side of reef management: a case study analysis of the socioeconomic framework of Montego Bay Marine Park." Coral Reefs 18 (1999) 369-380

Burke,L., Greenhalgh,S., Prager,D. and Cooper,E. "Coastal Capital - Economic Valuation of Coral Reefs in Tobago and St. Lucia." World Resources Institute (WRI) Washington, D.C., 2008

Burke,L., Kura,Y., Kassem,K., Revenga,C., Spalding,M. and McAllister,D. "Pilot analysis of Global Ecosystems: Coastal Ecosystems." World Resource Institute (WRI) Washington, D.C., 2001

Burke,L. and Maidens,J. "Reefs at risk in the Caribbean." World Resources Institute (WRI) Washington, D.C., 2004

Camarago ,C., Maldonalo, J.H., Alvarado, E., Moreno-Sánchez, R., Manrique,N., Mogollón,A., Osorio, J.D., Grajales,A. and Sánchez, J.A. " Community involvement in management for maintaining coral reef resilience and biodiversity in southern Caribbean marine protected areas.” Biodiversity Conservation 18 (2009) 935-956

Carr,L.M. and Heyman,W.D. "Jamaica bound? Marine reserves and management at a crossroads in Antigue and Barbuda.” The Geographical Journal 175 (2009) 17-38

Central Statistical Office of Trinidad and Tobago (CSO). Ministry of Planning and Development. Government of the Republic of Trinidad and Tonago. http://www.cso.gov.tt/

Cinner, J.E. "Designing marine reserves to reflect local socioeconomic conditions: lessons from long-enduring customary management systems." Coral Reefs 26 (2007) 1035-1045

Connell, J.H. "Diversity in tropical rain forests and coral reefs." Science 199 (1978) $1302-1310$

Cortés, J. "Coral Communities and reefs from Area de Conservacion Guanacaste, Costa Rica.” Revista de Biologia Tropical 45 (1997) 623-625

Costanza, R., et al. "The value of the world's ecosystem services and natural capital." Nature. 387 (1997) 253-260.

Crabbe, J.M, Martinez,E., Garcia,C., Chub,J., Castro, L. and Guy,J. “Is Capacity Building Important in Policy Development for Sustainability? A Case Study Using 
Action Plans for Sustainable Marine Protected Areas in Belize.” Society and Natural Resources 23 (2008) 181-190

Chrislip, D.D. "American Renewal: Reconnecting citizens with public life.” National Civic Review 83 (1994) 25-31

Day,J. "The need and practice of monitoring, evaluating and adapting marine planning and management - lessons learned from the Great Barrier Reef." Marine Policy 32 (2008) 823-831.

Davis,D. and Tisdell,C. "Economic Management of Recreational Scuba Diving and the Environment." Journal of Environmental Management 49 (1996) 229-248

Davis, D. and Tisdell, C. "Recreational scuba-diving and carrying capacity in marine protected areas." Ocean and Coastal Management 26 (1995) 19-40

DeCaro, D. and Stokes, M. "Social-Psychological Principles of Community-Based Conservation and Conservancy Motivation: Attaining Goals within an AutonomySupportive Environment.” Conservation Biology 22 (2008) 1443-1451

Depondt,F. and Green,E. "Diving user fees and the financial sustainability of marine protected areas: Opportunities and impediments." Ocean \& Coastal Management 49 (2006) 188-202

Deutsch,L., Folke,C. and Skånberg,K. "The critical natural capital of ecosystem performance as insurance for human well-being." Ecological Economics 44 (2003) 205217

Dharmaratne,G.S., Yee Sang,F. and Walling,L.J. "Tourism Potentials for Financing Protected Areas." Annals of Tourism of Research 27 (2000) 590-610

Diedrich,A. "The impacts of tourism on coral reef conservation awareness and support in coastal communities in Belize." Coral reefs 26 (2007) 985-996

Edwards,P.E.T. "Sustainable financing for ocean and coastal management in Jamaica: The potential for revenues for tourist user fees." Marine Policy 33(2009) 376-38

Emerton,L., Bishop,J. and Thomas,L. "Sustainable financing of protected areas: a global review of challenges and options." The World Conservation Union (IUCN) 2006

Field,B.C. and Field,M.K. "Environmental Economics : an introduction.” McGraw-Hill. Boston. 2006.

Few, R. "Conservation, Participation, and Power: Protected-Area Planning in the Coastal Zone of Belize." Journal of Planning Education and Research 19 (2000) 401-408

Giraud,K.L., Loomis,J.B. and Cooper,J.S. “ A Comparison of Willingness to Pay Estimation Techniques From Referendum Questions." Environmental and resource Economics 20 (2001) 331-346 
Goreau, T. F. "Buccoo Reef and Bon Accord Lagoon, Tobago: Observations and Recommendations Concerning the Preservation of the Reef and its Lagoon in Relation to Urbanisation of the Neighbouring Coastal Islands" Memorandum to Permanent Secretary (Agriculture), Economic Planning Unit, Prime Minister's Office, Government of Trinidad and Tobago (1967)

Granek, E.F. and Brown, M.A. "Co-management approach to Marine Conservation in Mohéli, Comoros Islands." Conservation Biology 19 (2005) 1724-1732

Gravestock,P., Roberts,C.M. and Bailey,A. "The income requirements of marine protected areas." Ocean \& Coastal Management 51 (2008) 272-283

Green, E., and Donnelly, R. "Recreational scuba diving in Caribbean Marine Protected Areas: do the users pay?" Ambio 32 (2003) 140-144

Guarderas,A.P., Hacker,S.D. and Lubchenco,J. "Current status of Marine Protected Areas in Latin America and the Caribbean." Conservation Biology 22 (2008) 1630-1640

Haab,T.C. "Estimation Using Contingent Valuation Data from a "Dichotomous Choice with Follow-up" Questionnaire: A Comment." Journal of Environmental Economics and Management 35 (1998) 190-194

Hanemann, M.W. "Valuing the Environment Through Contingent Valuation." Journal of Economic Perspectives 8 (1994) 19-43

Hanemann, M.W. "Welfare evaluations in contingent valuation experiments with discrete responses." Journal of American Agriculture 66 (1984) 331-341

Hanemann,M., Loomis,J. and Kanninen,B. "Statistical Efficiency of Double-Bounded Dichotomous Choice Contingent Valuation." American Journal of Agricultural Economics (1991) 1255-1263

Hawkins,J.P. et al. "Effects of Recreational Scuba Diving on Caribbean Coral and Fish Communities." Conservation Biology 13 (1999) 888-897

Heinen,J.T. " Human Behavior, Incentives, and Protected Area Management." Conservation Biology 10 (1996) 681-684

Hind, E.J., Hiponia, M.C and Gray, T.S. "From community-based to centralised national management - A wrong turning for the governance of the marine protected area in Apo Island, Philippines?" Marine Policy 34 (2010) 54-62

Inglis, G.J., Johnson, V.I. and Ponte, F. "Crowding Norms in Marine Settings: A Case Study of Snorkeling on the Great Barrier Reef." Environmental Management 24 (1999) 369-381

Jameson et al. "A coral damage index and its application to diving sites in the Egyptian Rea Sea." Coral Reefs 18 (1999) 333-339 
Juman, R., and Bacon, P. "Buccoo Reef Case Study, Caribbean Basins, LOICZ (LandOcean Interaction in the Coastal Zone) Global Change Assessment and Synthesis of River Catchment/Island-Coastal Sea Interaction and Human Dimensions; with a desktop study of Ocean Basins." Institute of marine Affairs (2002) www.ima.gov.tt

Kamukuru,A.T., Mgaya,Y.D. and Öhman,M.C. "Evaluating a marine protected area in a developing country: Mafia Island Marine Park,Tanzania." Ocean \& Coastal Management 27 (2004) 321-337

Kenny, J. S. "A Preliminary Study of the Buccoo Reef/Bon Accord Complex, with Special Reference to Development and Management." Department of Biological Sciences, University of the West Indies, Trinidad, (1976)

King, O.H. "Estimating the value of marine resources: a marine recreation case." Ocean \& Coastal Management 27 (1995) 129-141

Kostopoulou, S. and Kyritsis,I. “A Tourism Carrying Capacity Indicator for Protected Areas.” Anatolia: An International Journal of Tourism and Hospitality Research 17 (2006) 5-24

Lane, M.B. "Affirming New Directions in Planning Theory: Co-management of Protected Areas." Society and Natural Resources 14 (2001) 657-671

Laydoo, R.S., Bonair, K. and Alleng, G. "Buccoo Reef and Bon Accord Lagoon, Tobago, Republic of Trinidad and Tobago." Caribbean Coastal Marine Productivity (CARICOMP) Coral Reef, Seagrass and Mangrove Site Characteristics. UNESCO, Paris 1998

Laydoo, R. S. and Heileman, L."Environmental Impacts of the Buccoo and Bon Accord Sewage Treatment Plants, Southwestern Tobago.” A Preliminary Report. Institute of Marine Affairs and Crusoe Reef Society (1987)

León, R. and León, C.J. "Single or double bounded contingent valuation? A Bayesian test." Scottish Journal of Political Economy 50 (2003) 174-188

Leujak, W. and Ormond, R.F.G. "Quantifying acceptable levels of visitor use on Red Sea reef flats" Aquatic Conservation: Marine and Freshwater ecosystems 18 (2008) 930-944

Leujak, W. and Ormond, R.F.G. "Visitor Perception and the Shifting Social Carrying Capacity of South Sinai's Coral Reefs." Environmental Management (2007) 39:472-489

Liu,X., Wirtz,K.W., Kannen,A. and Kraft,D. "Willingness to pay among households to prevent coastal resources from polluting by oil spills: A pilot survey." Marine Pollution Bulletin 58 (2009) 1514-1521 
Lundquist, C.J. and Granek, E. "Strategies for Successful Marine Conservation: Integrating Socioeconomic, Political, and Scientific Factors.” Conservation Biology 19 (2005) 1771-1778

Maes,F. "The international legal framework for marine spatial planning." Marine Policy 32 (2008) 797-810

Martin,B.S. and Uysal,M. "An examination of the relationship between carrying capacity and the tourism lifecycle: management and policy implications." Journal of Environmental Management 31 (1990) 327-333

Mathieu,L.F., Langford,I.H. and Kenyon,W. " Valuing marine parks in a developing country: a case study of the Seychelles." Environment and Development Economics 8 (2003) 373-390

McClanahan,T.R. "Is there a future for coral reef parks in poor tropical countries" Coral Reefs 18 (1999) 321-325

McLeod, M.T. and Airey,D. "The politics of tourism development: a case studt of dual governance in Tobago." International Journal of Tourism x (200x) xxx-xxx

Mehta, J.N. \& Kellert, S.R. "Local attitudes toward community-based conservation policy and programmes in Nepal: a case study in the Makalu-Barun Conservation Area." Environmental Conservation 25 (1998) 320-333

Meng, P., et al. "A long-term survey on anthropogenic impacts to the water quality of coral reefs, southern Taiwan.” Environmental Pollution. 156 (2008) 67-75

Miller, Tyler G. and Spoolman, Scott. Environmental Science: Problems, Concepts and Solutions. Canada: Thomson, 2008

Mishra, B.K., Badola, R. and Bhardwaj, A.K. "Social issues and concerns in biodiversity conservation: experiences from wildlife protected areas in India." Tropical Ecology 50 (2009) 147-161

Mitchell, R.C. and Carson,R.T. "Using Surveys to value public goods: the contingent valuation method." Resources for the Future (1989) Washington, D.C.

Moberg,F. and Folke,C. "Ecological goods and services of coral reef ecosystems." Ecological Economics. 29 (1999) 215-233

Mora,C. "A clear human footprint in the coral reefs of the Caribbean." Proceedings of the Royal Society B 275 (2008) 767-773

"MPA Connections - Stakeholder Participation: A Synthesis of Current Literature." Newsletter of the National Marine Protected Areas Center. September/October (2004) 320 
National Tourism Policy of Trinidad and Tobago. Ministry of Tourism. September 2009. www.tourism.gov.tt

Needham,M.D. "Value orientations toward coral reefs in recreation and tourism settings: a conceptual and measurement approach" Journal of Sustainable Tourism 18 (2010) 757772

Nepal, S.K. "Involving Indigenous Peoples in protected Area Management: Comparative Perspectives from Nepal, Thailand, and China." Environmental Management 30 (2002) $748-763$

O'Reilly, A.M. "Tourism Carrying Capacity: Concepts and issues.” Tourism Management 7 (1986) 254-258

Peters,H. and Hawkins,J.P. "Access to marine parks: A comparative study in willingness to pay." Ocean \& Coastal Management 52 (2009) 219-228

Pollnac, R.B., Crawford, B.R. and Gorospe, M.L.G. "Discovering factors that influence the success of community-based marine protected areas in the Visayas, Philippines." Ocean \& Coastal Management 44 (2001) 683-710

Pomeroy,R.S., Watson,L.M., Parks,J.E. and Cid,G.A. "How is your MPA doing? A methodology for evaluating the management effectiveness of marine protected areas." Ocean \& Coastal Management 48 (2005) 485-502

Priskin, J. “ Tourist perceptions of degradation caused by coastal nature-based recreation." Environmental Management 32 (2003) 189-204

Ransom,K.P. and Mangi,S.C. " Valuing Recreational Benefits of Coral reefs: The case of Mombasa Marine National Park and Reserve, Kenya." Environmental Management 45 (2010) 145-154

Reid-Grant, K. and Bhat,M. "Financing marine protected areas in Jamaica: An exploratory study" Marine Policy 33 (2009) 128-136

Rodríguez-Martínez, R.E. "Community involvement in marine protected areas: the case of Puerto Morelos reef, México.” Journal of Environment Management 88 (2008) 11511160

Seaman,W. "Artificial habitats and the restoration of degraded marine ecosystems and fisheries." Hydrobiologia 580 (2007) 143-155

Shokry,M. and Ammar,A. " Assessment of Present Status and Future Needs of Four Coral Reef Sites Along the Gulf of Aqaba, Egypt.” The Open Environmental Pollution \& Toxicology Journal 1 (2009) 34-42

Smith,S.V. "Coral -reef area and the contribution of reefs to processes and resources of the world'soceans." Nature 273 (1978) 225-226 
Sorice,M.G., Oh,C. and Ditton,R.B. "Managing Scuba Divers to Meet Ecological Goals for Coral Reef Conservation.” Ambio 36 (2007) 316-322

Springer, E. "Community Participation in Marine protected Area Implementation: A Case Study of the Sitka Local Area Management Plan." Coastal Management 34 (2006) 455465

Spurgeon, J.P.G. "'The economic valuation of coral reefs." Marine Pollution Bulletin 24 (1992) 529-536

Stamieszkin,K., Wielgus,J. and Gerber,L.R. "Management of a marine protected area for sustainability and conflict resolution: Lessons from Loreto Bay National Park (Baja California Sur, Mexico).” Ocean \& Coastal Management 52 (2009) 449-458

Stone,K., Bhat, M., Bhatta, R., and Matthews, A. "Factors influencing community participation in mangroves restoration: A contingent valuation analysis."Ocean and Coastal Management 51 (2008) 476-484

Talge,H. "Impact of recreational divers on scleractinian corals at Loo Key, Florida. Prooceedings of the Seventh International Coral Reef Symposium 2 (1993) 1077-1082

Teh,L.C.L., Teh,L.S.L. and Chen Chung, F. “A private management approach to coral reef conservation in Sabah, Malaysia.” Biodiversity Conservation 17 (2008) 3061-3077

The New York Times. "Florida Coral Reefs Decline Rapidly." The New York Times, August 9, 1994 The Environmental Section

Thur,S. M. "User fees as sustainable financing mechanisms for marine protected areas: An application to the Bonaire National Marine Park." Marine Policy 34(2010) 63-69

Tissot, B.N., Walsh,W.J. and Hixon, M.A. "Hawaiian Islands Marine Ecosystem Case Study: Ecosystem and Community- Based Management in Hawaii." Coastal Management 35 (2009) 255-273

Tongson,E. and Dygico,M. "User Fee System for Marine Ecotourism: The Tubbataha Reef Experience." Coastal Management 32 (2004) 17-23

“Tobago Reefs" http://www.mytobago.info/diving06.php

Tourism Development Company Limited (TDC) $\underline{\text { www.tdc.co.tt }}$

US Department of Commerce, 1995. Florida keys National Marine Sanctuary Draft management Plan/environmental Impact Statement, vol. II. Sanctuaries and Reserves Division, National Oceanic and Atmospheric Administration, Washington, DC, pp.245

Uyarra,M.C., Watkinson,A.R. and Côté,I.M. "Managing Dive Tourism for the Sustainable Use of Coral Reefs: Validating Diver Preceptions of Attractive Site Features.” Environmental Management 43 (2009) 1-16 
Wainwright, C. \& Wehrmeyer, W. (1998) "Success in integrating conservation and development? A study from Zambia.” World Development 26 (1998) 933-944.

Wells, M.P. and Brandon, K. "People and Parks: Linking Protected Area Management with Local Communities." The World Bank, U.S. Agency for International Development and World Wildlife Fund, Washington, D.C (1992)

Wells, M.P. and McShane, T.O. "Integrating Protected Area Management with Local Needs and Apsirations." Ambio: A Journal of the Human Environment 33 (2004) 513519

World Commission on Protected Areas (WCPA). Mandate 2009-2012. International Union for Conservation of Nature (1999) www.iucn.org

World Travel and Tourism Council (WTTC). WTTC Regional and Country Reports (1997) www.wttc.org

Zakai,D. and Chadwick-Furman,N.E. "Impacts of intensive diving on reef coral at Eilat northern Rea Sea." Biological Conservation 105 (2002) 179-187 


\title{
APPENDIX I - Local Resident Survey
}

\author{
Florida International University \\ Department of Earth and Environment
}

Survey of Local Resident Perception of the Buccoo Reef Marine Park in Tobago W.I.

Your participation in the interview is voluntary. There are no penalties for not answering some or all of the questions. You can refuse to answer any questions during the interview process or stop the interview at any time. No question in the questionnaire will identify you as an individual. The purpose of this study is to evaluate the perception of local residents of the Buccoo Reef. This study is being conducted by Dionne Da Costa, a Master's Student at Florida International University, Miami, USA. If you have questions about the survey, please contact student's advisor, Dr. Mahadev Bhat at +1 (305) 348-1210 or bhatm@fiu.edu.

1. Are you aware that Bucco Reef is a Marine Protected Area? Y N

2. Are you familiar with the management rules of the Buccoo Reef Marine Park: $\mathrm{Y}$ $\mathrm{N}$

3. If yes, how did you become familiar with them?

4. Are you in favour of the rules? YES (all) YES (some) NO

5. Please explain your answers: (open ended)

6. Have you or any family members ever been fined or reprimanded for any violation of the rules in Buccoo Reef Marine Park?

Y N

7. If yes to \#5, please explain (open ended): 
8. Do you agree with Buccoo Reef becoming a protected Marine Park? Y N

9. Why or why not? (open ended):

10. Please circle the answer that best fits your opinions for the following questions:

a. I like the fact that Buccoo Reef was designated a protected Marine Park:

agree neutral disagree

why (open ended)

b. The Buccoo Reef Marine park has increased job opportunities:

agree neutral disagree do not know

why (open ended)

c. The staff of the Marine Park are professional and courteous:

agree neutral disagree do not know

why (open ended)

d. In general, the Buccoo Reef is well managed:

agree neutral disagree do not know

why (open ended) 
11. What are major disadvantages of living near the marine park?

12. What are the major advantages of living near the marine park?

13. Have you ever attended a public meeting concerning the marine park? $\mathrm{Y} \quad \mathrm{N}$

14. If yes, was the experience: Positive neutral Negative

Why?

15. If no, why? (open ended)

16. Please circle the answer that best fits your opinion on each question:

a. The corals are better protected with the implementation of the marine park:

Agree neutral disagree do not know

b. Fish numbers are increasing in the Buccoo Reef:

Agree neutral disagree do not know

c. The current rules are adequate:

Agree neutral disagree do not know

d. Tourism is properly managed in the Buccoo Reef:

Agree neutral disagree do not know 
e. Overall, I am glad that Buccoo Reef was designated a marine park:

$$
\text { Agree neutral disagree do not know }
$$

\section{Reminder: you may refuse to answer any questions.}

1. What is your age? years

2. Are you married? yes no

3. Are you? Female Male (Interviewer: Don't ask this question; mark accordingly)

4. Including yourself, how many people are there in your household?

5. Education level: No formal education elementary high school College

Vocational education

6. Please indicate the appropriate category for total household income? (in USD)

\begin{tabular}{ll}
- & $<\$ 10,000$ \\
& $\$ 10,001-\$ 15,000$ \\
& $\$ 15,001-\$ 20,000$ \\
& $\$ 20,001-\$ 25,000$ \\
& $\$ 25,001-\$ 30,000$ \\
\hline & $\$ 30,001-\$ 35,000$ \\
& $\$ 35,001-\$ 40,000$
\end{tabular}

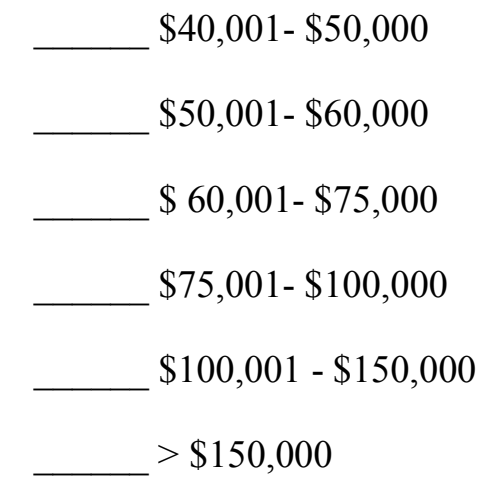

Thank you very much for your cooperation 


\section{APPENDIX II}

Florida International University

Department of Earth and Environment

Survey of Non-consumptive Users of the Buccoo Reef in Tobago W.I

Your participation in the interview is voluntary. There are no penalties for not answering some or all of the questions. You can refuse to answer any questions during the interview process or stop the interview at any time. No question in the questionnaire will identify you as an individual. The purpose of this study is to evaluate the perception of visitors of the Buccoo Reef . This study is being conducted by Dionne Da Costa, a Master's Student at Florida International University, Miami, USA. If you have questions about the survey, please contact student's advisor, Dr. Mahadev Bhat at +1 (305) 348-1210 or bhatm@fiu.edu.

Interview Site:

Type of Day: ___ Weekday___ Weekend___ Holiday

1. What is the primary purpose of your trip to Tobago?

Recreation or vacation Business/Pleasure combined Visit Family/Friends

Business Other(specify)

2. What is the primary recreational activity you are here for?

Glass-bottom boat riding

Snorkeling

Others (indicate the purpose)

3. If the visit to Buccoo Reef in particular is NOT the SOLE purpose of your trip to Trinidad \& Tobago, what portion of your trip (time-wise) would you spend on visiting this particular recreational site?

In days OR In hours OR In percentage

4. What is the city of your origin ?

5. Approximately, what is the distance that you traveled from your city of origin to Tobago

Via air miles? 
Via cruiseship

By road miles?

miles?

6. On an average, under each trip how many people are in your group $?$

7. Including this visit, how many times did you visit the Buccoo Reef in the past FIVE years?

During the above visits, how many times did you participate in

Glass-bottom boat riding

Scuba diving

Snorkeling

Recreational fishing

Reef walking

Other (please specify)

8. On an average, how many days did you spend during each trip to Tobago, not including the travel

period?

9. We would like to know what the costs of your ENTIRE trip would be.

Airfare

US\$ per person

Hotel accommodation

US\$ per person

Local transportation

US\$ per person

Food

US\$ per person

Recreational activities US\$ per person (for entry free, tour boats, equipment rental, etc.)

Other

US\$ per person

No, we don't have all the information above because we paid for the trip as a package. The costs of the package were US\$ per person OR US\$ per group.

10. During each visit, on an average how many boats (commercial or recreational) of other visitors did you encounter WHILE you were engaged in a recreational activity? 
11. Based on this visit to Buccoo Reef or on previous visits, how satisfied were you? (circle your answer)

Very satisfied Satisfied Neutral Disappointed Very disappointed

12. Are you aware that Buccoo Reef is designated a marine park? (circle answer) YES NO

13. If YES (\#7) how did you know?

14. Are you aware of the regulations implemented by the Buccoo Reef management?

YES NO

15. If YES (\#9) what regulations are you aware of?

16. Experts say that coral reefs provide necessary habitat for many marine fishes and an improvement of the existing reef habitat may result in higher fish abundance. If the fish population doubles in size because of the improvement in the health of the reef habitat and all your personal conditions remain the same, your number of visits to Buccoo Reef in a FIVE year period would remain (circle the appropriate choice):

the same $\quad 1$ time more $\quad 2$ times more $\quad 3$ times more $\quad 4$ times more

5 times more $\quad$ More than 5 times

17. Experts say that quality of the corals at this reef has declined over the years. A proper coral reef management plan might improve the reef quality and diversity. Because of such management plan, if the coral quality improves by 100 percent in the future and all your personal conditions remain the same, your number of visits to Buccoo Reef in a FIVE year period would remain (circle the appropriate choice):

the same $\quad 1$ time more $\quad 2$ times more 3 times more $\quad 4$ times more 
18. Experts say that coral reefs provide vital services for many coastal regions. Due to increased coastal development and increased pollution entering marine systems, water quality has decreased and has affected these vital services that coral reefs provide. Suppose that the government would come up with a plan to improve the water quality of the reef by 100 percent from the current level. Given that all your personal conditions remain the same, your number of visits to Buccoo Reef in a FIVE year period would remain (circle the appropriate choice):

the same $\quad 1$ time more $\quad 2$ times more 3 times more $\quad 4$ times more

5 times more $\quad$ More than 5 times

19. How much did you pay/will you be paying for the boat tour to Buccoo Reef? US\$/person $[\mathrm{X}]$ ?

20. There is a general feeling that there is not adequate funding to manage the Buccoo Reef Marine Park and the surrounding area in terms of fish abundance, coral health and water quality protection. Also, the current funding source may not sustain in the future. In order to meet the expenses toward coral reef conservation and administration, suppose that there is a proposal to increase the boat tour fee. This extra boat fee collected would be exclusively used for Buccoo Reef protection and conservation program. In the previous question, you indicate that currently you are paying a boat tour fee of US\$ $[\mathrm{X}]$ per person. Keeping in mind your budget and other financial commitments, would you be willing to pay an additional boat tour fee of [Y] dollar per person?

[Note for the Interviewer: pick at random one of the following amounts for [Y]. Make sure that each of the amounts is picked approximately the same number of times in the sample.

Foreign tourists: US\$ 5, 10, 15, 20, 30, 50, 75, 100

Domestic tourists: US\$ 1, 2, 5, 10, 15, 20

Yes NO Not sure

21. If willing to pay the above additional boat fee, what are the most important reasons you are willing to do so? Check as many as relevant

I deeply care about marine environment protection

I feel or know that Buccoo Reef coral reef, fish and water quality have declined over the years 
As a tourist coming from outside, it gives me a higher satisfaction

I believe that coral reefs are important and should be conserved and protected

I believe it is important to preserve our environment for future generations

22. If NOT willing to pay the above additional boat fee, what are the most important reasons you are not willing to do so? Check as many as relevant

_ I I we can not trust a public/private agency with additional money

_ the new system will not work

the fee proposed is too high

we are happy with the current coral reef quality

It is not fair to increase the price on tourists

23. Just to help us understand your intention and ability to pay, please answer this question. You said YES to increasing the boat fee amount by $[\mathrm{Y}] \$ \_$_ above. Would you be willing to pay double that amount, i.e., 2 times [Y].

Yes _ NO N N Not sure

24. Just to help us understand your intention and ability to pay, please answer this question. You said NO to increasing the boat fee amount by $[\mathrm{Y}] \$ \_$_ above. Would you be willing to pay at least half that amount, i.e., 0.5 times [Y].

Yes _ NO N N Not sure

Profile of the respondents

\section{Reminder: you may refuse to answer any questions.}

7. What is your age? years

8. Are you married? yes no 
9. Are you? Female Male (Interviewer: Don't ask this question; mark accordingly)

10. Including yourself, how many people are there in your household?

11. Education level: No formal education elementary high school College

\section{Vocational education}

12. Please indicate the appropriate category for total household income? (in USD)

\begin{tabular}{ll}
- & $<\$ 10,000$ \\
& $\$ 10,001-\$ 15,000$ \\
& $\$ 15,001-\$ 20,000$ \\
& $\$ 20,001-\$ 25,000$ \\
& $\$ 25,001-\$ 30,000$ \\
\hline & $\$ 30,001-\$ 35,000$ \\
& $\$ 35,001-\$ 40,000$
\end{tabular}

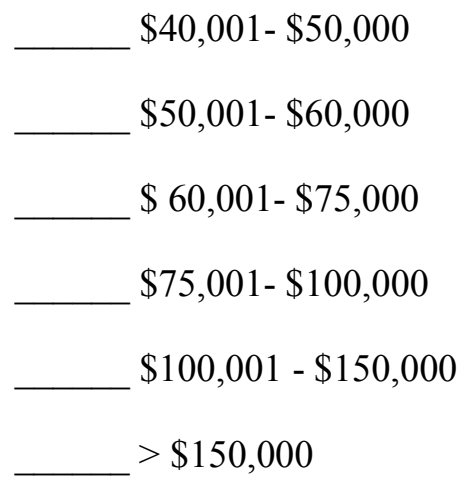

Thank you very much for your cooperation 


\section{APPENDIX III}

\begin{tabular}{|c|c|c|c|}
\hline BIDVALUE (US\$) & $\mathrm{P}(\mathrm{YES})$ Entire Sample & P(YES)Domestic & $\mathrm{P}(\mathrm{YES})$ International \\
\hline 0 & 0.802 & 0.718 & 0.916 \\
\hline 0.5 & 0.792 & 0.705 & 0.911 \\
\hline 1 & 0.782 & 0.693 & 0.906 \\
\hline 1.5 & 0.772 & 0.680 & 0.901 \\
\hline 2 & 0.761 & 0.667 & 0.896 \\
\hline 2.5 & 0.750 & 0.654 & 0.890 \\
\hline 3 & 0.739 & 0.640 & 0.884 \\
\hline 3.5 & 0.727 & 0.626 & 0.878 \\
\hline 4 & 0.715 & 0.612 & 0.871 \\
\hline 4.5 & 0.703 & 0.598 & 0.864 \\
\hline 5 & 0.690 & 0.583 & 0.857 \\
\hline 5.5 & 0.677 & 0.569 & 0.850 \\
\hline 6 & 0.664 & 0.554 & 0.842 \\
\hline 6.5 & 0.651 & 0.539 & 0.834 \\
\hline 7 & 0.637 & 0.525 & 0.826 \\
\hline 7.5 & 0.623 & 0.510 & 0.817 \\
\hline 8 & 0.609 & 0.495 & 0.808 \\
\hline 8.5 & 0.595 & 0.480 & 0.798 \\
\hline 9 & 0.581 & 0.465 & 0.789 \\
\hline 9.5 & 0.566 & 0.450 & 0.778 \\
\hline 10 & 0.551 & 0.436 & 0.768 \\
\hline 10.5 & 0.536 & 0.421 & 0.757 \\
\hline 11 & 0.522 & 0.406 & 0.746 \\
\hline 11.5 & 0.507 & 0.392 & 0.735 \\
\hline 12 & 0.492 & 0.378 & 0.723 \\
\hline 12.5 & 0.477 & 0.364 & 0.711 \\
\hline 13 & 0.462 & 0.350 & 0.698 \\
\hline
\end{tabular}




\begin{tabular}{|c|c|c|c|}
\hline BIDVALUE (US\$) & $\mathrm{P}(\mathrm{YES})$ Entire Sample & $\mathrm{P}(\mathrm{YES})$ Domestic & $\mathrm{P}(\mathrm{YES})$ International \\
\hline 13.5 & 0.447 & 0.337 & 0.686 \\
\hline 14 & 0.433 & 0.324 & 0.673 \\
\hline 14.5 & 0.418 & 0.311 & 0.659 \\
\hline 15 & 0.404 & 0.298 & 0.646 \\
\hline 15.5 & 0.389 & 0.286 & 0.632 \\
\hline 16 & 0.375 & 0.274 & 0.618 \\
\hline 16.5 & 0.361 & 0.262 & 0.604 \\
\hline 17 & 0.348 & 0.251 & 0.590 \\
\hline 17.5 & 0.334 & 0.240 & 0.575 \\
\hline 18 & 0.321 & 0.229 & 0.560 \\
\hline 18.5 & 0.308 & 0.219 & 0.546 \\
\hline 19 & 0.296 & 0.209 & 0.531 \\
\hline 19.5 & 0.284 & 0.199 & 0.516 \\
\hline 20 & 0.272 & 0.190 & 0.501 \\
\hline 20.5 & 0.260 & 0.181 & 0.486 \\
\hline 21 & 0.249 & 0.172 & 0.471 \\
\hline 21.5 & 0.238 & 0.164 & 0.457 \\
\hline 22 & 0.227 & 0.156 & 0.442 \\
\hline 22.5 & 0.217 & 0.148 & 0.427 \\
\hline 23 & 0.207 & 0.141 & 0.413 \\
\hline 23.5 & 0.197 & 0.134 & 0.398 \\
\hline 24 & 0.188 & 0.127 & 0.384 \\
\hline 24.5 & 0.179 & 0.120 & 0.370 \\
\hline 25 & 0.170 & 0.114 & 0.356 \\
\hline 25.5 & 0.162 & 0.108 & 0.343 \\
\hline 26 & 0.154 & 0.103 & 0.329 \\
\hline 26.5 & 0.147 & 0.097 & 0.316 \\
\hline 27 & 0.139 & 0.092 & 0.304 \\
\hline 27.5 & 0.132 & 0.087 & 0.291 \\
\hline
\end{tabular}




\begin{tabular}{|c|c|c|c|}
\hline BIDVALUE (US\$) & $\mathrm{P}(\mathrm{YES})$ Entire Sample & $\mathrm{P}(\mathrm{YES})$ Domestic & $\mathrm{P}(\mathrm{YES})$ International \\
\hline 28 & 0.126 & 0.083 & 0.279 \\
\hline 28.5 & 0.119 & 0.078 & 0.267 \\
\hline 29 & 0.113 & 0.074 & 0.256 \\
\hline 29.5 & 0.107 & 0.070 & 0.245 \\
\hline 30 & 0.102 & 0.066 & 0.234 \\
\hline 30.5 & 0.096 & 0.063 & 0.223 \\
\hline 31 & 0.091 & 0.059 & 0.213 \\
\hline 31.5 & 0.086 & 0.056 & 0.203 \\
\hline 32 & 0.082 & 0.053 & 0.194 \\
\hline 32.5 & 0.077 & 0.050 & 0.185 \\
\hline 33 & 0.073 & 0.047 & 0.176 \\
\hline 33.5 & 0.069 & 0.045 & 0.167 \\
\hline 34 & 0.066 & 0.042 & 0.159 \\
\hline 34.5 & 0.062 & 0.040 & 0.151 \\
\hline 35 & 0.059 & 0.038 & 0.144 \\
\hline 35.5 & 0.055 & 0.036 & 0.137 \\
\hline 36 & 0.052 & 0.034 & 0.130 \\
\hline 36.5 & 0.050 & 0.032 & 0.123 \\
\hline 37 & 0.047 & 0.030 & 0.117 \\
\hline 37.5 & 0.044 & 0.028 & 0.111 \\
\hline 38 & 0.042 & 0.027 & 0.105 \\
\hline 38.5 & 0.039 & 0.025 & 0.100 \\
\hline 39 & 0.037 & 0.024 & 0.094 \\
\hline 39.5 & 0.035 & 0.022 & 0.089 \\
\hline 40 & 0.033 & 0.021 & 0.085 \\
\hline
\end{tabular}


